\title{
Forecasting future energy production using hybrid artificial neural network and arima model
}

\author{
Maryam Khodaverdi
}

Follow this and additional works at: https://researchrepository.wvu.edu/etd

\section{Recommended Citation}

Khodaverdi, Maryam, "Forecasting future energy production using hybrid artificial neural network and arima model" (2018). Graduate Theses, Dissertations, and Problem Reports. 4004.

https://researchrepository.wvu.edu/etd/4004

This Problem/Project Report is protected by copyright and/or related rights. It has been brought to you by the The Research Repository @WVU with permission from the rights-holder(s). You are free to use this Problem/Project Report in any way that is permitted by the copyright and related rights legislation that applies to your use. For other uses you must obtain permission from the rights-holder(s) directly, unless additional rights are indicated by a Creative Commons license in the record and/ or on the work itself. This Problem/Project Report has been accepted for inclusion in WVU Graduate Theses, Dissertations, and Problem Reports collection by an authorized administrator of The Research Repository @ WVU. For more information, please contact researchrepository@mail.wvu.edu. 


\title{
FORECASTING FUTURE ENERGY PRODUCTION USING HYBRID ARTIFICIAL NEURAL NETWORK AND ARIMA MODEL
}

\author{
by \\ Maryam Khodaverdi \\ Problem report submitted to the College of Engineering and Mineral \\ Resources \\ at West Virginia University \\ in partial fulfillment of the requirements \\ for the degree of \\ Master of Science \\ in \\ Industrial Engineering
}

\author{
Approved by \\ Majid Jaridi, Ph.D., Committee Chairperson \\ Rashpal Ahluwalia, Ph.D. \\ Stacey Culp, Ph.D.
}

Department of Industrial and Management Systems Engineering

Morgantown, West Virginia

2018

Keywords: Artificial neural network, Time series, Forecasting, Future energy sources

Copyright 2018 Maryam Khodaverdi 


\section{Abstract \\ FORECASTING FUTURE ENERGY PRODUCTION USING HYBRID ARTIFICIAL NEURAL NETWORK AND ARIMA MODEL \\ by Maryam Khodaverdi}

The objective of this research is to obtain an accurate forecasting model for the amount of electricity (in kWh) that is generated from different primary energy sources in the U.S. In this research, Artificial Neural Network (ANN) and hybrid ARIMA and ANN algorithms were developed that can be used for forecasting the amount of energy production in the short, as well as, in the long run.

Based on the inferences made from the available data provided by Energy Information Administration from January 2004 to December 2014, two different forecasting models for each primary energy source were constructed. These two models were validated with available data from January 2015 to November 2017, and their performance, as measured by forecasting errors computed, were compared. The results show that ANN algorithm is good for fossil fuels sources such as coal, petroleum, and natural gas. However, ARIMA - ANN hybrid works more accurately for renewable energy sources such as geothermal, hydroelectric, solar, and wind.

Finally, the best predictor was selected for each primary energy source which provides valuable information regarding the future electricity generation, and future dominant energy source to generate electricity. This information will hopefully influence energy sector forecasting models and help the government to develop future regulations to shift toward dominant energy sources of the future. 


\section{Acknowledgments}

I would like to express my sincere gratitude to my advisor, Prof. Majid Jaridi for the continuous support of my study. His guidance helped me in all the time of research and writing of this problem report.

Besides my advisor, I would like to thank the rest of committee: Prof. Rashpal Ahluwalia and Dr. Stacey Culp for their insightful comments.

Last but not the least, I would like to thank my family: my husband and my parents for supporting me spiritually throughout writing this report and my life in general. 


\section{Table of contents}

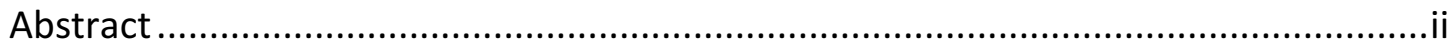

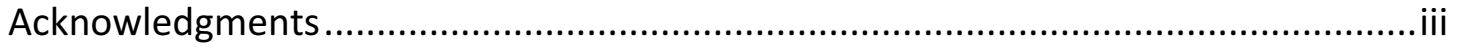

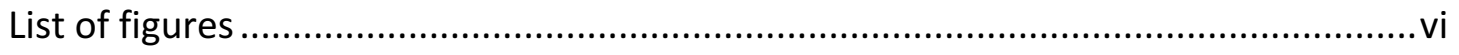

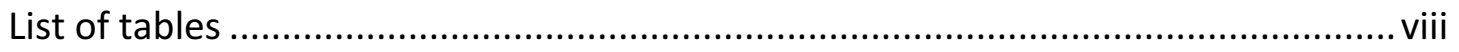

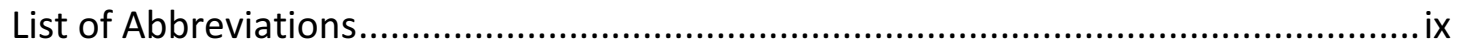

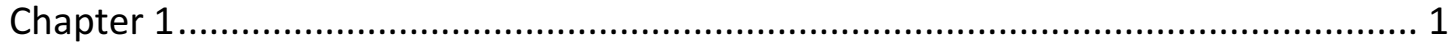

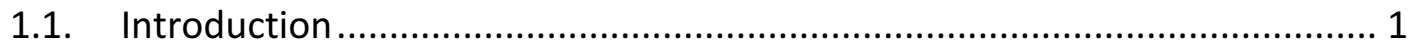

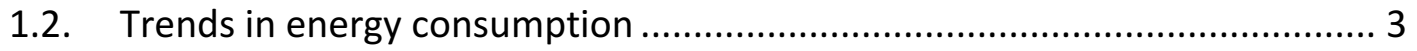

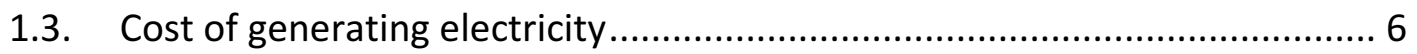

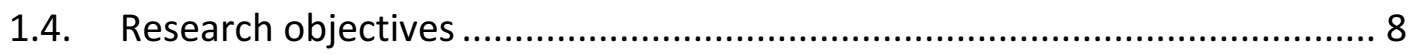

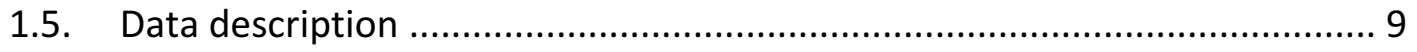

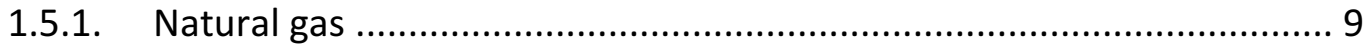

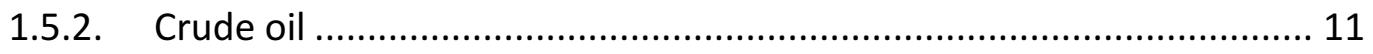

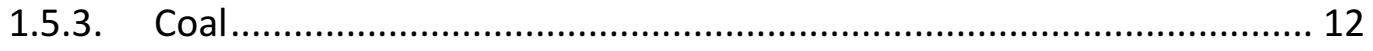

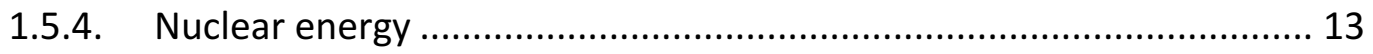

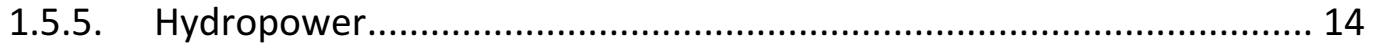

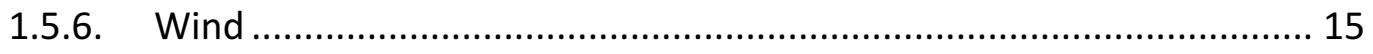

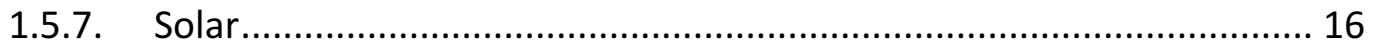

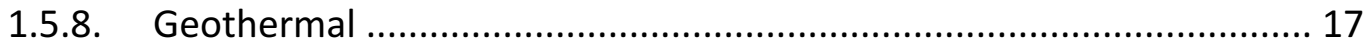

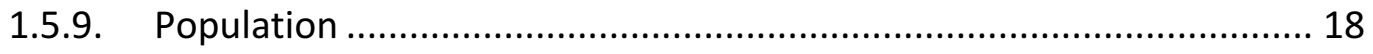

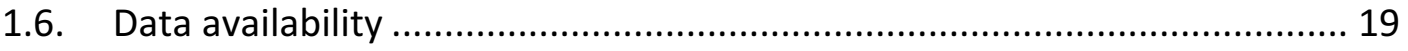

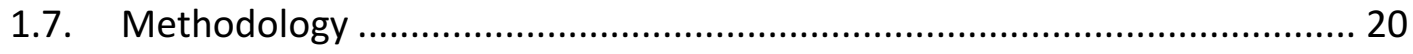

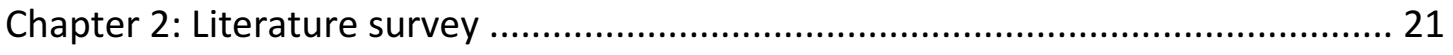

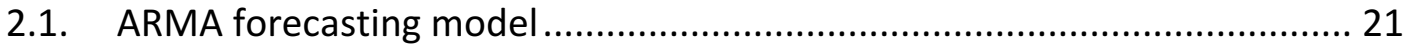

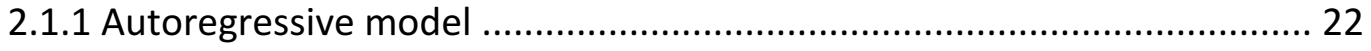

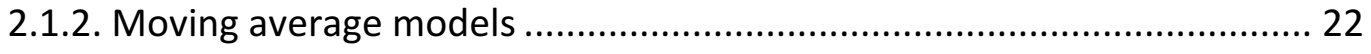

2.1.3. Autoregressive moving average models ............................................. 23

2.1.4. General form of ARMA models ............................................................ 24

2.2. Neural network forecasting models .................................................... 26

2.2.1. The optimal architecture of a neural network .................................. 28

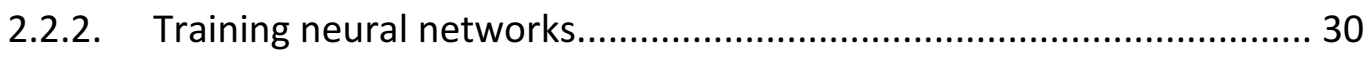

2.2.3. Performance of a neural network .................................................. 32 


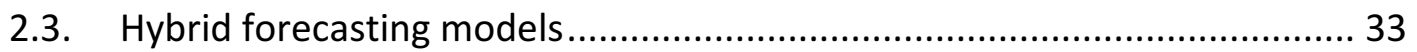

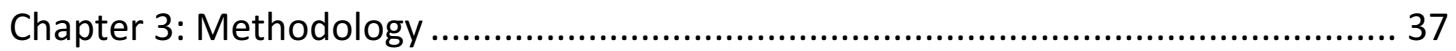

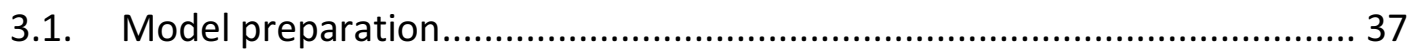

3.1.1. The market price of primary energy sources.................................... 37

3.1.2. Heat rate of primary energy sources ...................................................... 39

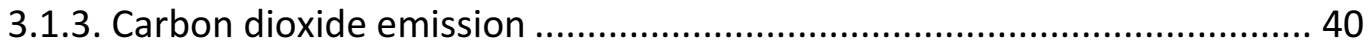

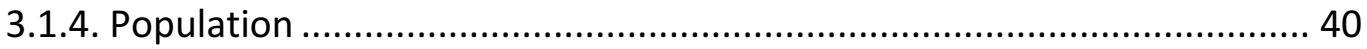

3.2. Multiple linear regression for generated electricity............................... 40

3.3. Non-linear regression for generated electricity .................................... 43

3.3.1. Design of a Neural network .............................................................. 43

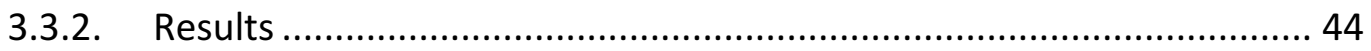

3.4. ARIMA model for generated electricity ................................................. 51

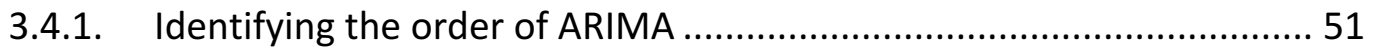

3.4.2. Fitting non- linear function of the residuals ................................... 52

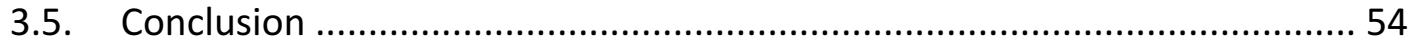

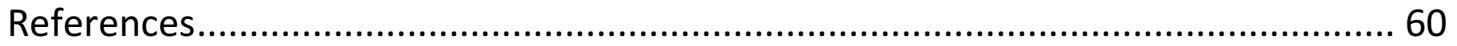

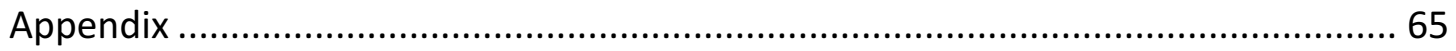

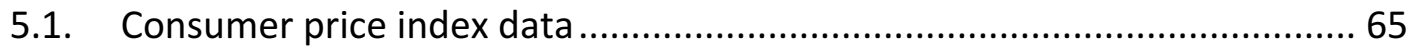

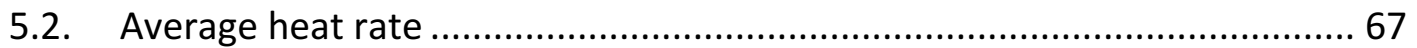

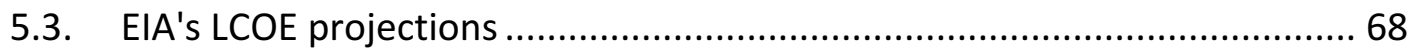

5.4. The predicted value of electricity generation using the ANN and the hybrid

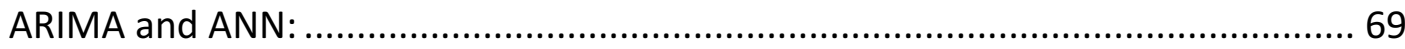




\section{List of figures}

Figure 1- Total energy used in the U.S. by four different sectors ............................ 3

Figure 2- Total consumption of energy in the U.S................................................ 4

Figure 3-Electric power plant primary energy consumption percent share of total

primary energy consumed in the U.S. ................................................................. 4

Figure 4- Amount of energy used in electric power sector in the U.S........................ 5

Figure 5- Average annual cost of generating electricity in term of dollar per mWh.... 6

Figure 6- Yearly LCOE projections for types of power plants in term of dollars per

mWh

Figure 7- U.S. electricity generation in term of billion $\mathrm{kWh}$...................................... 8

Figure 8- Data pertaining natural gas in term of billion cubic feet.......................... 10

Figure 9- Average data pertaining oil in term of thousand barrels per day ............... 11

Figure 10- Data pertaining coal in term of thousand short tons .............................. 13

Figure 11- Nuclear electricity net generation in the U.S. ..................................... 14

Figure 12- Hydroelectric net power consumption in the U.S................................. 15

Figure 13- Wind electricity net consumption in the U.S. ......................................... 16

Figure 14- Solar electricity net consumption in the U.S....................................... 17

Figure 15- Geothermal energy consumption in the US....................................... 18

Figure 16- U.S. population data obtained from U.S. Census Bureau.......................... 18

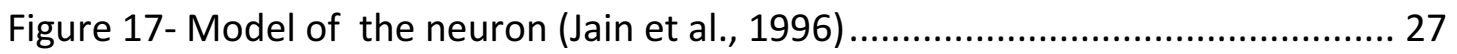

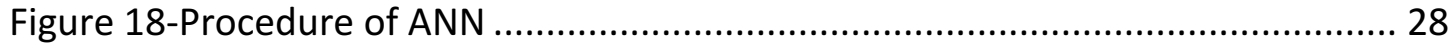

Figure 19- Example of feedforward neural network (Davim, 2011)......................... 29

Figure 20- Example of a recurrent neural network (Quiza \& Davim, 2009) ............... 29

Figure 21- pseudocode of hybrid ARMA and ANN algorithm applied in (Gairaa et al., 2016)

Figure 22- pseudocode of hybrid ARMA and ANN algorithm proposed in (Rose, 2015)

Figure 23- pseudocode of hybrid ARMA and ANN algorithm proposed in (Khashei \&

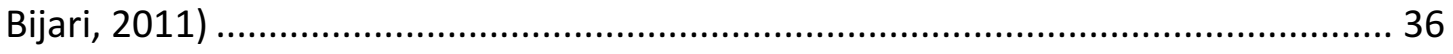

Figure 24- Nominal and the real price of coal, natural gas, and crude oil ................. 39 
Figure 25-Summary of MLR result

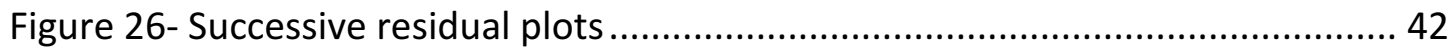

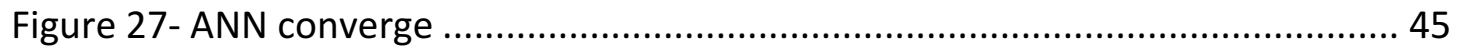

Figure 28- Linear regression between ANN outputs and targets ........................... 47

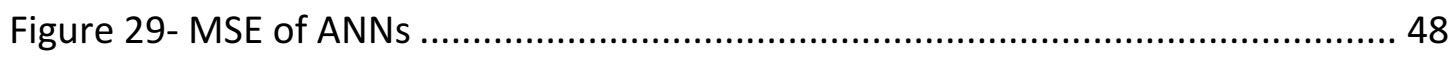

Figure 30- Tracking signal of predicted data (January 2014-November 2017) .......... 50

Figure 31- ARIMA model and predicted values ................................................... 52

Figure 32- Linear regression between ANN outputs and targets for residuals ......... 53

Figure 33- The fitted value of generated electricity vs. actual value ........................ 57

Figure 34- The predicted value of generated electricity vs. actual value.................. 59 


\section{List of tables}

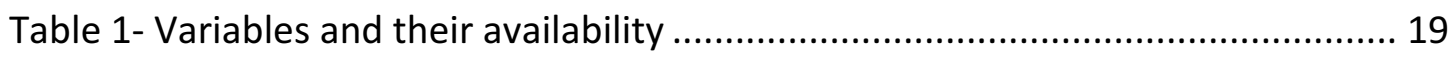

Table 2- MSE obtained from ANN and hybrid ARIMA and ANN .............................. 54

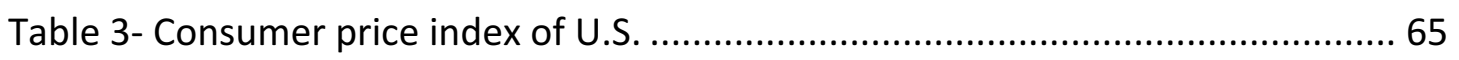

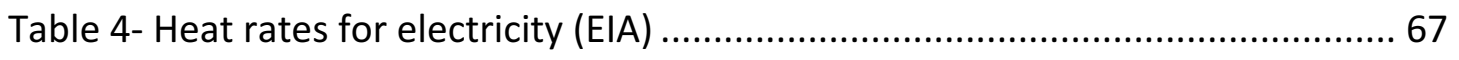

Table 5- Actual and predicted value of electricity generation from coal and oil between 2004 to 2017

Table 6- Actual and predicted value of electricity generation from natural gas and geothermal between 2004 to 2017

Table 7- Actual and predicted value of electricity generation from hydroelectric and solar between 2004 to 2017

Table 8- Actual and predicted value of electricity generation from wind and nuclear between 2004 to 2017 


\section{List of Abbreviations}

\begin{tabular}{|c|c|}
\hline EIA & Energy Information Administration \\
\hline NAICS & North American Industry Classification System \\
\hline WTI & West Texas Intermediate Crude Oil \\
\hline BTU & British Thermal Unit \\
\hline PSIA & Pounds per Square Inch Absolute \\
\hline $\mathrm{CPI}$ & Consumer Price Index \\
\hline LCOE & The Levelized Cost of Electricity \\
\hline AR & Autoregressive \\
\hline MA & Moving Average \\
\hline ARMA & Autoregressive Moving Average \\
\hline ARIMA & Autoregressive Integrated Moving Average \\
\hline ANN & Artificial Neural Network \\
\hline GLAR & Generalized Linear Auto Regression \\
\hline AIC & Akaike Information Criterion \\
\hline $\mathrm{BIC}$ & Bayesian Information Criterion \\
\hline BP & Back Propagation \\
\hline LM & Levenberg-Marquardt \\
\hline RBF & Radial Basis Function \\
\hline MSE & Mean Square Error \\
\hline MLR & Multiple Linear Regression \\
\hline NG & Natural Gas \\
\hline $\mathrm{CO}_{2}$ & Carbon dioxide \\
\hline
\end{tabular}




\section{Chapter 1}

\subsection{Introduction}

Energy is one of the main factors that influence economic and societal development. There are many known energy resources in the world which we categorize them into three types: fossil fuel, renewable energy, and nuclear energy. The very first inanimate energy source is wood (Tillman, 2012). With an increase in the world population, this resource fell short of the demand for fuel. Also, the amount of wood and charcoal that was available decrease due to deforestation. Then, coal or disposed wood was discovered as a new source which had a much larger return on investment compared to wood. This discovery led to industrial revolution. Finally, oil and gas were discovered, which like to coal, are non-renewable resources.

As concerns about the decrease in the amount of world's oil and supplies were raised, renewable sources such as solar and wind started to gain notice as sustainable sources. Today, there are many known energy resources in the world. In general, energy sources are divided into three groups: fossil fuels, renewable energy, and nuclear energy.

Fossil fuels were formed from ancient plant and organism during the Carboniferous period. Different combination of organic matter, temperature, time, and pressure have created a different type of fossil fuels around the world. Coal, oil, and natural gas are three main types of fossil fuels. Fossil fuels are non-renewable sources of energy due to time takes to form them, and they will not be replenished in a human lifetime once they are used.

Today, we gather most of our energy from fossil fuels. Fossil fuel is the world's dominant energy source with a variety of applications such as generating electricity, production plants, and transportation. Also, a variety of products such as cosmetic products, plastics, etc. are produced using fossil fuels which have powered industrialization over time. They are also largest emitters of greenhouse gas such as carbon dioxide in the world which negatively impact both the environment and human 
health. Climate change, global warming, air quality deterioration, oil spills, and acid rain are results of using fossil fuels.

Renewable energy sources naturally replenish themselves in a human lifetime which means that they never will run out. Examples of renewable energy sources are solar, wind, hydro, geothermal, biomass, rain, wave, and tides. Using this kind of energy has advantages including creating no direct greenhouse gas emissions, decreasing pollution, reliability, and stability in their price in the long run. These sources also face some challenges and disadvantages including difficulty to generate large-scale power, their high capital investment, their intermittency, and their ecological distractions.

Renewable energy sources supply minority of world's energy demand. The good news is that advances in technology make renewable energy sources more affordable and accessible. Renewable sources are now the fastest growing energy source on the planet.

Nuclear energy is obtained from the nucleus of an atom by applying two different type of reactions: Fission and Fusion. Energy or heat is produced through fission by splitting atoms typically using Uranium. Energy is produced through fusion by colliding atomic nuclei; the same process occurred in the sun. After the collision of atomic nuclei at high speed in this reaction, they joint and form a new atomic nucleus. This reaction has not been successfully used in large scale since creating conditions to start this process faces some major scientific and engineering challenges. Today, fission reaction is used in every operating nuclear plant.

Nuclear energy has some advantages including not emitting greenhouse gas, large capacity to generate energy and low operating cost of nuclear plants, and their easy integration into existing electricity grids. However, using nuclear energy is still a controversial topic. First, nuclear plants face a variety of environmental and human health issues. One of the largest concerns is generating radioactive wastes that can remain radioactive for thousands of years. Second, nuclear plants require large initial capital cost which means large financial risk to investors. 


\subsection{Trends in energy consumption}

Growing world population has necessitated enhanced effort to provide sufficient energy to meet the demand across the globe. Energy demand also tends upwards in the U.S. Figure 1 presents the trend in the total amount of energy used in the U.S. by four different sectors: residential, commercial, industrial, and transportation from 1950 to 2016. Also, it is important to keep in mind that we live in a time that we should be able to guarantee both competitiveness and affordable energy for the current and future use. Today, the number of energy sources are more than ever before and, customer expectations have led to energy markets to become more complex than ever. For these reasons, planning for the future energy resources is a vital decision which may have a profound effect on a country's development and prosperity.

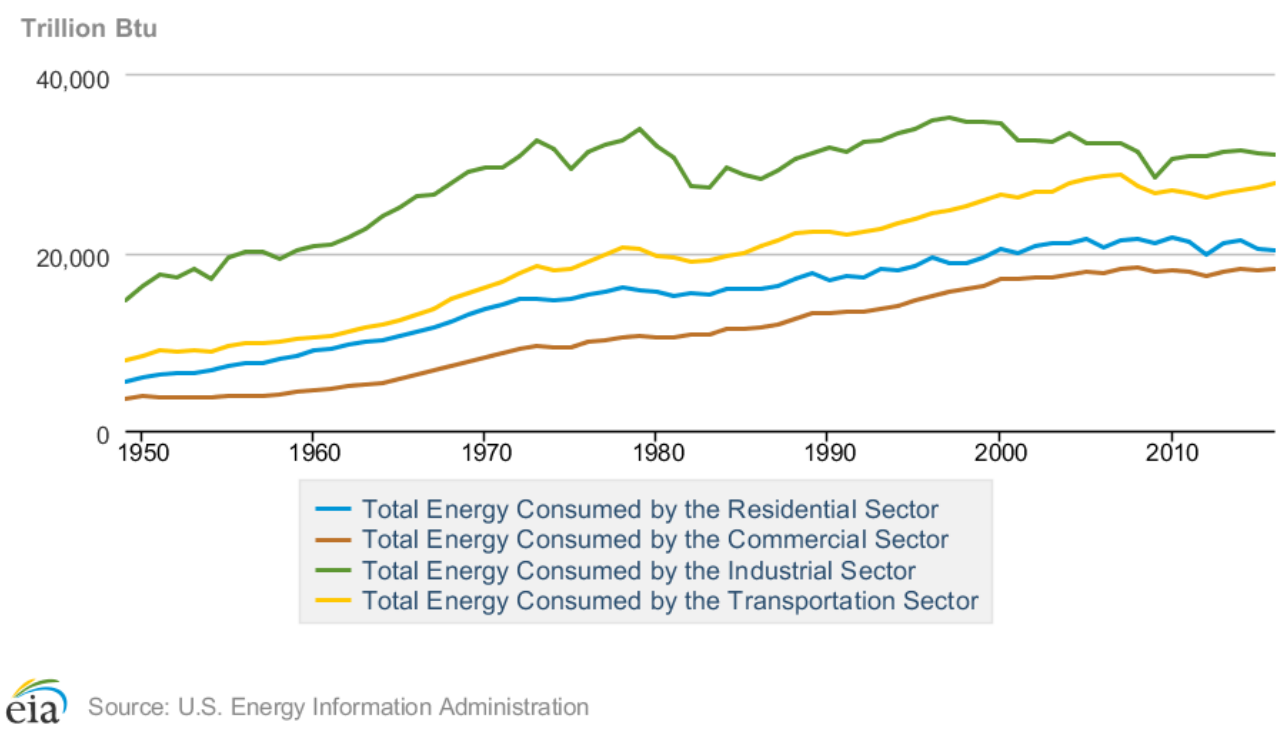

Figure 1-Total energy used in the U.S. by four different sectors

Looking at energy consumption pattern over time can help the decision makers to plan for providing and exploring energy resources, and change policies and technologies in a way that provide all required energy in the future. Figure 2 demonstrates the total consumption of energy in the U.S. from 1776 to 2012 (EIA, 2012). As you can see, wood was used dominantly through 1885 . Then, coal was discovered and replaced as a dominant energy source in the late $19^{\text {th }}$ century. After the middle of $19^{\text {th }}$ century, oil and natural gas consumption increased exponentially. As demonstrated in Figure 2, renewable and nuclear energy use started to rise in the middle of $20^{\text {th }}$ century. 


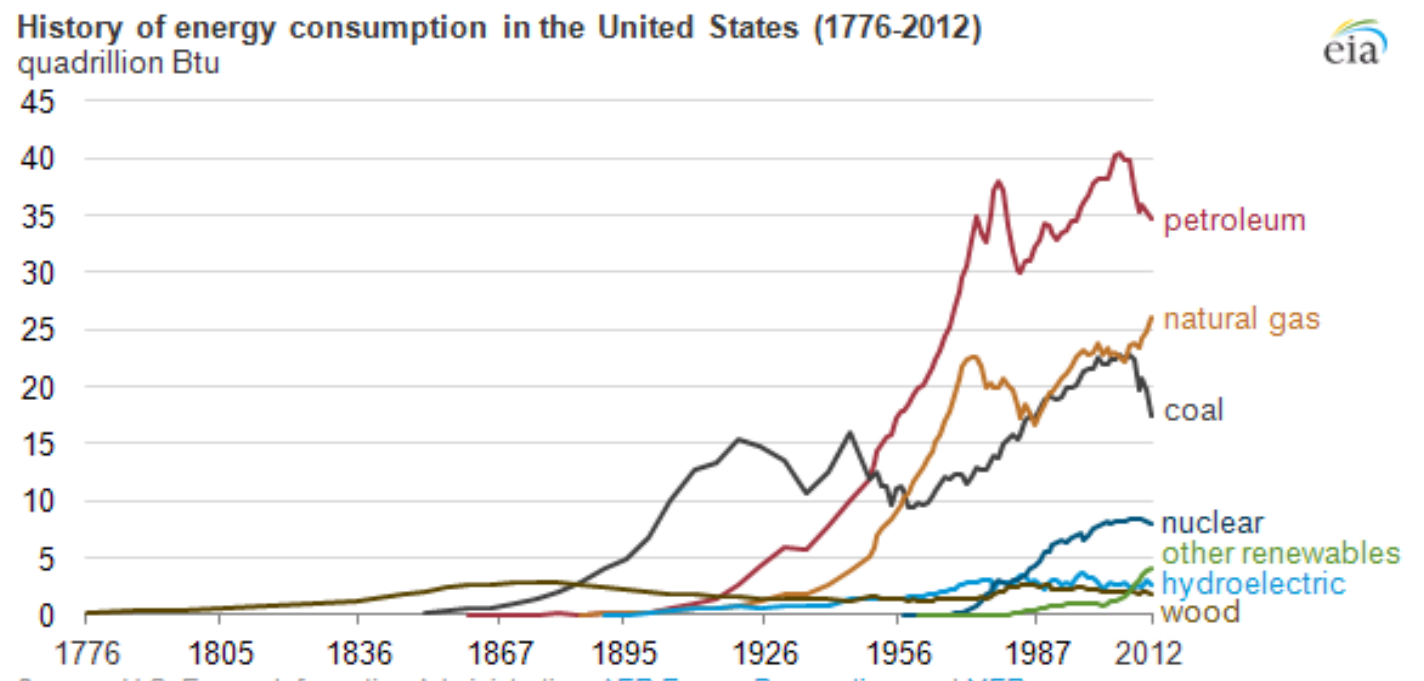

Source: U.S. Energy Information Administration, AER Energy Perspectives and MER.

Figure 2- Total consumption of energy in the U.S.

Electricity is a secondary energy source meaning that it is generated from one of the primary sources of energy such as fossil fuels, renewable, or nuclear energy. Energy consumed for electric power sector accounts for more than $40 \%$ of total primary energy consumption in the U.S. during 2017. Figure 3 shows the electric power plant primary energy consumption percent share of total primary energy consumed in the U.S. which is calculated by dividing electric power sector primary energy consumption by total primary energy consumption in the U.S. annually from 1949 to 2016.

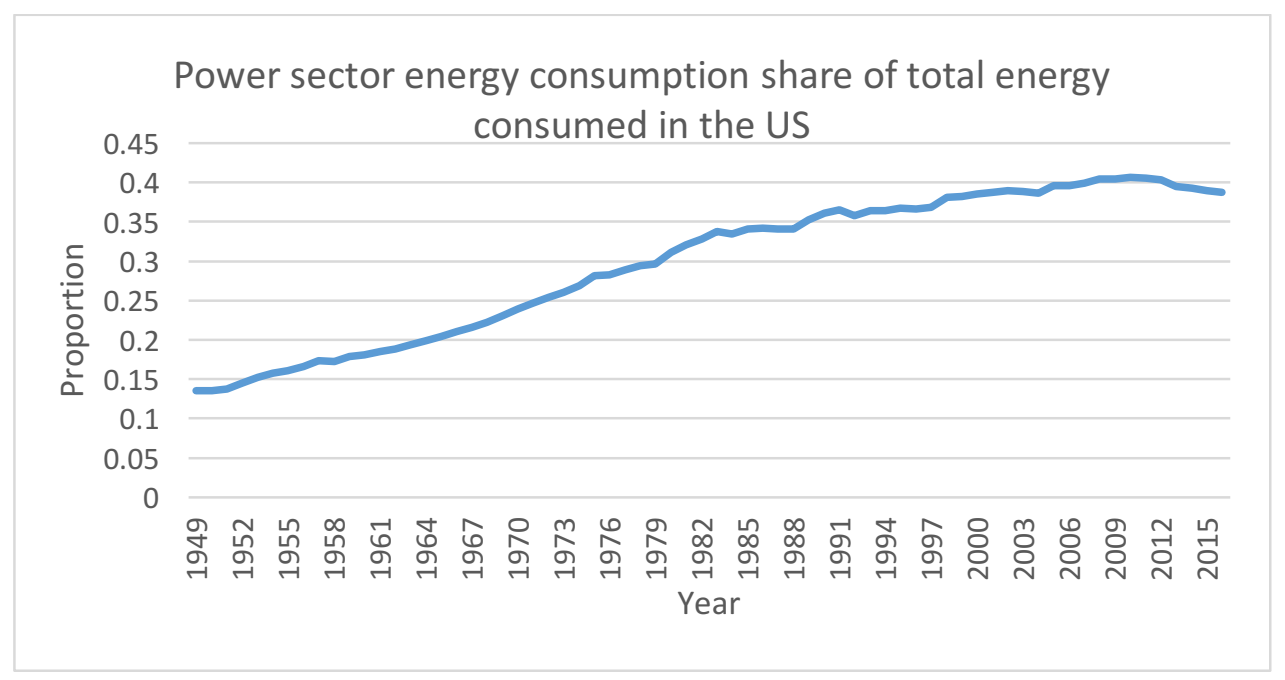

Figure 3-Electric power plant primary energy consumption percent share of total primary energy consumed in the U.S. 
Most of U.S. electricity is generated using fossil fuels. Based on Energy Information Administer (EIA) report, the largest energy source for U.S. electricity generation is natural gas which is the source of about 34\% of U.S. electricity generation in 2016. Coal is the second-largest energy source for electricity generation in 2016 with about $30 \%$. Nuclear and renewable energy also provided $20 \%$ and $15 \%$ of the U.S. electricity generation in 2016. The U.S. electricity generation uses mainly hydropower and wind power as renewable energy. Hydropower provides about 7\%, and wind power provides about 6\% of electricity generation in 2016.

Figure 4 shows the amount of fossil fuels, renewable, and nuclear energy used in electric power sector in the U.S. from 1949 to 2016 . The vertical axis is the amount of energy consumed in the U.S. in term of trillion British Thermal Unit (BTU), and the horizontal axis represents years. As one can see in Figure 4, fossil fuels consumed by electricity power plants tend to decrease. However, renewable and nuclear energy consumed by electric power plants tend to increase in recent years.

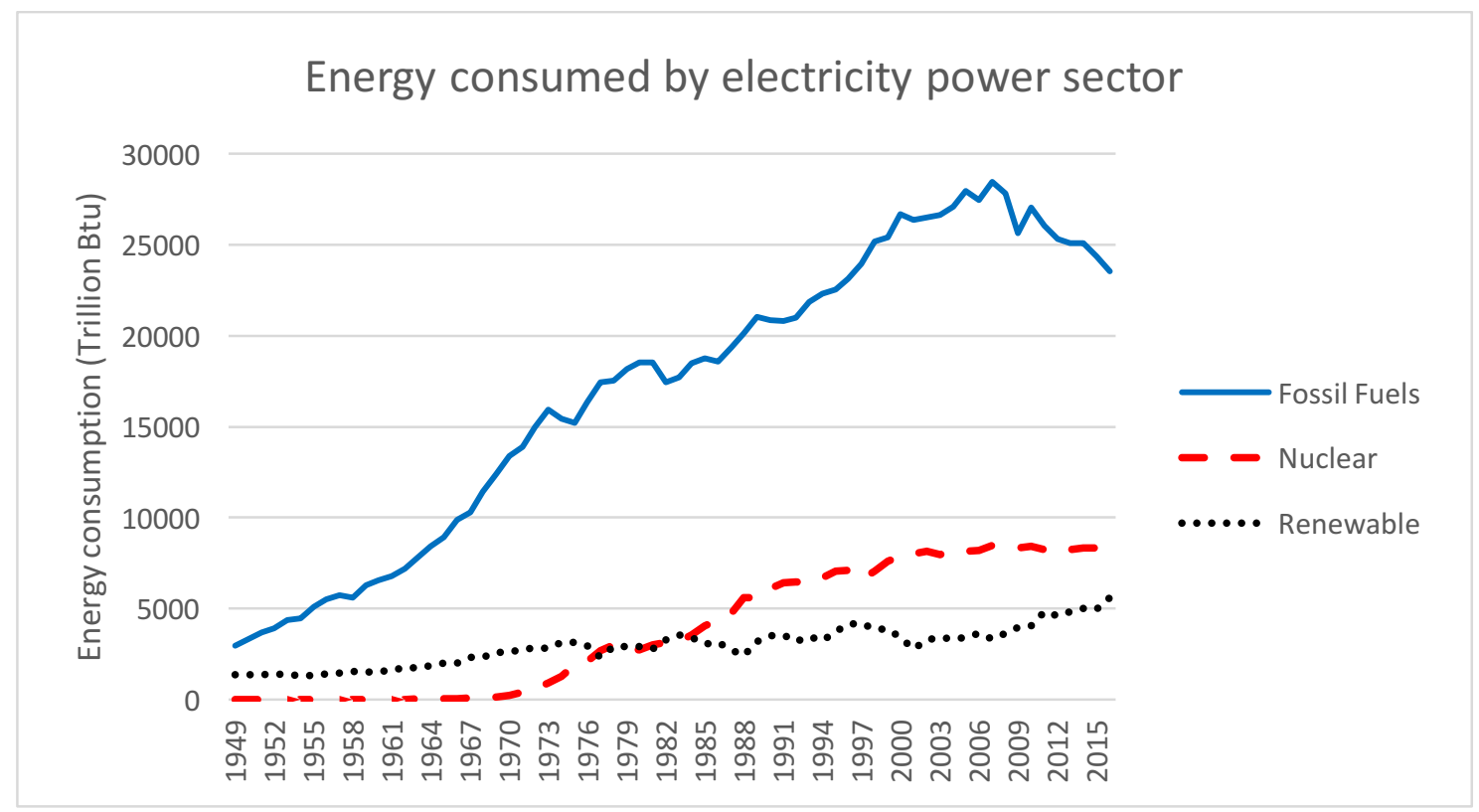

Figure 4- Amount of energy used in electric power sector in the U.S. 
The most important question regarding the future of energy resources is how we will use energy resources to generate electricity since electric power sector is one of the major energy consumers in the U.S. As Figure 4 demonstrates, the U.S. primary energy consumption pattern to produce electricity changes over time which makes it a difficult task to answer the above question.

\subsection{Cost of generating electricity}

Cost is one of the key factors that influence the choice of primary energy source to generate electricity. Figure 5 shows the average annual cost of different power plants from 2005 to 2015 in term of dollars per megawatt-hours (mWh). Note that conventional hydroelectric and pumped storage are included in the hydroelectric category. Also, gas turbine, internal combustion, photovoltaic, and wind plants are considered in the gas turbine category. This historical data on the average annual cost of power plants including operation, maintenance, and fuel costs are obtained from Federal Energy Regulatory Commission.

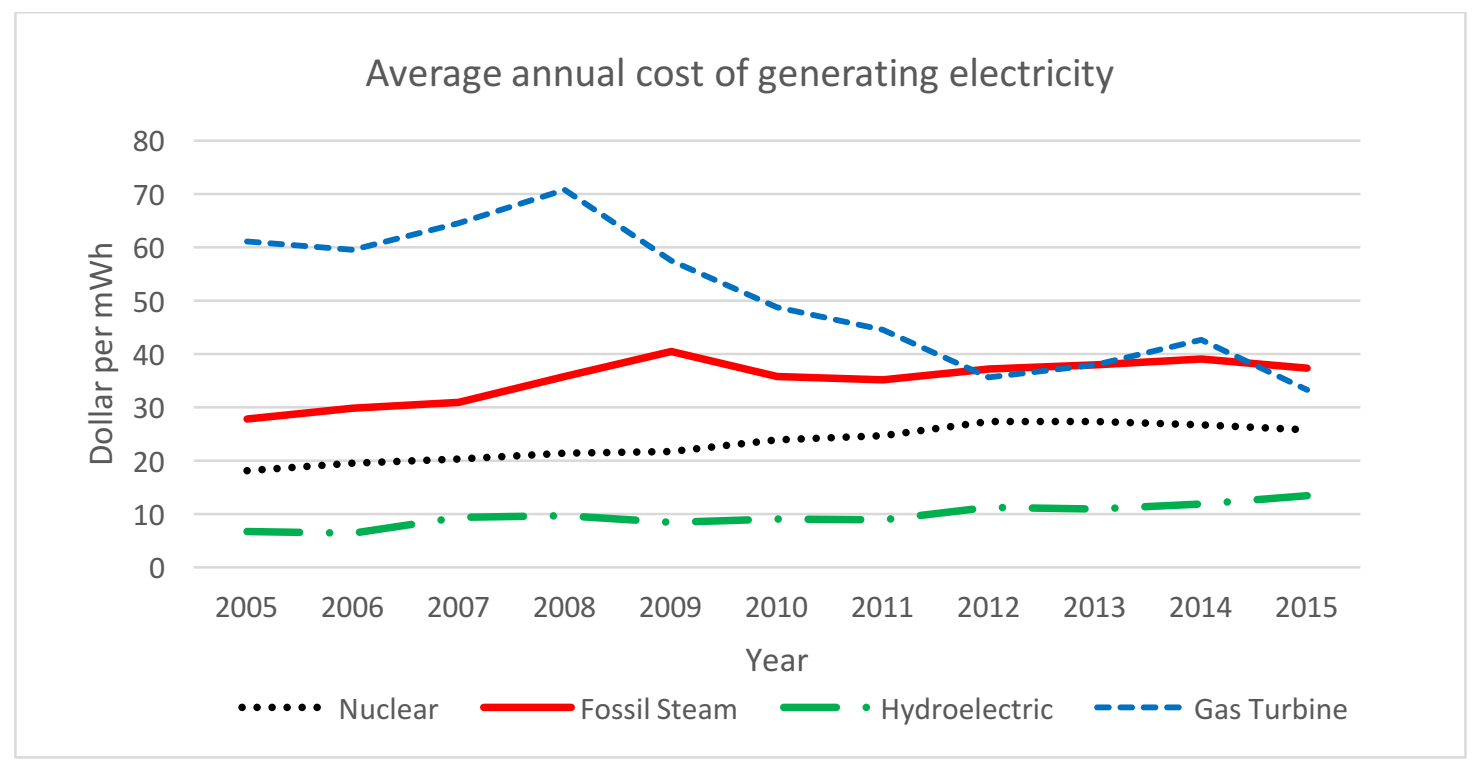

Figure 5-Average annual cost of generating electricity in term of dollar per $\mathrm{mWh}$ 
As illustrated in Figure 5, recent improvements in turbine technology have decreased the cost of generating electricity by wind. These developments will allow consumers to use low and affordable electricity rates in the next years.

The levelized cost of electricity (LCOE) is another economic assessment which represents the average minimum unit cost of electricity which represents the average price of unit electricity that power plants receive to break even over their lifetime. LCOE consists of the total cost of building or initial investment, operations, maintenance, and cost of fuel. This can be calculated by dividing the power plant's costs by the amount of generated electricity over the lifetime of a power plant which is usually between 20 to 40 years.

EIA has published yearly LCOE-projections for various types of future power plants from 2010 in term of dollars per mWh based on a 30-year cost recovery period (see Appendix 5.3). Figure 6 depicts the annual LCOE-projections for different types of power plants from 2010 to 2016 in term of dollars per $\mathrm{mWh}$. Figure 6 also shows that the economic value of two primary energy, i.e., onshore wind and solar PV, have improved significantly over the last years.

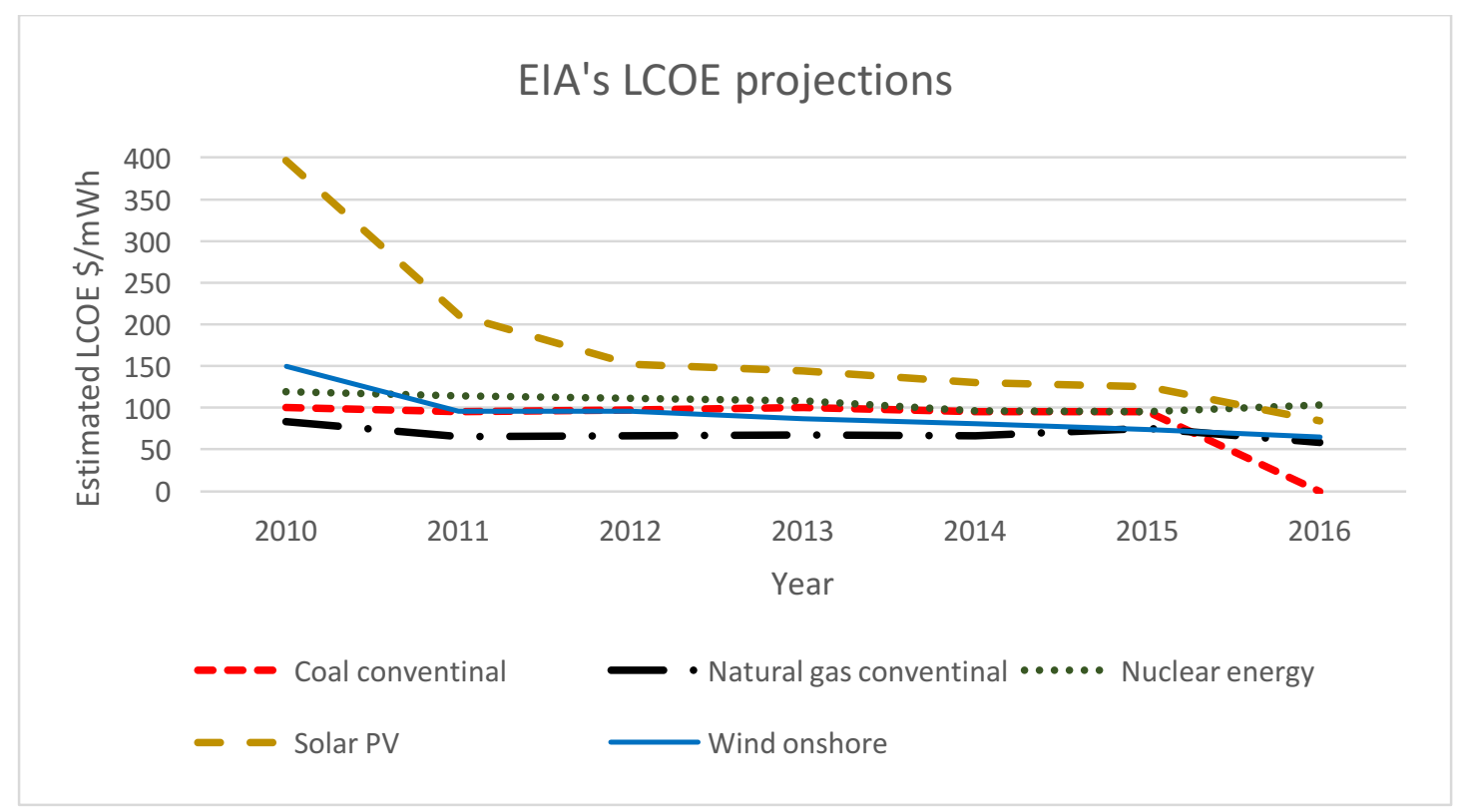

Figure 6- Yearly LCOE projections for types of power plants in term of dollars per $m W h$ 


\subsection{Research objectives}

The main objective of this research is to obtain an accurate forecasting model for the amount of electricity that is generated from different primary energy sources in the U.S. and to estimate each energy resource's share of total primary energy consumption to generate electricity in the U.S. The forecasting model will be constructed based on inferences made from the available energy data provided by EIA from January 2004 to December 2014 and will be validated on data between January 2015 to November 2017.

The model will provide a monthly forecast for each primary energy consumption to generate electricity in the U.S. Figure 7, provided by EIA, illustrates the amount of electricity generated with each primary energy source in the past 67 years (19492016). As demonstrated, the amount of coal used to generate electricity has been decreasing since 2007, and the amount of natural gas, renewable, and nuclear energy used to generate electricity has increased.

Our forecast models will provide valuable information regarding the future electricity generation and future dominant energy sources to generate electricity. This information will hopefully influence energy sector forecasting models and help the government to develop future regulations to shift toward dominant energy sources of the future.

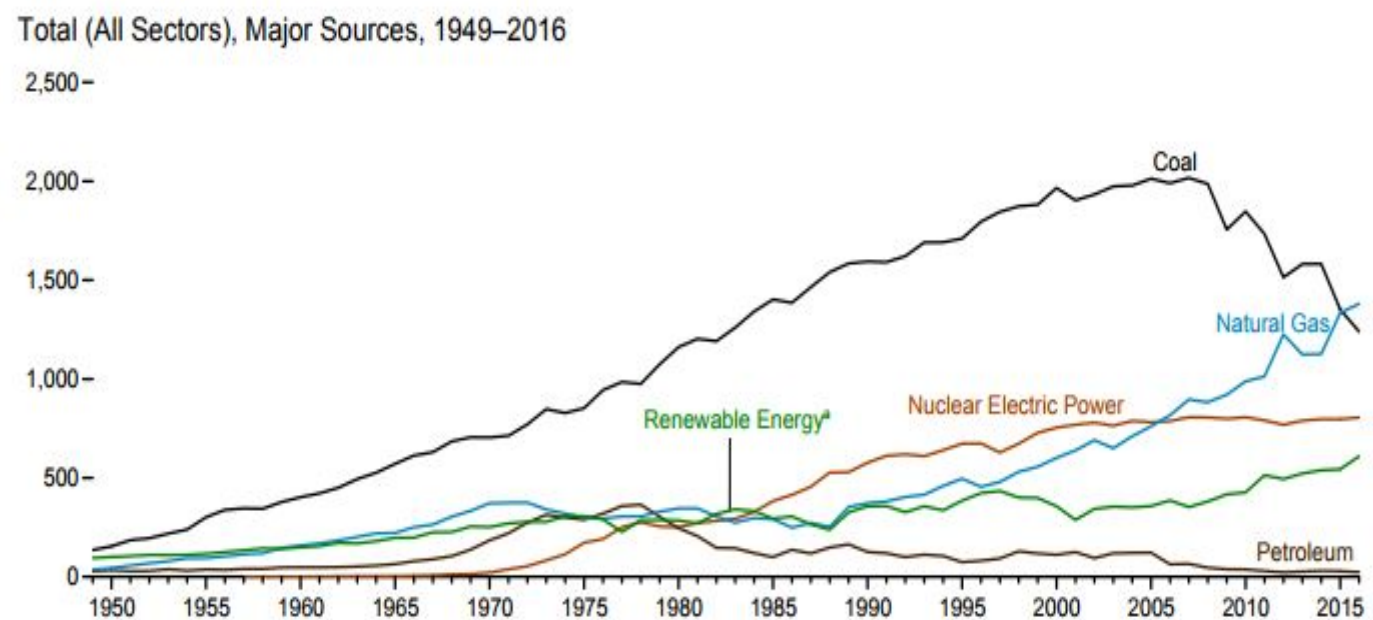

Figure 7- U.S. electricity generation in term of billion $\mathrm{kWh}$ 


\subsection{Data description}

The source of historical data about the factors of interest in this research is energy information administration (EIA). The exact geographic coverage of the data sets is all the 50 states and the District of Columbia. The detailed description and availability of the historical data are reported below.

\subsubsection{Natural gas}

Natural gas withdrawals, natural gas consumed by electricity power sector, natural gas imports statistics are available from 1949 to 2017. The description of each variable is presented below. All volumes of natural gas are reported on a pressure of 14.73 Psia and 60 Fahrenheit in our data set.

- Natural gas withdrawals present the total volume (in billion cubic feet) of gas per year withdraws from natural gas, crude oil, coalbed, and shale gas wells in the U.S. including natural gas, natural gas plant liquids, and nonhydrocarbon gases.

- Natural gas consumed by electric power sector data presents the total volume of natural gas consumed in the U.S. by electric power sector comprises electricity-only and combined-heat-and-power plants within the NAICS 22 category whose primary business is to sell electricity to the public.

- Natural gas imports statistics show the total annual volume of gas imported into the U.S.

Figure 8 demonstrates the data pertaining natural gas from 1949 to 2017. 


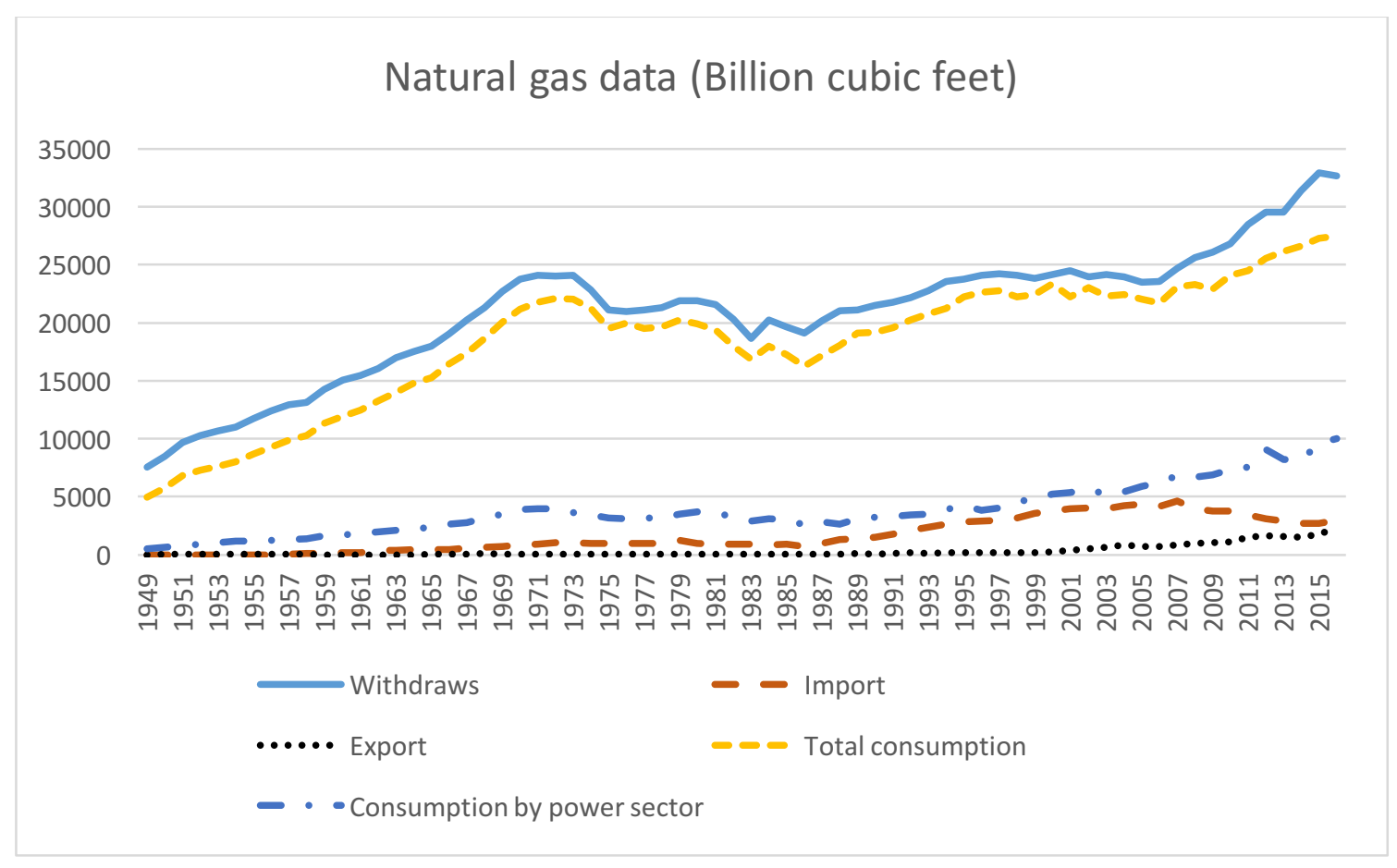

Figure 8- Data pertaining natural gas in term of billion cubic feet

Another factor of interest is Henry Hub natural gas spot prices. The data is available from January 1997 to December 2017 provided by EIA. Henry Hub natural gas price shows the monthly value of natural gas at Henry Hub.

Henry Hub is a distribution hub on the natural gas pipeline system in Louisiana. Natural gas price at Henry Hub is the primary price set in the U.S. natural gas market, and wellhead prices are closely correlated to this set. Henry Hub natural gas price data set is denominated in the dollar in millions of British Thermal Units. 


\subsubsection{Crude oil}

Average of crude oil production, crude oil consumed to generate electricity, crude oil imports for each year, are available from 1949 to 2017. The description of each variable is presented below. All volumes of crude oil are reported in term of thousand barrels per day in our data set.

- Crude oil production presents the average volume of crude oil per day produced on leases in the U.S. each year.

- Crude oil consumed by electric power sector data represents the average volume of crude oil consumed in the U.S. per day by the electric power sector. It comprises electricity-only and combined-heat-and-power plants within the NAICS 22 category whose primary business is to sell electricity to the public.

- Crude oil imports statistics show the average volume of crude oil per day imported into the U.S. each year.

- Crude oil exports statistics show the average volume of crude oil per day exported from the U.S. per year.

Figure 9 demonstrates the data pertaining oil from 1949 to 2017.

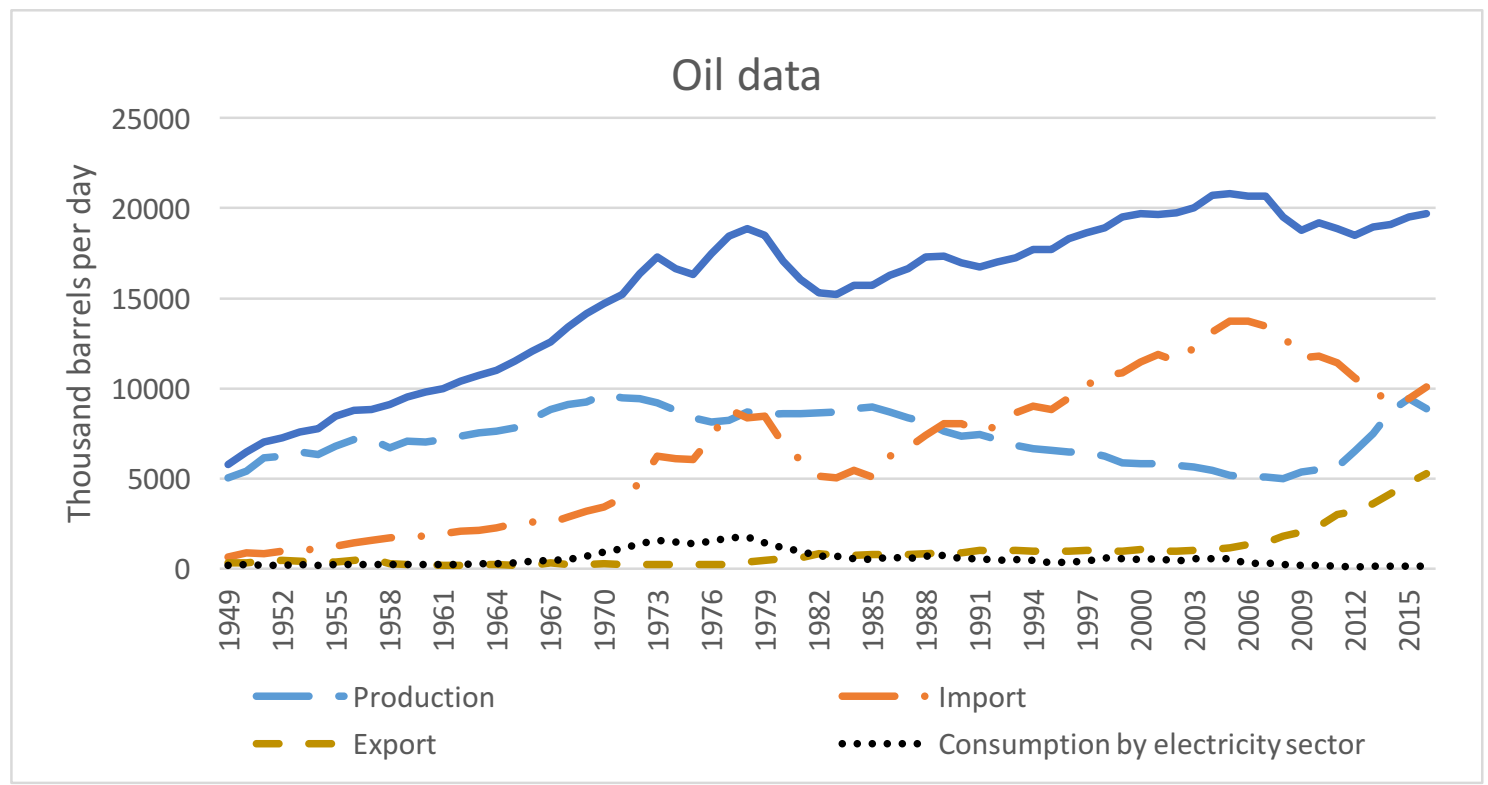

Figure 9- Average data pertaining oil in term of thousand barrels per day 
Another factor of interest is crude oil price. U.S. average. Monthly West Texas Intermediate Crude Oil (WTI) spot price in Cushing, Oklahoma is available from January 1986 to December 2017 in terms of U.S. dollars per barrel. WTI spot price represents the crude oil price in the U.S. per month.

\subsubsection{Coal}

Coal production, coal consumed to generate electricity, coal imports statistics are available from 1949 to 2017. The description of each variable is presented below. All volumes of coal are reported in term of thousand short tons in our data set.

- Coal production presents the total volume of coal produced in the U.S. including a small amount of refuse recovery in which coal recaptured from a refuse mine and cleaned to reduce the concentration of noncombustible materials.

- Coal consumed by electricity power sector data represents the total volume of coal consumed in the U.S. by the electric power sector. It comprises electricityonly and combined-heat-and-power plants within the NAICS 22 category whose primary business is to sell electricity to the public.

- Coal imports statistics show the total volume of coal imported into the U.S. per year.

Figure 10 demonstrates the data pertaining coal from 1949 to 2017.

Another factor of interest is the price of coal. Columbia monthly coal prices from January 2004 to December 2017 in terms of U.S. dollar per metric ton of coal. The coal price is obtained from Index Mundi database ${ }^{1}$.

\footnotetext{
${ }^{1}$ http://www.indexmundi.com/commodities/?commodity=colombian-coal\&months=360
} 


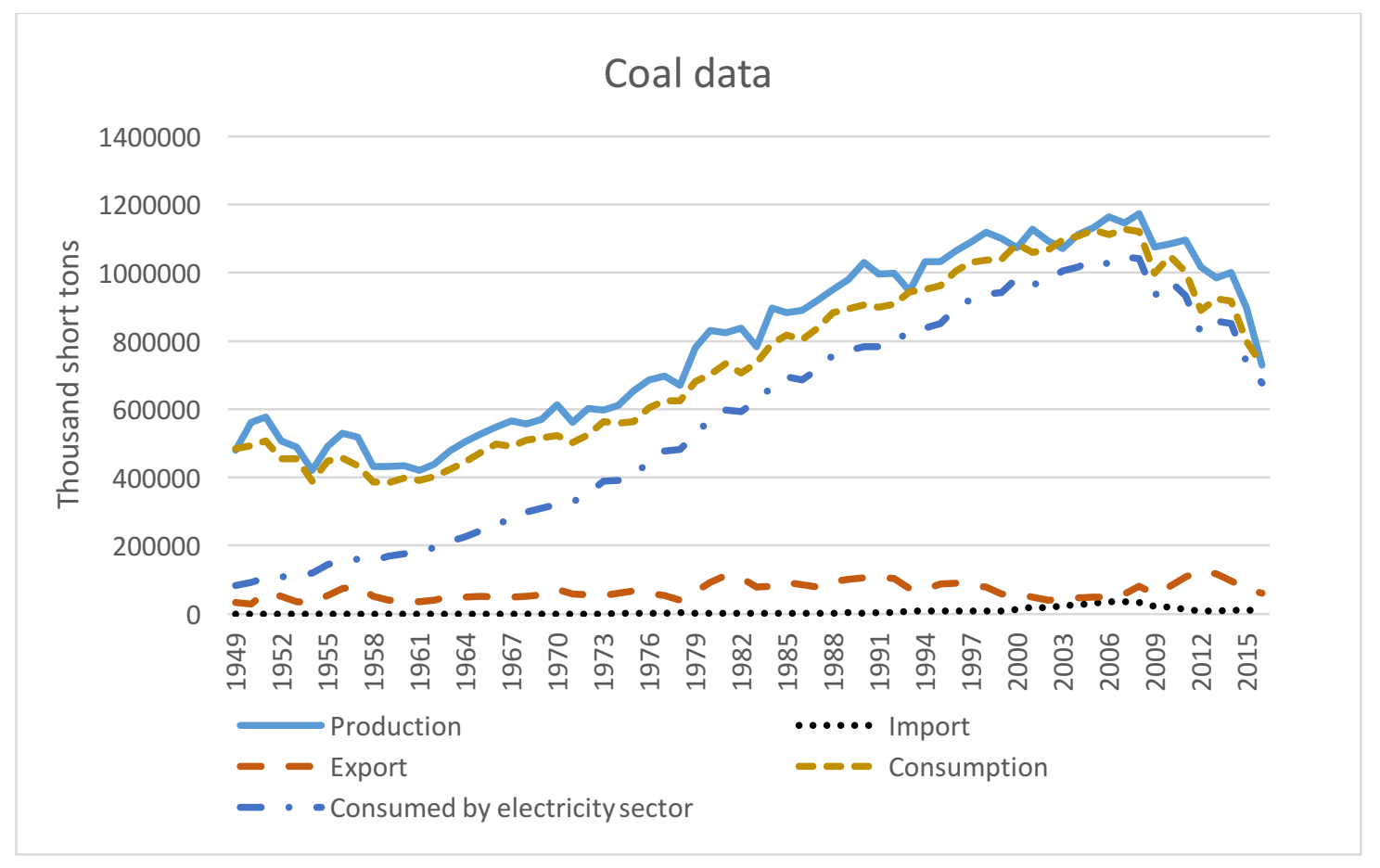

Figure 10-Data pertaining coal in term of thousand short tons

\subsubsection{Nuclear energy}

Nuclear electricity net generation in the U.S. is another factor of interest. The description of this variable is presented below. This data is available from 1957 to 2017 in terms of million kWh.

- Nuclear electric net generation shows the amount of electricity that was generated in the U.S. by nuclear energy per year.

Figure 11 shows nuclear electric net generation in the U.S. from 1949 to 2017. Note that nuclear electricity net generation before 1957 is negligible. 


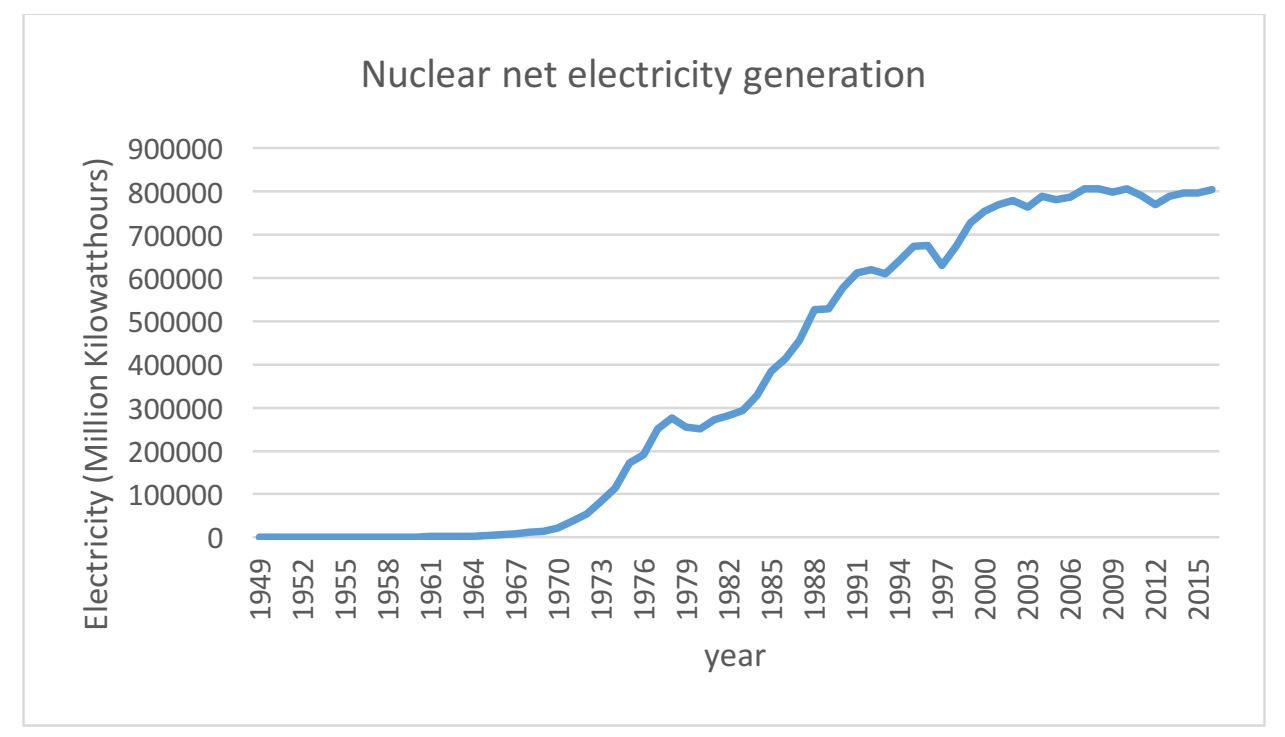

Figure 11- Nuclear electricity net generation in the U.S.

\subsubsection{Hydropower}

Hydroelectric power is one of the most important renewable sources in the U.S. The description for hydroelectric power consumption in the U.S. is presented below. This data is available from 1949 to 2017 in terms of trillion BTU.

- Hydroelectric power consumption represents the total volume of conventional hydroelectricity consumed in the U.S. This data set converted to BTU by multiplying the total fossil fuels heat rate factors (see Appendix 5.2).

Figure 12 shows hydroelectric net power consumption in the U.S. from 1949 to 2017. As can be seen from this figure, consumption from this source rose exponentially in the middle of the $20^{\text {th }}$ century. 


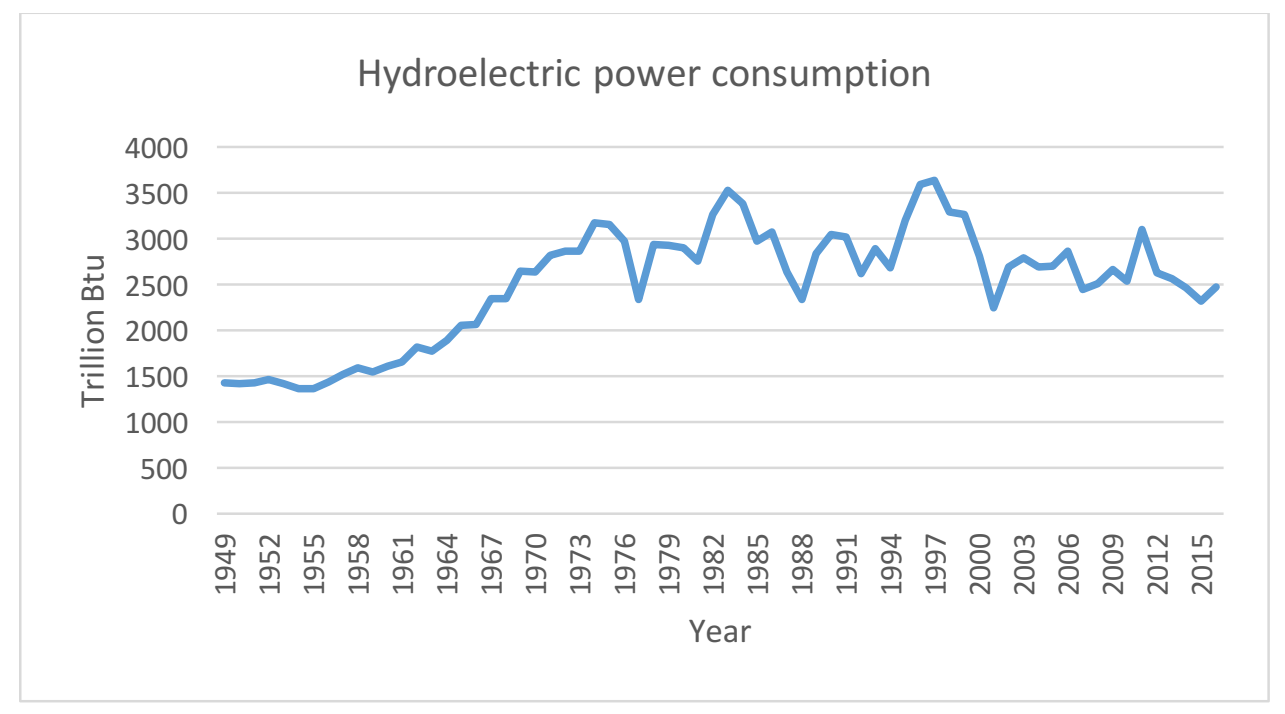

Figure 12- Hydroelectric net power consumption in the U.S.

\subsubsection{Wind}

The amount of wind energy consumed in the U.S. is another factor of interest in this research. The description of this variable is presented below. This data is available from 1983 to 2017 in terms of trillion BTU.

- Wind energy consumption represents the total volume of electricity generated from wind consumed in the U.S. This data set was converted to BTU by multiplying the total fossil fuels heat rate factors (see Appendix 5.2).

Figure 13 shows wind electricity net consumption in the U .S. from 1983 to 2017 . As Figure 13 demonstrates, wind energy consumption has increased exponentially over the last decade. 


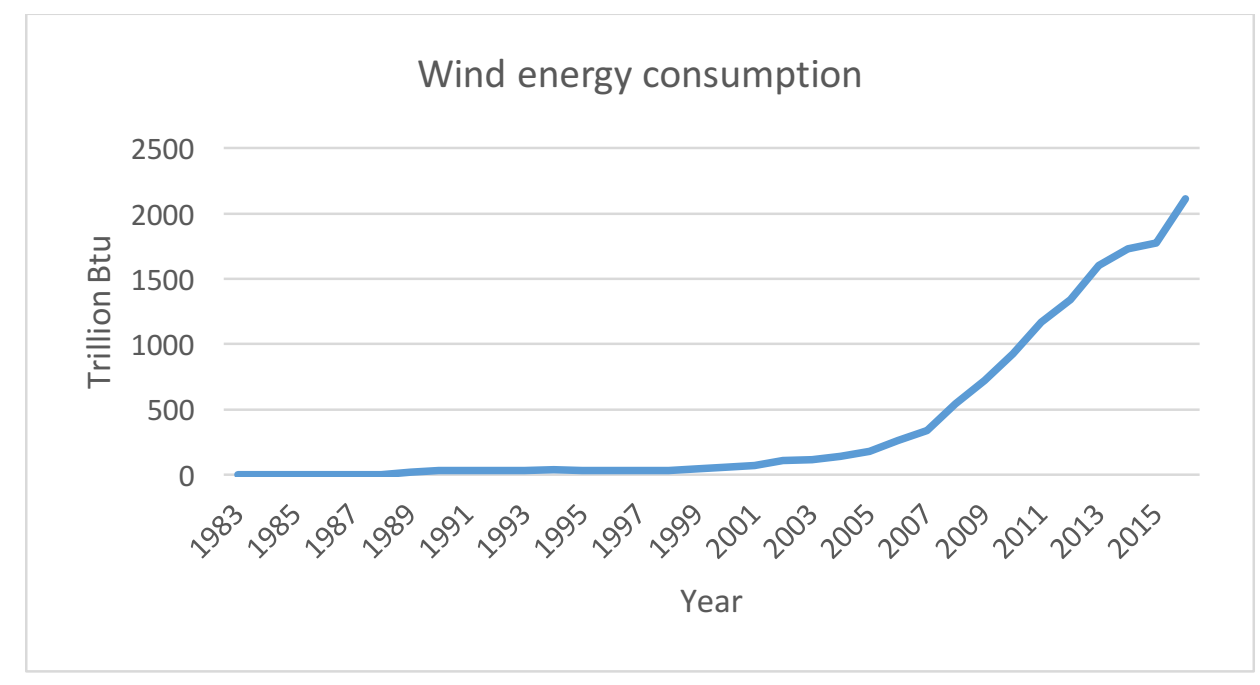

Figure 13- Wind electricity net consumption in the U.S.

\subsubsection{Solar}

Solar energy generated and consumed in the U.S. is a factor of interest in this research. The description of this variable is presented below. This data is available from 1984 to 2017 in terms of trillion BTU.

- Solar energy consumption represents the total volume of solar electricity consumed in the U.S. This data set converted was to BTU by multiplying the total fossil fuels heat rate factors (see Appendix 5.2).

Figure 14 shows solar electricity net consumption in the U.S. from 1984 to 2017. As demonstrated in Figure 14, it has increased exponentially in recent years. 


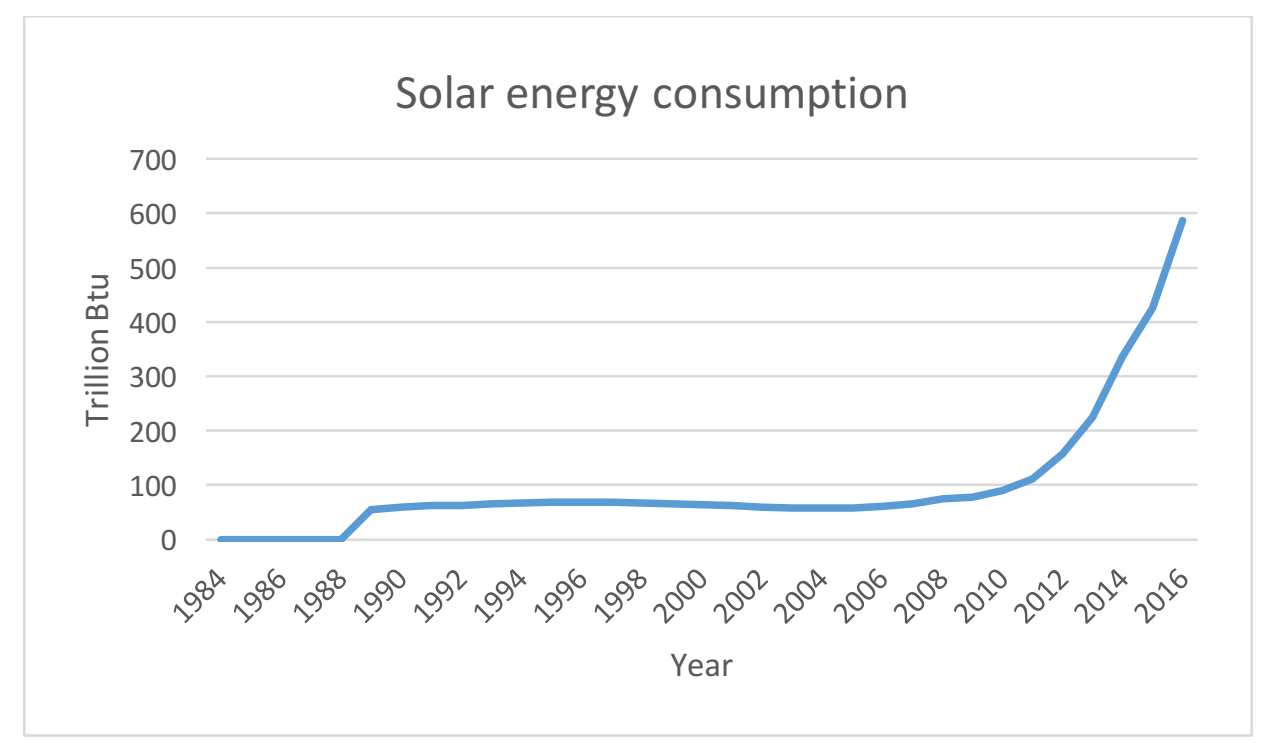

Figure 14- Solar electricity net consumption in the U.S.

\subsubsection{Geothermal}

Consumption of geothermal energy in the U.S. is another important factor considered in this research. The description for geothermal energy consumption is presented below. The dataset is available from 1960 to 2017 in terms of trillion BTU.

- Geothermal energy consumption represents the total volume of geothermal energy consumed in the U.S. This data set was converted to BTU by multiplying the total fossil fuels heat rate factors (see Appendix 5.2).

Figure 15 shows geothermal energy consumption in the U.S. from 1960 to 2017. As demonstrated in Figure 15, geothermal energy consumption has experienced a considerable increase over time. 


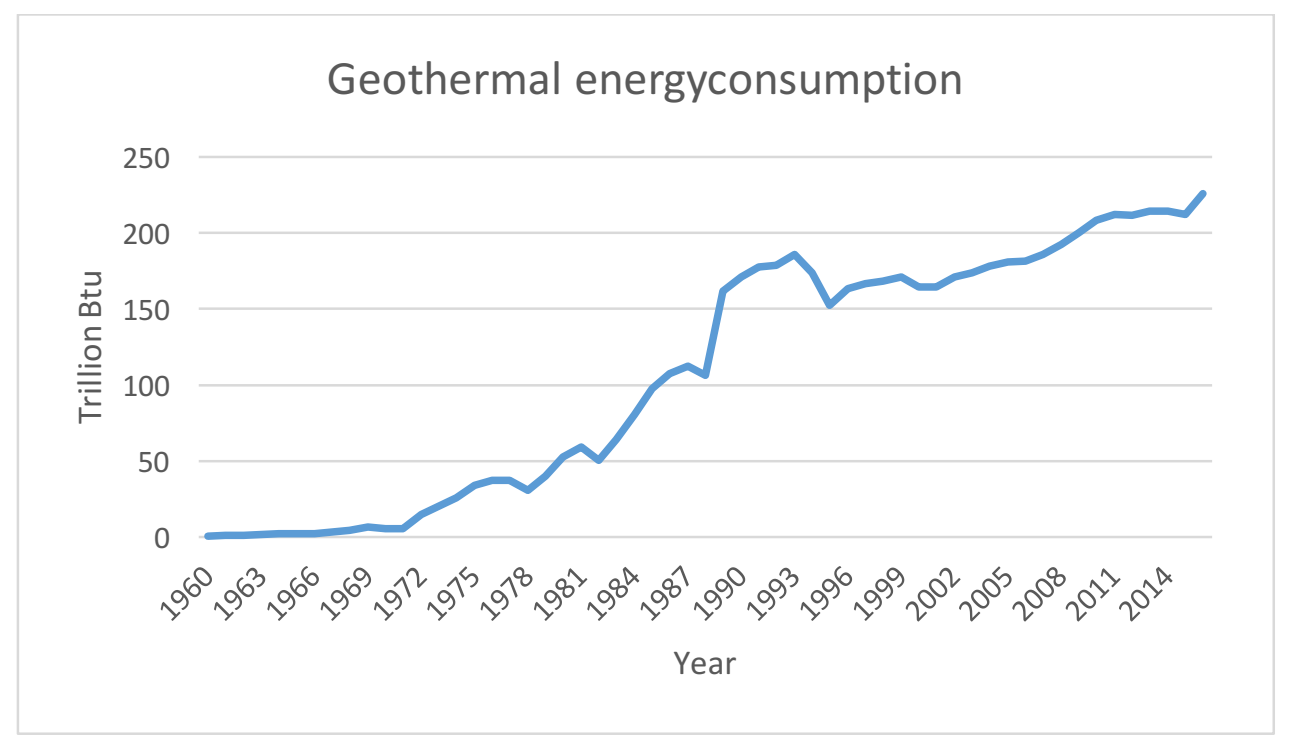

Figure 15- Geothermal energy consumption in the US.

\subsubsection{Population}

Another factor of interest to estimate the energy consumption is the population of the U.S. This data set which is produced by U.S. Census Bureau, is available from 1949 to 2017. Figure 16 illustrates increasing trend of the U.S. population from the middle of the $20^{\text {th }}$ century.

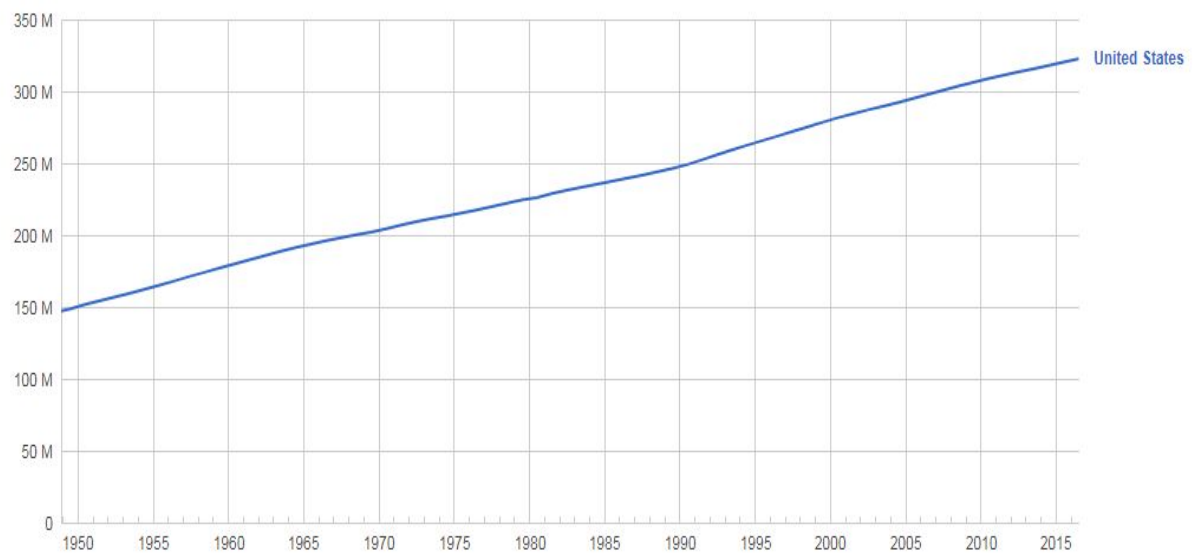

Figure 16- U.S. population data obtained from U.S. Census Bureau. 


\subsection{Data availability}

Time period considered to be used in this research is from 2004 to 2017 . Table 1 summarizes factors and their availability.

Table 1- Variables and their availability

\begin{tabular}{|c|c|c|}
\hline No. & Variable & Availability (Year) \\
\hline 1 & NG withdrawal & $1949-2017$ \\
\hline 2 & $\begin{array}{l}\text { NG consumed by the electricity } \\
\text { sector }\end{array}$ & $1949-2017$ \\
\hline 3 & NG import & $1949-2017$ \\
\hline 4 & NG price & $1997-2017$ \\
\hline 5 & Oil production & 1949-2017 \\
\hline 6 & $\begin{array}{l}\text { Oil consumed by the electricity } \\
\text { sector }\end{array}$ & $1949-2017$ \\
\hline 7 & Oil import & 1949-2017 \\
\hline 8 & Oil price & $1986-2017$ \\
\hline 9 & Coal production & $1949-2017$ \\
\hline 10 & $\begin{array}{l}\text { Coal consumed by the electricity } \\
\text { sector }\end{array}$ & 1949-2017 \\
\hline 11 & Coal import & $1949-2017$ \\
\hline 12 & Coal price & $1949-2017$ \\
\hline 13 & Nuclear electricity generation & $1957-2017$ \\
\hline 14 & Hydroelectric power consumption & $1949-2017$ \\
\hline 15 & Wind energy consumption & $1983-2017$ \\
\hline 16 & Solar energy consumption & $1984-2017$ \\
\hline 17 & Geothermal energy consumption & $1960-2017$ \\
\hline 18 & U.S. population & $1949-2017$ \\
\hline 19 & Fossil stream plant operating cost & $2006-2017$ \\
\hline 20 & Hydro-electric plant operating cost & $2006-2017$ \\
\hline 21 & Gas turbine plant operating cost & 2006-2017 \\
\hline 22 & Nuclear plant operating cost & 2006-2017 \\
\hline
\end{tabular}




\subsection{Methodology}

In this research, we aim to analyze historical data by quantitative forecasting methods to identify the relationship between market prices, efficiency or heat rate, $\mathrm{CO}_{2}$ emission, population and generated electricity from each primary energy source. We aim to extrapolate this finding to predict the future share of various energy sources to generate electricity.

First, historical data was collected which is described in section 1.5. Artificial Neural Network (ANN) is implemented in this research as the primary quantitative forecasting method. This method is reviewed in section 2.2. Next, in order to have accurate forecasting, variables were scaled and updated as shown in section 3.1. Three variables including scaled real market price, scaled heat rate, scaled $\mathrm{CO}_{2}$ emission and scaled U.S. population were incorporated in the model. Finally, the neural network algorithm and the hybrid ARIMA and ANN algorithm were constructed in section 3.3 and 3.4 respectively since multiple linear regression (MLR) did not fit a model with uncorrelated residuals in section 3.2.

Two ANN and hybrid ARIMA and ANN algorithms were implemented, and their performance associated with forecasting error is compared in section 3.5. The software that was used in this research is MATLAB, a high-performance language. MATLAB supports ANN computations to train complex models (Vedaldi \& Lenc, 2015). R software was used to fit MLR and ARIMA models to our data. 


\section{Chapter 2: Literature survey}

This chapter reviews some time-series forecasting techniques and intelligent forecasting algorithms as well as discussion and findings of the cited literature.

Time-series is a collection of observations that occur sequentially. The main characteristic of a time series is the dependency between the observations. The future pattern of a time series can be projected based on the behavior of current and past observations. Forecasting models that represent the statistical relation between current and previous observations are used to forecast future processes. Many statistical approaches are available to forecast the status of future processes, and an appropriate approach is chosen based on the purpose of forecasting exercise.

\subsection{ARMA forecasting model}

Forecasting models consist of deterministic and stochastic categories. Stochastic models express uncertainty associated with future observations. "Every environment is changing, and a good forecasting model captures the way in which things are changing (Hyndman \& Athanasopoulos, 2014)." In some models, the stochastic component or random noise is simply assumed independent of the process. However, this is not always a valid assumption. Autoregressive Moving Average (ARMA) is a model that incorporates both the dependency of random noise and deterministic components (Montgomery, Jennings, \& Kulahci, 2015).

ARMA is obtained by uniting the Autoregressive (AR) and Moving Average model (MA) models. 


\subsubsection{Autoregressive model}

AR models are presented by Yule (1926) as a representation of a type of random process. In an AR stochastic model, the predicted variable depends linearly on its own, previous values, and an error term. The AR model is:

$X_{t}=c+\varphi_{1} X_{t-1}+\varphi_{2} X_{t-2}+\cdots+\varphi_{p} X_{t-p}+\varepsilon_{t}$

When $X_{i}$ is the value of time series at time $i, \varphi_{1}, \varphi_{2}, \ldots, \varphi_{p}$ are parameters of the model, $c$ is a constant, and $\varepsilon_{t}$ is normal random noise at time $t$. The parameter $p$ is known as the order of AR model, and represents the number of previous time series values incorporated into the model.

Equation (2-1) can be rewritten in the following form:

$\varphi(B) X_{t}=c+\varepsilon_{t}$

when: $\varphi(B)=1-\varphi_{1} B-\varphi_{2} B^{2}-\cdots-\varphi_{p} B^{p}$

Here $B$ is the backward shift operator which is defined as:

$B x_{t}=x_{t-1}$

AR process can be stationary or nonstationary. The absolute value of roots of equation $\varphi(B)=0$ should be more than 1 when it is considered as a polynomial of $B$ in a stationary AR process. Equation (2-3) can be rewritten in a form of equation (2-5) where the roots of the equation are $G_{1}^{-1}, G_{2}^{-1}, \ldots, G_{p}^{-1}$.

$\varphi(B)=\left(1-G_{1} B\right)\left(1-G_{2} B\right) \ldots\left(1-G_{p} B\right)$

\subsubsection{Moving average models}

Slutzky (1937) introduced Moving Average (MA) models in which the predicted variable depends linearly on the current and various past values of white noise or random shock terms. MA has the form of:

$X_{t}=\mu+\varepsilon_{t}-\theta_{1} \varepsilon_{t-1}-\theta_{2} \varepsilon_{t-2}-\cdots-\theta_{q} \varepsilon_{t-q}$

When $X_{t}$ is the value of time series at time $t, \theta_{1}, \theta_{2}, \ldots, \theta_{q}$ are coefficients of the model, $\mu$ is a constant value, and $\varepsilon_{i}$ is normal random noise at time $i$. The parameter 
$q$ is known as the order of the MA model, and represents the number of previous time series values incorporated into the model. Random shocks at each point are supposed to have the same distribution, typically a Normal distribution with mean equal to zero and standard deviation equal to one.

Equation (2-6) can be rewritten in the following form where $B$ is the backward shift operator.

$\theta(B) \varepsilon_{t}=X_{t}-\mu$

when: $\theta(B)=1-\theta_{1} B-\theta_{2} B^{2}-\cdots-\theta_{q} B^{q}$

Since the MA model is obtained by the finite sum of weighted random shocks, the process is always stationary. No additional condition is required to make MA model with finite weights stationary. Invertibility condition for MA model ensures that present events are associated with the past events in a sensible way. To satisfy invertibility condition for the MA model, the absolute value of roots of equation $\theta(B)=0$ should be greater than one.

\subsubsection{Autoregressive moving average models}

AR model combined with MA model is used to build a more complicated mixed model called the ARMA. The ARMA model with $p$ AR terms and $q$ MA terms has the form of:

$$
\begin{gathered}
X_{t}=c+\left(\varphi_{1} X_{t-1}+\varphi_{2} X_{t-2}+\cdots+\varphi_{p} X_{t-p}\right)-\left(\theta_{1} \varepsilon_{t-1}+\theta_{2} \varepsilon_{t-2}+\cdots+\theta_{q} \varepsilon_{t-q}\right) \\
+\varepsilon_{t}
\end{gathered}
$$

The equation (2-9) can be rewritten as:

$X_{t}=c+\sum_{i=1}^{p} \varphi_{i} X_{t-i}-\sum_{i=1}^{q} \theta_{i} \varepsilon_{t-i}+\varepsilon_{t}$

$\varphi(B) X_{t}=c+\theta(B) \varepsilon_{t}$

For the process to be stationary, the absolute value of the roots of the function $\varphi(B)=0$ should be greater than one. To satisfy the invertibility condition, the absolute value of the roots of the function $\theta(B)=0$ must be greater than one. When 
a time series data does not have a constant mean, the process is not stationary. In a non-stationary process, autoregressive operator $\varphi(B)$ has roots that are greater than one.

ARMA model is estimated by Box-Jenkins method developed in Box, Jenkins, Reinsel, and Ljung (2015). Torres et al. (2005) perform a study to predict the hourly average wind speed via ARMA model. In this research, parameters are estimated by BoxJenkins method. Because of non-stationary nature of hourly wind speed, they first adjusted the time series. Their study also demonstrates that adjustments to the nonGaussian time series, transformation, and standardization, allow the ARMA model to behave significantly better. Pappas et al. (2008) successfully fit an ARMA model to electricity demand loads in Greece.

Some studies only focus on short-term forecasting (Brown, 1959), (Harrison, 1965). Harrison (1965) develops two methods to forecast short-term seasonal sale forecasts which are usually made during lead time. In this study, Brown's technique (1959) has been developed to improve seasonal forecasting. Some studies focus on non-Gaussian process (Samorodnitsky \& Taqqu, 1994), (Al-Smadi \& Wilkes, 1995). Al-Smadi and Wilkes (1995) present a new technique to estimate the order of a non-Gaussian ARMA process. They use higher order statistics based on the minimum eigenvalue of a family of covariance matrices derived from the observed data.

\subsubsection{General form of ARMA models}

A general form of an ARMA model to forecast non-stationarity data is Autoregressive integrated moving average (ARIMA). ARIMA was introduced by Box- Jenkins (Box et al., 2015). The ARIMA process with $(p, d, q)$ order is:

$$
\begin{gathered}
X_{t}=c+\left(\varphi_{1} \dot{X}_{t-1}+\varphi_{2} \dot{X}_{t-2}+\cdots+\varphi_{p} \dot{X}_{t-p}\right)-\left(\theta_{1} \varepsilon_{t-1}+\theta_{2} \varepsilon_{t-2}+\cdots+\theta_{q} \varepsilon_{t-q}\right) \\
+\varepsilon_{t}
\end{gathered}
$$

When $\dot{X}_{t}=\nabla^{d} X_{t}$. Here, $d$ time differencing $\left(\nabla^{d} X_{t}\right)$ produces a stationary $\operatorname{ARMA}(p, q)$ process. 
In an ARMA model, suppose that $\varphi(B)$ has $d$ roots, we can write the following equation:

$\phi(B)=\varphi(B)(1-B)^{d}$

Thus, non-stationary ARMA model can be written in the form of the following equation:

$\varphi(B)(1-B)^{d} X_{t}=c+\theta(B) \varepsilon_{t}$

Consider $\dot{X}_{t}=(1-B)^{d} X_{t}=\nabla^{d} X_{t}$, note that $(1-B) X_{t}=X_{t}-X_{t-1}=\nabla X_{t}$, and rewrite above equation. The ARMA model for non-stationary process is:

$\varphi(B) \dot{X}_{t}=c+\theta(B) \varepsilon_{t}$

The above equation shows that a stationary model can describe a non-stationary process after applying $d$ time differencing.

Tse (1997) fits real estate prices in Hong Kong into an ARIMA model. Since in the classical version of the ARIMA model, seasonal variation is not addressed, multiplicative seasonal ARIMA model is developed by Box-Jenkins (Box et al., 2015). Mohan and Vedula (1995) use multiplicative seasonal ARIMA model for monthly inflows into a reservoir system with logarithmic transformation. Their comparison of forecasted flows with the actual flows demonstrates that the ARIMA model is adequate for long-term forecasting of inflows (Mohan \& Vedula, 1995).

There is an idea that some information is lost through the modeling process. To determine the order of forecasting model, minimization information criteria that measure information loss is suggested (Burnham \& Anderson, 2003), (Hannan \& Quinn, 1979), (Akaike, 1974), (Schwarz, 1978). Akaike (1974) introduces Akaike Information Theoretical Criterion (AIC), and minimum information theoretical criterion estimate to maximum likelihood estimates of the parameters. Schwarz (1978) introduces Bayesian Information Criterion (BIC) to select one of the models of a different dimension. Liang et al. (1993) propose minimum description length criterion to determine the order of forecasting model. They analyze the effect of the ARMA root locations in pole-zero diagrams. The information criteria techniques are 
widely used to determine the best forecasting model (Watanabe, 2010), (Tan \& Biswas, 2012), (De'ath \& Fabricius, 2000).

\subsection{Neural network forecasting models}

Artificial neural network (ANN) is a flexible computing method inspired by organization and functioning of biological neurons in the brain (Hill et at. 1994). ANN is widely used as a forecasting method since it can learn and capture patterns among variables. The structure of neural network and learning process was first described by Donald O. Hebb who was a psychologist and worked in the area of neuropsychology (Hebb, 1980). Based on Hebb's rules, scientists developed the first ANN during 195060 's.

ANN became a modeling approach to solve problems requiring knowledge that is difficult to specify (Zhang, Patuwo, \& Hu, 1998). Thus, ANN has been utilized in many different fields such as business, industry and science, and many applications such as classification, identifications, optimization, and prediction. Zhang et al. (1998) provide a comprehensive review of research successfully used ANN to forecast a variable.

Like the human brain, a neural network is a collection of nodes called neurons which are computing units. Each of these neurons is connected to others and transmits signals through synapses (Jain, Mao, \& Mohiuddin, 1996). Synapses' job is to take a value from the input, multiply it by a specific weight, and output the results. Neurons take and send signals to several other neurons. Figure 17 demonstrates a simplified illustration of a neuron.

Neurons take input signals from synapses $\left(X_{i}\right)$, and apply combination or transfer function to output one value. The most popular function as combination function is the weighted sum. In Figure 17, this function is shown by a circle. Then, neurons apply output function which is defined for each neuron. This function is called the activation function, and allows the ANNs to model non-linear patterns. Depending on the application of ANN, different output functions can be selected. For example, the linear 
function is proper for linear regression problem. This function is shown by a square in Figure 17.

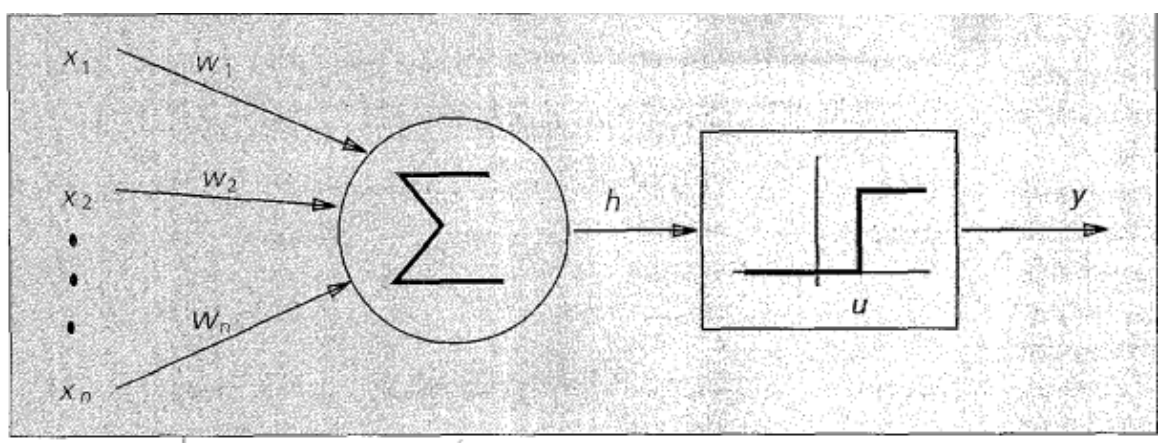

Figure 17- Model of the neuron (Jain et al., 1996)

Neural networks have different architectures according to the application for which they are used. Also, the way of knitting neurons together differs. Finding the optimal architecture of the neural network is a complicated job which is discussed in section 2.2.1. After designing a neural network, different algorithms are used to train the network.

The difference between the ideal output value and the actual output value in a neural network is called the error function. The error function depends on the synaptic weights. Since the value of error represents how a neural network fits the data set, the neural network learns weights on synapses and estimate them to minimize the error function. Trying different weights to find the best combination of weights is time-consuming, and impossible for a problem with a large number of neurons and synapses.

Fortunately, the problem of minimizing continuous functions has been widely studied, and many approaches are directly applicable to the training of neural networks efficiently. Some of the popular learning algorithms and their underlying concepts are reviewed in section 2.2.2.

The procedure for modeling an ANN is summarized in the following pseudocode. 


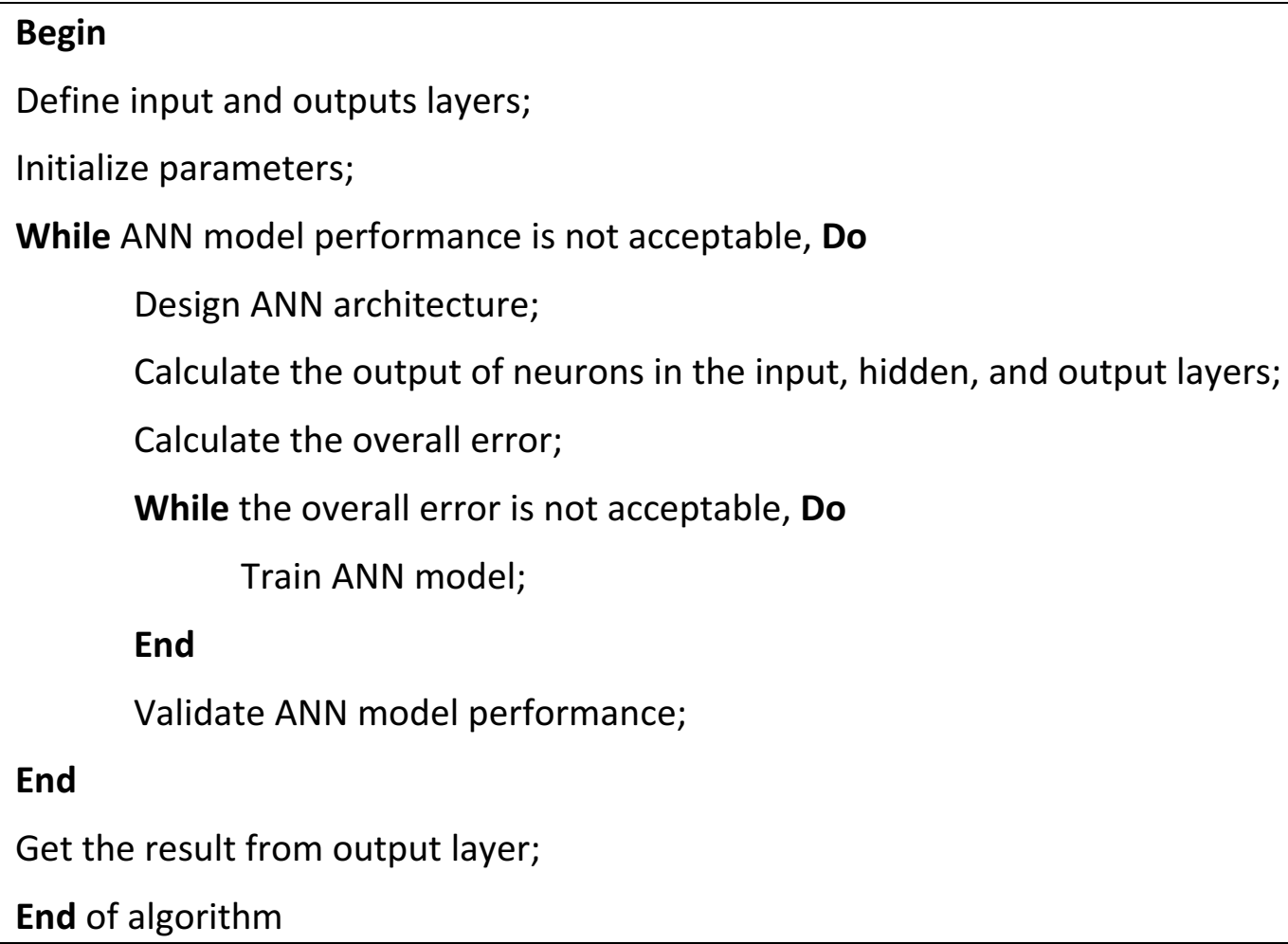

Tang and Fishwick (1993) study neural networks as models for long-term and shortterm time series forecasting. This study compares the performance of the neural networks with the Box-Jenkins method in different experiments. Tang and Fishwich's experiment indicate that neural network outperformed the Box-Jenkins model applied for short-term time series. They also state that neural networks and Box-Jenkins method generate comparable results for the long-term forecast.

\subsubsection{The optimal architecture of a neural network}

There are many types of neural networks. Feedforward and recurrent neural network are two of the more popular types. Feedforward ANN is a popular design which consists of three different input, hidden, and output layers. We may define more than one layer as a hidden layer (Sandberg, 2001).

If only one layer is defined as a hidden layer, then, the feedforward network is called three-layer feedforward network. In this design, neurons of the input layer feed neurons in the next layer which is a hidden layer. Neurons in the hidden layer process 
the input data, and feed the layer above them or the output layer. Figure 19 shows a sample of three-layer feedforward network.

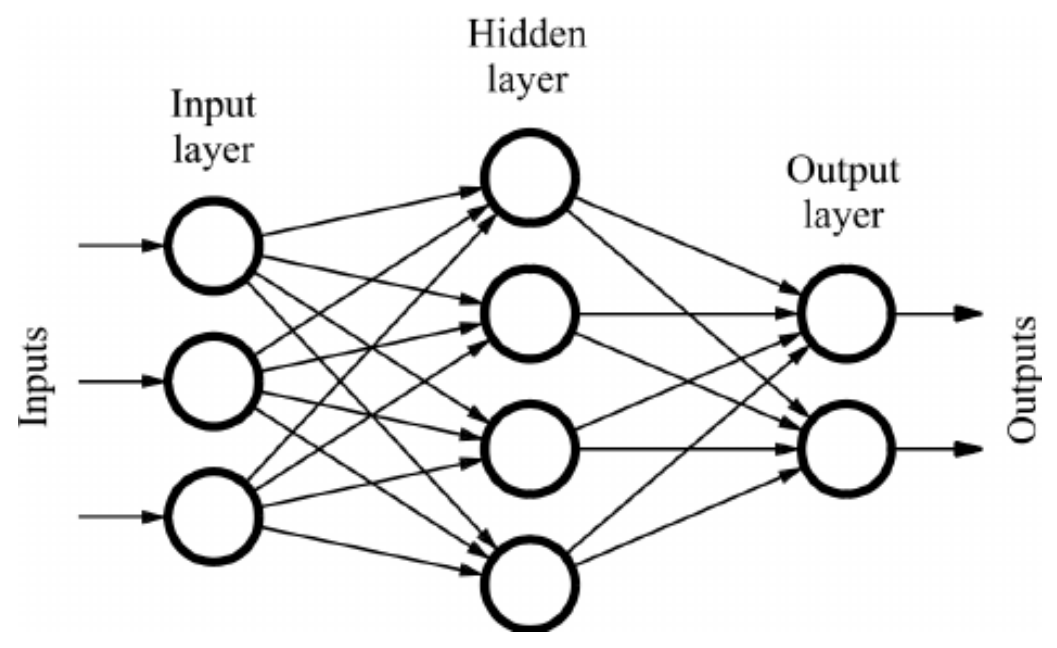

Figure 19- Example of feedforward neural network (Davim, 2011)

Another type of network is a recurrent or recursive network in which neurons can feed themselves, neurons of preceding layers, and neurons of the same layer. Figure 20 shows an example of a recurrent network.

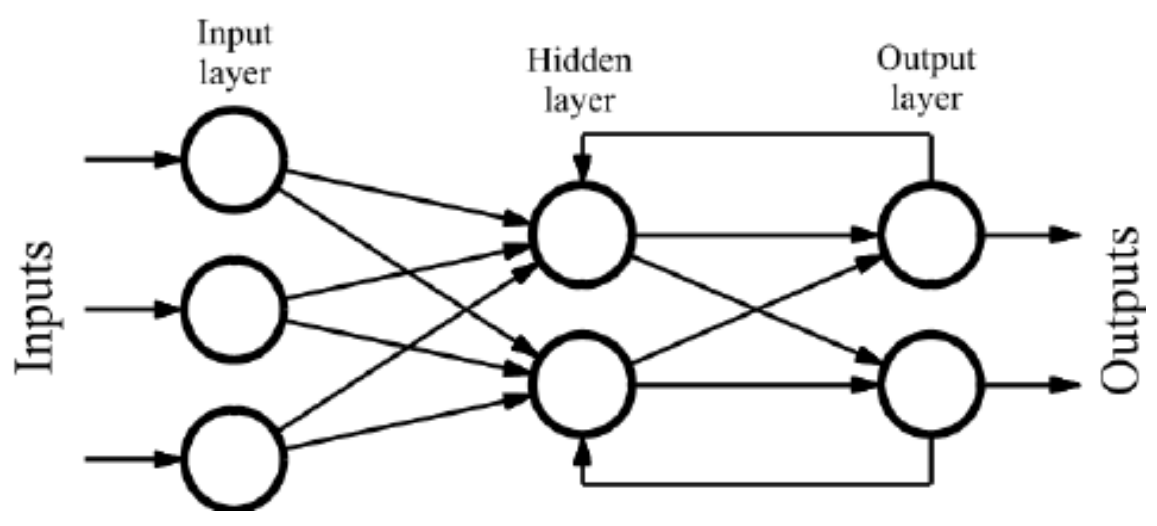

Figure 20- Example of a recurrent neural network (Quiza \& Davim, 2009)

Finding the optimal architecture of a neural network is a complex job. The number of layers, the number of nodes in layers, and the number of synapses in a network should be determined to build a neural network. Many different approaches are developed 
to determine these parameters and design a network (Karnin, 1990), (Reed, 1993), (Cottrell et al. 1995). However, applying these methods does not guarantee that the optimal architecture can be found.

Tang and Fishwick (1993) find out that the number of hidden nodes on neural network model affects forecasting performance. However, this effect is not significant, and neural networks are robust. Zhang et al. (1998) consider the number of input nodes as the most critical decision variable for a time series forecasting problem in a neural network. They argue that input nodes contain information about the complex autocorrelation structure in the data. They also suggest determining the number of input nodes by theoretical research in nonlinear time series analysis.

The number of output nodes is another important parameter in neural network architecture which is determined by the forecasting horizon. Only one output node will be assigned to a neural network to forecast one period or multiple periods in the future using Box-Jenkins iterative forecasting in which predicted value is iteratively used as input to generate the next forecast. More output nodes will be assigned to neural network forecasting direct multiple periods. Zhang et al. (1998) state that direct multiple period forecasting is better than iterative forecasting method in the neural network.

\subsubsection{Training neural networks}

Training algorithms for neural networks are developed to search and find optimum synaptic weights at which the error function takes a minimum value (Bishop, 2013). In general, the error function is non-linear. The basic idea to find optimal weights in training algorithms is to generate a sequence of weight vectors so that the error function is reduced at each iteration of the algorithm. The initial weight vector can be chosen randomly. When a specified condition is satisfied, the algorithm stops.

Back-Propagation (BP) is one of the popular learning algorithms. BP was first described by Werbos (1994). In this algorithm, derivatives of error functions with respect to network weight are computed. Then, non-linear optimization algorithms such as 
gradient descent or quasi-Newton method are applied to find the best weights in each iteration, and the network weights are updated based on obtained partial derivatives. The BP as a learning algorithm has many variations. Gradient descent BP steps may apply after each observation, called one-line learning, or after passing all data points through the network called batch learning. In addition to gradient descent, other nonlinear optimization algorithms such as Newton's method, quasi-Newton, LevenbergMarquardt can be used in BP to train the neural network.

Gradient descent may be used as an optimization algorithm to move toward minimum error. This method considers a point as a start point $a_{n}$, takes a step proportional to the negative of the gradient $\nabla F\left(a_{n}\right)$, then moves to a new point $a_{n+1}$. In this optimization algorithm, gradienthe $t$ is the direction that the error function decreases most rapidly, and can be found from derivatives.

$a_{n+1}=a_{n}-\gamma \nabla F\left(a_{n}\right)$

Newton's method is another optimization algorithm that may be applied to move toward the minimum error point. In this optimization algorithm, the second derivatives of the error function and inverse Hessian $\left(H_{n}^{-1}\right)$ are used to find the direction of the next move.

$a_{n+1}=a_{n}-\gamma H_{n}^{-1} \nabla F\left(a_{n}\right)$

when: $\quad f\left(a_{n}+\Delta x\right)=f\left(a_{n}\right)+\nabla f\left(a_{n}\right)(\Delta x)+0.5 \Delta x^{T} H \Delta x$

The quasi-newton method builds an approximation to the inverse Hessian $J$ which only needs first derivatives of the error function. Thus, it requires fewer operations to evaluate compared to the Newton method. This algorithm converges faster than gradient descent.

$a_{n+1}=a_{n}-\gamma\left(J_{n}\right) \nabla F\left(a_{n}\right)$

The Levenberg-Marquardt algorithm is primarily used to solve the least square problem (Yu \& Wilamowski, 2011). This method computes the approximation for Hessian matrix and gradient with the Jacobian matrix. The gradient vector of the least square function is computed as equation 2-20 where e is a vector of errors. 
Also, Hessian matrix is computed with the following expression where $\lambda$ is a factor to ensure the positivity of the Hessian and $I$ is the identity matrix.

$H=2 \cdot\left(J^{T} \cdot J+\lambda \cdot I\right)$

Thus, Levenberg-Marquardt improvement process is defined as:

$a_{n+1}=a_{n}-\left(J_{n}^{T} \cdot J_{n}+\lambda_{n} \cdot I\right)^{-1}\left(2 \cdot J_{n}^{T} \cdot e_{n}\right)$

When $\lambda$ is zero, equation $2-22$ is similar to Newton's method. Also, when $\lambda$ is large, this algorithm tends to become similar to gradient descent. This algorithm works well for small and medium size networks.

\subsubsection{Performance of a neural network}

The performances of the neural network compared to statistical models is questionable since neural network performance depends on many architectural and design factors. Many studies compare the results of statistical forecasting and neural networks.

Ho, Xie, and Goh (2002) perform a study to compare the performance of Box-Jenkins ARIMA and the ANNs forecasting models for a repairable compressor system failure. They conclude that recurring neural network, at the optimal weighting factor, performs better than the ARIMA model. Lam and Oshodi (2016) also compare ARIMA and neural network forecasting results on the volume of construction work in Hong Kong. They find that neural network model provides accurate forecast compared to the ARIMA for their medium-term planning.

Niaki and Hoseinzade (2013) forecast the daily direction of Standard \& Poor's 500 index by ANN. They select the most influential factors affecting the response (daily direction of S\&P 500) in the first step of their study. They present the results of developed ANN. Gorr, Nagin, and Szczypula (1994) compare the results obtained by linear regression, stepwise polynomial regression, and single middle layer ANNs model for predicting student grade point averages. Their study shows that there are no 
significant statistical differences between the performance of the different methods applied.

Many algorithms are developed to enhance the performance of forecasting with ANNs. Pelikan et al. (1992) suggest combining several neural networks. This study shows that the result obtained from the suggested method is better than applying a single neural network. Ginzburg and Horn (1994) also combine two ANNs as a new predictor. In their study, the first network models the time series, and the second network models the residual from the first network. They test the new combined network; results demonstrate that the combined network is better than a single network.

Moreover, Reed (1993) presents pruning algorithm to reduce the complexity of the network and improve the results. Reed trains a network that is larger than necessary and removes unnecessary parts. Cottrell et al. (1995) propose a stepwise statistical method which is a systematic methodology to simplify neural network architecture by determining nonsignificant weights. They combine the statistical techniques of linear and nonlinear time series with the connectionist approach in their study. Lachtermacher and Fuller (1995) implement mixed Box-Jenkins and ANNs method to minimize the size of the network. In their study, Box-Jenkins method is implemented to identify the appropriate ARIMA model.

\subsection{Hybrid forecasting models}

Different hybrid methods have been proposed in the literature to improve forecasting outcomes. Yu, Wang, and Lai (2005) integrate generalized linear autoregression (GLAR) with ANN to obtain accurate forecasting model for the exchange rate. Their nonlinear ensemble model is used to forecast foreign exchange market rate. They compare the results obtained by the proposed method with ANN and GLAR forecasting models, the linear combination model, and the hybrid model. They show that the prediction with the nonlinear ensemble model is better than the other models included in the comparison. 
Gairaa et al. (2016) state that since the ARMA model is unable to capture the nonlinear characteristics of the data, ANN as a nonlinear modeling method can be combined with ARMA to capture both linear and nonlinear patterns. Gairaa et al. (2016) apply combined ARMA and ANN algorithm and estimate the daily global solar radiation by using the new method.

They first perform ARMA to model the linear part of the daily global radiation. Then, ANN is used to model the obtained ARMA residuals as a nonlinear component. Faruk (2010) also applies the same procedure to predict a water quality time series. In Gairaa's study, global solar radiation data recorded from 2012 to 2013 for two Algerian climate sites are used to test the developed method. They show that the obtained results improved by implementing their combined method compared to ARMA and ANN models.

The pseudocode for their algorithm is summarized in Figure 21.

\section{Begin}

Estimate ARMA model as linear component $(L)$;

Calculate the residuals of $\operatorname{ARMA}(e=y-\hat{L})$;

Use ANN and model $e=\theta(B) \varepsilon$ as non-linear component $(N)$;

Combine estimations $(y=L+N)$;

End of hybrid ARMA and ANN algorithm

Figure 21- The pseudocode of hybrid ARMA and ANN algorithm applied in (Gairaa et al., 2016)

Hybrid ARMA and ANN can be designed with two different chains of neurons: a chain to represent $A R$, and a chain to represent MA section of the ARMA model. Each neuron of $A R$ and MA sub-network receives inputs and outputs the results. In this hybrid algorithm, the output of neurons passes to the next neurons in the same sub-network. Thus, both $A R$ and MR sub-networks operate identically. However, the AR subnetwork receives time series value as an input, but the MA sub-network receives shocks. This algorithm is proposed by Rose (2015). Figure 22 represents the pseudocode of this hybrid ARMA and ANN algorithm. 


\section{Begin}

Design ANN with two sub-networks;

Use first sub-network of ANN and model MA component $(L)$;

Use second sub-network of ANN and model AR component $(N)$;

Combine estimations $(y=L+N)$;

End of hybrid ARMA and ANN algorithm

Figure 22- pseudocode of hybrid ARMA and ANN algorithm proposed in (Rose, 2015)

Some studies combine ARIMA and ANN to take advantage of the strengths of both models in linear and nonlinear modeling. Zhang (2003) implements a hybrid method that combines ARIMA and ANN. The underlying idea for his approach is similar to the approach used in (Gairaa et al., 2016). He uses the ARIMA model instead of the ARMA in Gairaa's algorithm (2016).

In their study, three datasets including Wolf's sunspot data, Canadian lynx data, and British pound/US dollar exchange rate are used to test the proposed hybrid method. Zhang shows that combined method improves the forecasting accuracy compared to the results achieved by either of the models used separately for the three datasets.

Tseng et al. (2002) aim to predict seasonal time series data. They apply a hybrid model that combines the seasonal ARIMA and the ANN. In this study, two seasonal time series datasets including total production value of Taiwan machinery industry and soft drink consumption are tested. They compare the performance of their developed method with seasonal ARIMA model, neural network models with differenced data, and neural network models with deseasonalized data. They also show that their obtained model generates the best result with the lowest error.

However, Khashei and Bijari (2011) believe that using hybrid models to forecast time series is risky. They refer to the common assumption in hybrid algorithms that the relationship between the linear and nonlinear components is additive. They also explain how this assumption may affect the performance of the predictors. They also 
mention that the residuals of the linear component may not comprise valid nonlinear patterns (Khashei \& Bijari, 2011).

Khashei and Bijari (2011) propose hybridization of ANN and ARIMA models without assuming additivity between linear and non-linear components aiming to achieve more generality of the application of their proposed method. They guarantee that the performance of the proposed model is superior to the separate use of ARIMA and ANN models. Figure 23 represents the pseudocode of their hybrid ARIMA and ANN algorithm.

They test the new hybrid method and compare the accuracy of the obtained forecasting model with traditional hybrid ARIMA-ANNs models. In this study, three real datasets are used to test the proposed method against those tested by Zhang (2003) including Wolf's sunspot data, the Canadian lynx data, and the British pound/US dollar exchange rate data.

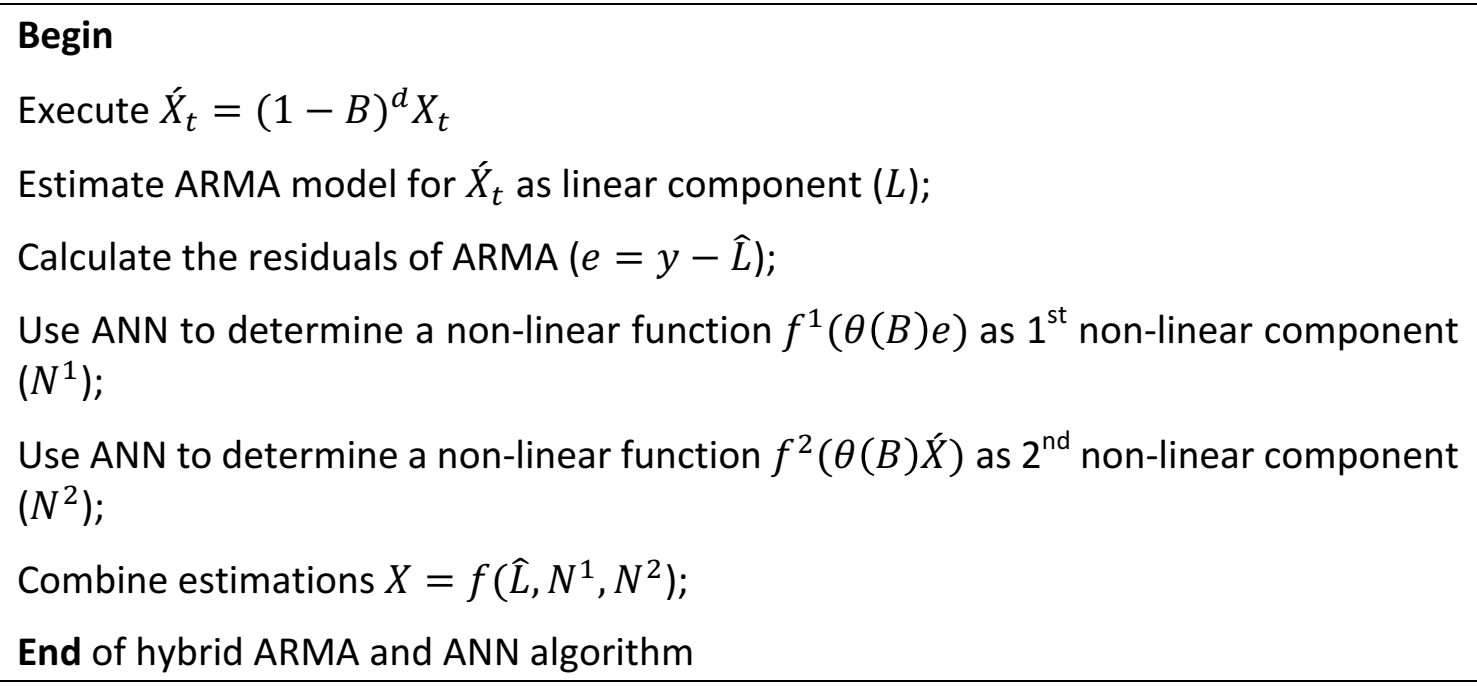

Figure 23-pseudocode of hybrid ARMA and ANN algorithm proposed in (Khashei \& Bijari, 2011) 


\section{Chapter 3: Methodology}

This chapter applies MLR, ANN forecasting algorithm, ARIMA model, and hybrid ARIMA and neural network algorithm to find an accurate forecasting model for the amount of electricity in terms of kWh that is generated from different primary energy sources including fossil fuel, renewable energy, and nuclear.

\subsection{Model preparation}

To forecast the future amount of electricity generated from various primary energy sources, four independent variables were considered. They are market price of primary energy sources, heat rate, carbon dioxide emission, and population. This section defines the four independent variables.

\subsubsection{The market price of primary energy sources}

The market price of primary energy sources is an important factor that influences the amount of electricity that is generated from them. In this study, the adjusted price of natural gas, crude oil, and coal was calculated to remove the effect of changes in the purchasing power of the dollar since the available data is the nominal price of natural gas, crude oil, and coal that have not been adjusted for inflation.

The real, or adjusted, prices are used to remove the effect of changes in the purchasing power of the dollar. In this research, real prices are computed by dividing the nominal price in each month by the ratio of the Consumer Price Index (CPI- See Appendix 5.1) in that month to the CPI in November 2017 as the base period. Consequently, all real prices are expressed in the 2017 base dollar. This enables us to compare prices with the past and projected real prices since prices are expressed in the same dollar values. Figure 24 demonstrates the adjusted, or real, and nominal prices that were used in this research. 


$$
R P_{i t}=\frac{\text { Price of energy type } i \text { in month } t}{\frac{\text { CPI in month } t}{\text { CPI in November, } 2017}}
$$

In the next step, the real price of primary energy was calculated in terms of $\$ / k W h$ by using the following equations:

$P_{\text {Coal }, t}\left(\frac{\$}{k W h}\right)=\frac{R P_{\text {Coal }, t}\left(\frac{\$}{\text { metric tons }}\right) \times \text { Heat rate }_{\text {Coal }}\left(\frac{B T U}{k W h}\right) \times 0.907184}{19.78 \times 10^{6}}$

$P_{N G, t}\left(\frac{\$}{k W h}\right)=\frac{R P_{N G, t}\left(\frac{\$}{\text { million BTU }}\right) \times \text { Heat rate } \text { ra }\left(\frac{B T U}{k W h}\right)}{10^{6}}$

$P_{\text {Oil }, t}\left(\frac{\$}{k W h}\right)=\frac{R P_{\text {Oil }, t}\left(\frac{\$}{\text { barrel }}\right) \times \text { Heat rate }_{\text {Oil }}\left(\frac{B T U}{k W h}\right)}{5.8 \times 10^{6}}$

To produce a dimensionless variable, $P R_{i t}$ was defined as:

$$
P R_{i t}=\frac{P_{i t}}{\operatorname{maximum} P_{i}}
$$

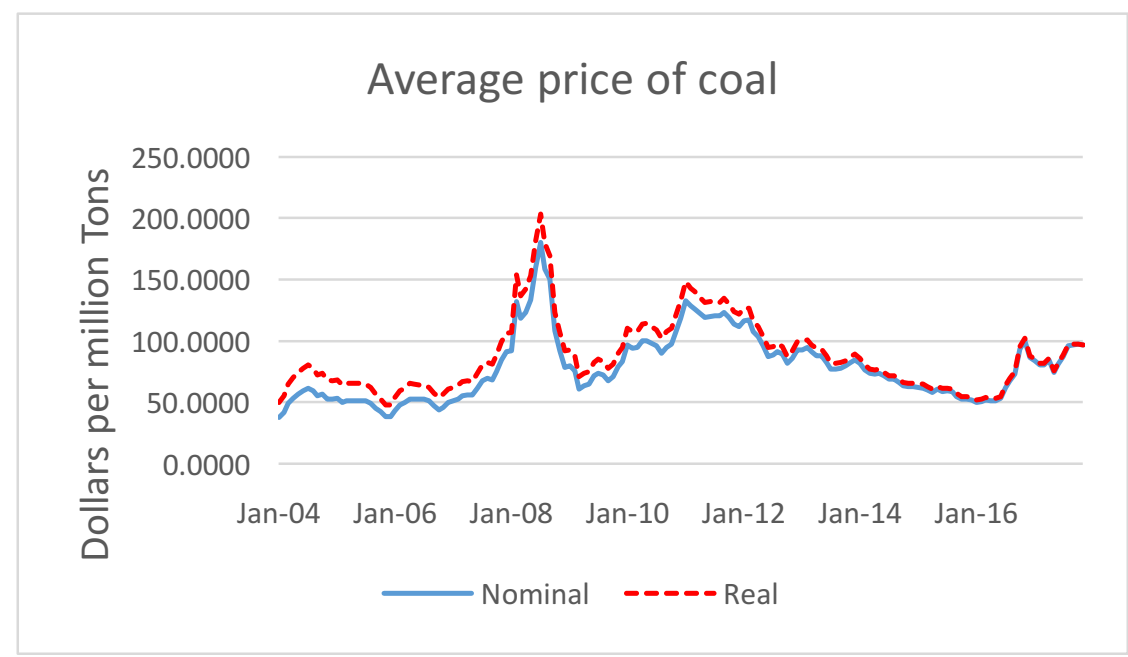



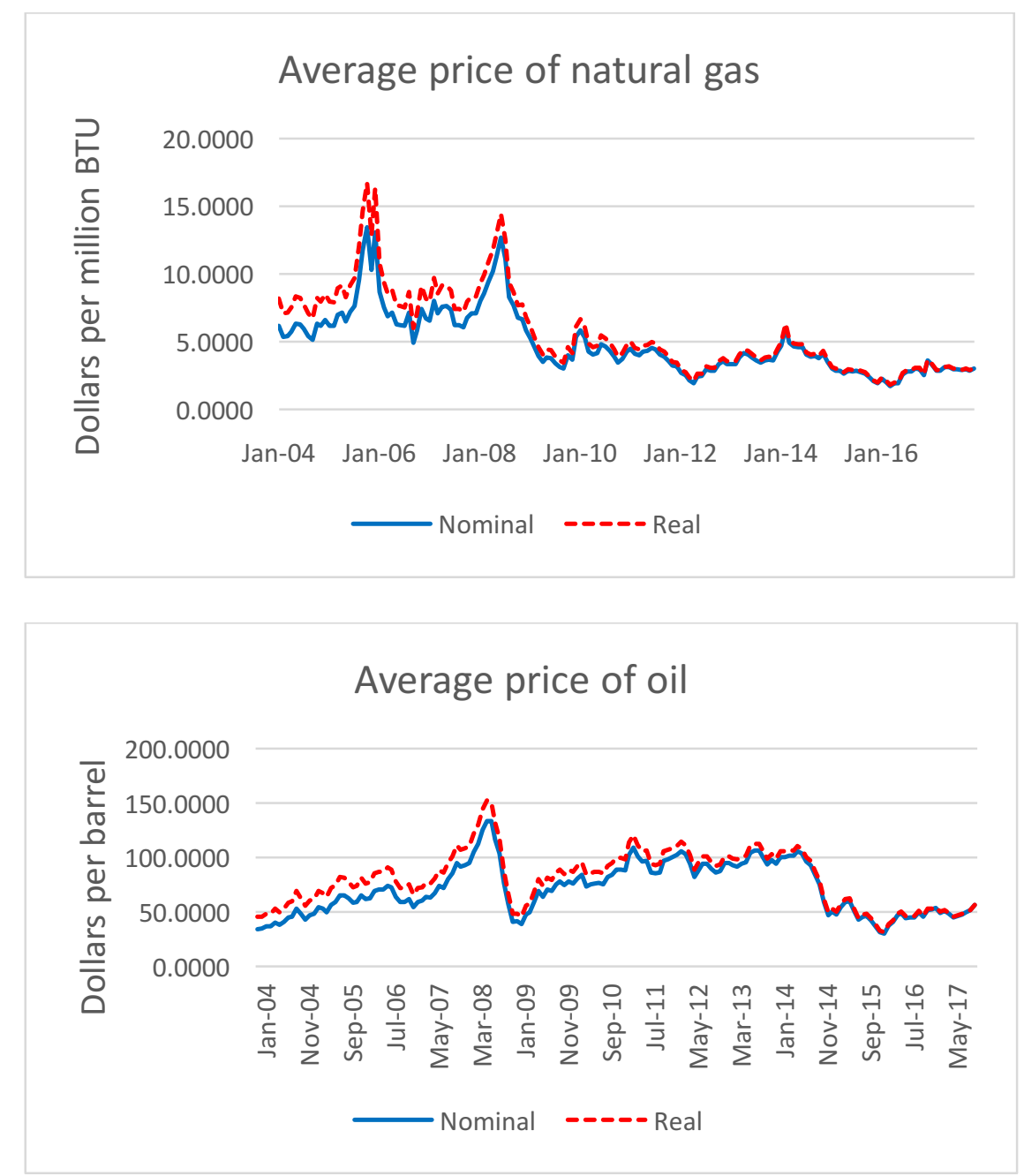

Figure 24- Nominal and the real price of coal, natural gas, and crude oil

\subsubsection{Heat rate of primary energy sources}

To incorporate the efficiency of different primary energy sources in our model, scaled heat rate was calculated. The heat rate is the amount of primary energy used by a power plant to generate a unit $(1 \mathrm{kWh})$ of electricity. The heat rate for different primary energy sources from 2004 to 2017 was obtained from the EIA in terms of Btu per kWh (Appendix 5.2).

To make the heat rate dimensionless, the independent variable $h_{i t}$ was defined by the following equation:

$h_{i t}=\frac{\text { Heat rate of energy type } i \text { at year } t(B t u / k W h)}{\text { maximum heat rate of energy type } i(B t u / k W h)}$ 


\subsubsection{Carbon dioxide emission}

Carbon dioxide $\left(\mathrm{CO}_{2}\right)$ emissions from power plants is another factor of interest. Equation 3-7 was used to compute the rate of $\mathrm{CO}_{2}$ emissions for different types of power plants.

$C E_{i t}\left(\frac{\text { ton }}{k W h}\right)=\frac{\left.\mathrm{CO}_{2} \text { emitted from energy } i \text { at month } t \text { (million metric ton }\right)}{\text { Electricity generated from energy } i(\text { million } \mathrm{kWh})}$

To make this rate scale-less, variable $C_{i t}$ was defined as below:

$C_{i t}=\frac{C E_{i t}\left(\frac{t o n}{k W h}\right)}{\text { maximum } C E_{i}}$

\subsubsection{Population}

To incorporate U.S. population, the scaled population was calculated and incorporated in our model.

$Q_{t}=\frac{U . S . \text { population at month } t}{\text { maximum population }}$

\subsection{Multiple linear regression for generated electricity}

Multiple linear regression (MLR) was first used to fit a model of the amount of electricity generated from different primary energy sources. The obtained results are summarized in Figure 25.

A good MLR forecasting method results in uncorrelated residuals. To detect the presence of autocorrelation at lag 1 in the residuals, the Durbin-Watson test was used (Durbin \& Watson, 1950). The null hypothesis of this test is uncorrelated residuals against the alternative that residuals follow a first-order autoregressive process. The corresponding $\mathrm{p}$-value of each test is reported in Figure 25. Also, the correlation between successive residuals was computed and reported in Figure 25. 
Coal:

\begin{tabular}{|l|l|}
\hline $\begin{array}{l}\text { Residual standard } \\
\text { error }\end{array}$ & 15.83 \\
\hline R square & 0.6825 \\
\hline $\begin{array}{l}\text { Cor. successive } \\
\text { residual }\end{array}$ & 0.6873 \\
\hline $\begin{array}{l}\text { Durbin-Watson } \mathrm{p}- \\
\text { value }\end{array}$ & $7.365 \mathrm{e}-16$ \\
\hline
\end{tabular}

Oil:

\begin{tabular}{|l|l|}
\hline $\begin{array}{l}\text { Residual standard } \\
\text { error }\end{array}$ & 1.304 \\
\hline R square & 0.821 \\
\hline $\begin{array}{l}\text { Cor. successive } \\
\text { residual }\end{array}$ & 0.4633 \\
\hline $\begin{array}{l}\text { Durbin-Watson p- } \\
\text { value }\end{array}$ & $1.782 \mathrm{e}-09$ \\
\hline
\end{tabular}

Hydroelectric:

\begin{tabular}{|l|l|}
\hline $\begin{array}{l}\text { Residual standard } \\
\text { error }\end{array}$ & 4.101 \\
\hline R square & 0.0111 \\
\hline $\begin{array}{l}\text { Cor. successive } \\
\text { residual }\end{array}$ & 0.6945 \\
\hline $\begin{array}{l}\text { Durbin-Watson } \mathrm{p}- \\
\text { value }\end{array}$ & $2.2 \mathrm{e}-16$ \\
\hline
\end{tabular}

Wind:

\begin{tabular}{|l|l|}
\hline $\begin{array}{l}\text { Residual standard } \\
\text { error }\end{array}$ & 1.759 \\
\hline R square & 0.8815 \\
\hline $\begin{array}{l}\text { Cor. successive } \\
\text { residual }\end{array}$ & 0.6270 \\
\hline $\begin{array}{l}\text { Durbin-Watson } \mathrm{p}- \\
\text { value }\end{array}$ & $4.89 \mathrm{e}-14$ \\
\hline
\end{tabular}

Natural Gas:

\begin{tabular}{|l|l|}
\hline $\begin{array}{l}\text { Residual standard } \\
\text { error }\end{array}$ & 14.59 \\
\hline R square & 0.5077 \\
\hline $\begin{array}{l}\text { Cor. successive } \\
\text { residual }\end{array}$ & 0.6414 \\
\hline $\begin{array}{l}\text { Durbin-Watson } \mathrm{p}- \\
\text { value }\end{array}$ & $4.531 \mathrm{e}-15$ \\
\hline
\end{tabular}

Geothermal:

\begin{tabular}{|l|l|}
\hline $\begin{array}{l}\text { Residual standard } \\
\text { error }\end{array}$ & 0.0512 \\
\hline R square & 0.3282 \\
\hline $\begin{array}{l}\text { Cor. successive } \\
\text { residual }\end{array}$ & -0.0131 \\
\hline $\begin{array}{l}\text { Durbin-Watson } \mathrm{p}- \\
\text { value }\end{array}$ & 0.4063 \\
\hline
\end{tabular}

Solar:
\begin{tabular}{|l|l|}
\hline $\begin{array}{l}\text { Residual standard } \\
\text { error }\end{array}$ & 0.3168 \\
\hline R square & 0.4927 \\
\hline $\begin{array}{l}\text { Cor. successive } \\
\text { residual }\end{array}$ & 0.9608 \\
\hline $\begin{array}{l}\text { Durbin-Watson } \mathrm{p}- \\
\text { value }\end{array}$ & $2.2 \mathrm{e}-16$ \\
\hline
\end{tabular}

Nuclear:
\begin{tabular}{|l|l|}
\hline $\begin{array}{l}\text { Residual standard } \\
\text { error }\end{array}$ & 5.091 \\
\hline R square & 0.0006 \\
\hline $\begin{array}{l}\text { Cor. successive } \\
\text { residual }\end{array}$ & 0.3980 \\
\hline $\begin{array}{l}\text { Durbin-Watson p- } \\
\text { value }\end{array}$ & $5.775 \mathrm{e}-07$ \\
\hline
\end{tabular}

Figure 25-Summary of MLR result

Figure 26 illustrates the relation between successive residuals. Based on the result of the Durbin-Watson test and successive residuals plots, it can be concluded that the obtained residuals are correlated. 
Coal:

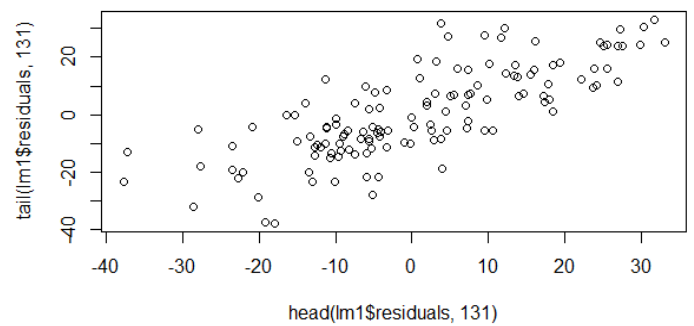

Oil:

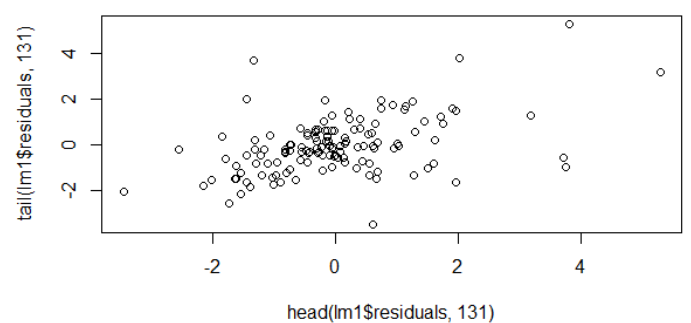

Hydroelectric:

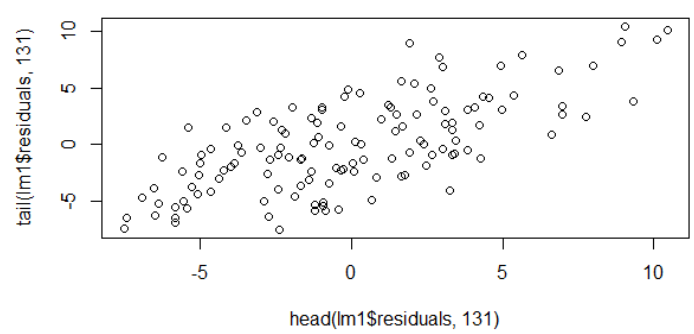

Wind:

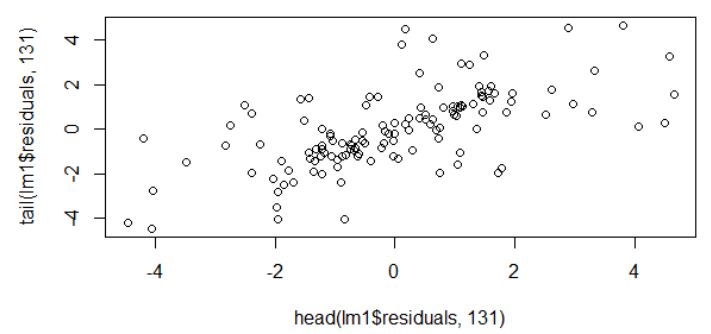

Natural Gas:

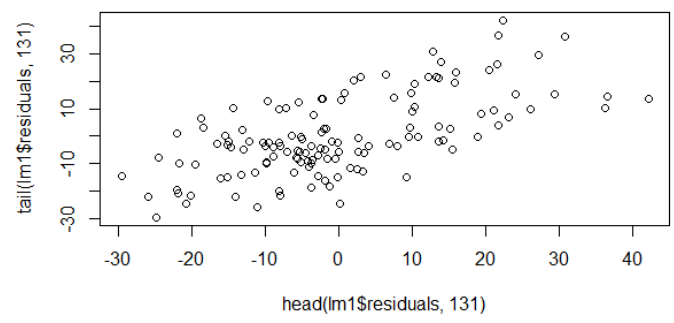

Geothermal:

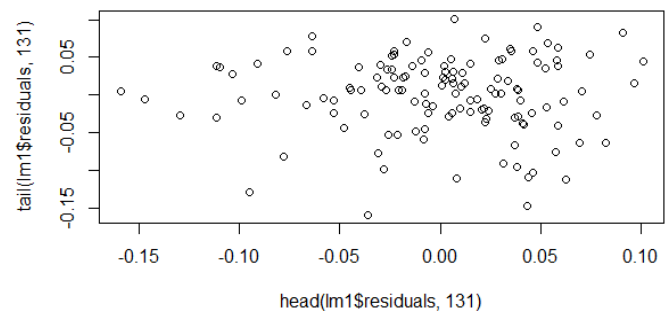

Solar:

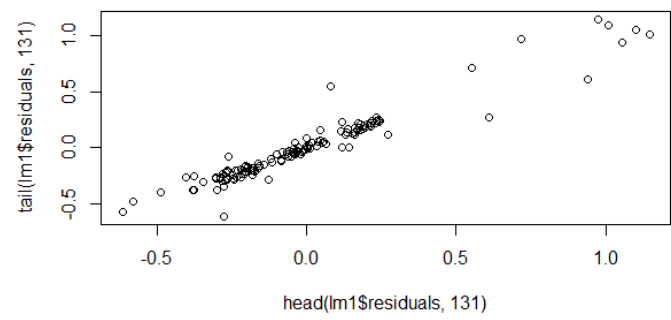

Nuclear:

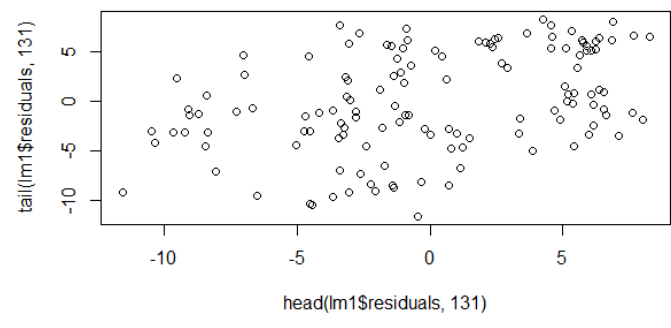

Figure 26- Successive residual plots 


\subsection{Non-linear regression for generated electricity}

\subsubsection{Design of a neural network}

Any ANN can be characterized by the architecture of the network, training algorithm, and the activation function. There are different types of networks for different applications. A feed-forward network with one hidden layer was used in this study since feed-forward networks with multilayer perceptron are the most widely used designs for time series modeling and forecasting (Zhang et al., 1998).

Different training algorithms were discussed in section 2.2.2. In this research, The BP with Levenberg-Marquardt (LM) was chosen as the training algorithm (Levenberg, 1944). Combination function defines the output of a node when a set of inputs are given (See section 2.2). In BP network, the Sigmoid and Tangent functions are commonly defined as activation functions for the hidden layers, and a linear transfer function is utilized for the output layer. We used a tangent-sigmoid transfer function in the hidden layer and a linear transfer function in the output layer.

In this study, four nodes in the input layer (corresponding to market price, heat rate, $\mathrm{CO}_{2}$ emission, U.S. population), and ten nodes in the hidden layer are defined for coal, natural gas, and oil neural networks. Three nodes in the input layer (corresponding to heat rate, $\mathrm{CO}_{2}$ emission, and U.S. population), and ten nodes in the hidden layer are defined for the geothermal neural network. Also, two nodes in the input layer (corresponding to heat rate and U.S. population), and 200, 150, 300, and 350 nodes in the hidden layer are defined for hydroelectric, solar, wind, and nuclear neural networks respectively.

Also, $75 \%$ of data points (92 points) were assigned for training; $15 \%$ of data points (20 points) were assigned for validating to measure network generalization and to halt training when generalization stops improving; $15 \%$ of data points (20 points) were assigned for testing that provides an independent measure of network performance during and after training. 


\subsubsection{Results}

The convergence of ANNs are illustrated in

Figure 27. The ANNs stop if the magnitude of the calculated gradient becomes less than $10^{-5}$, or the number of successive iterations that the validation performance fails to decrease reaches 6 .

Coal:

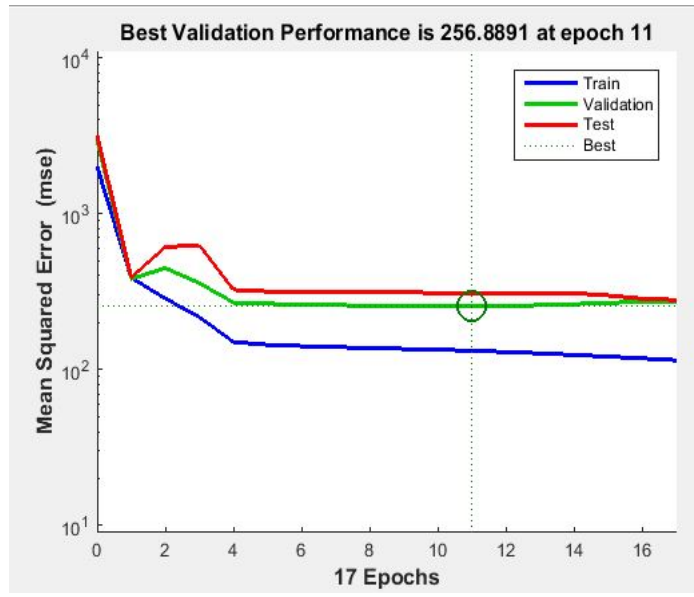

Oil:

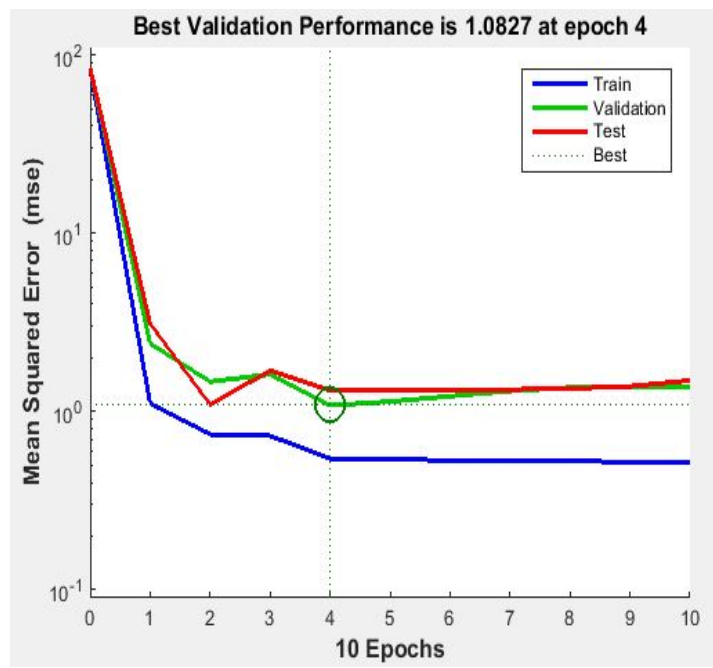

Natural Gas:

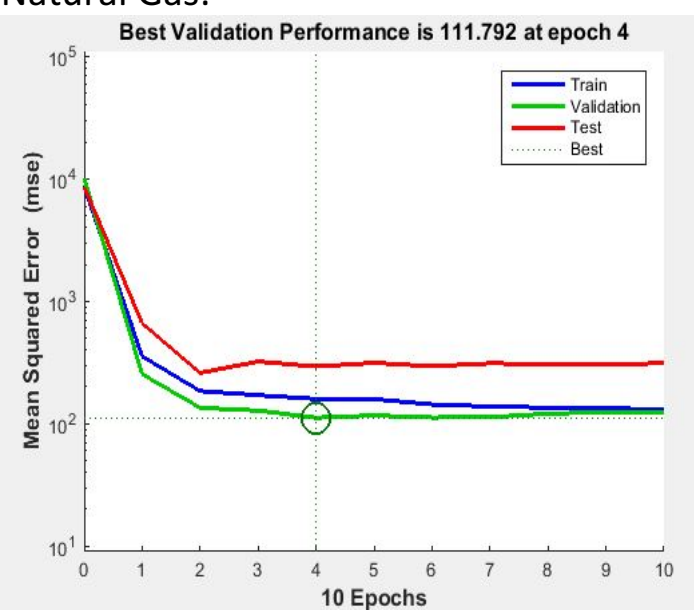

Geothermal:

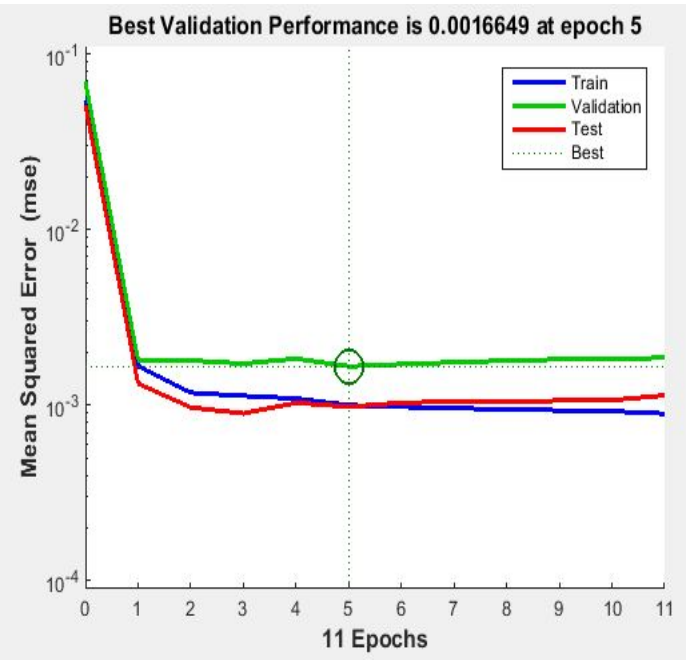


Hydroelectric:

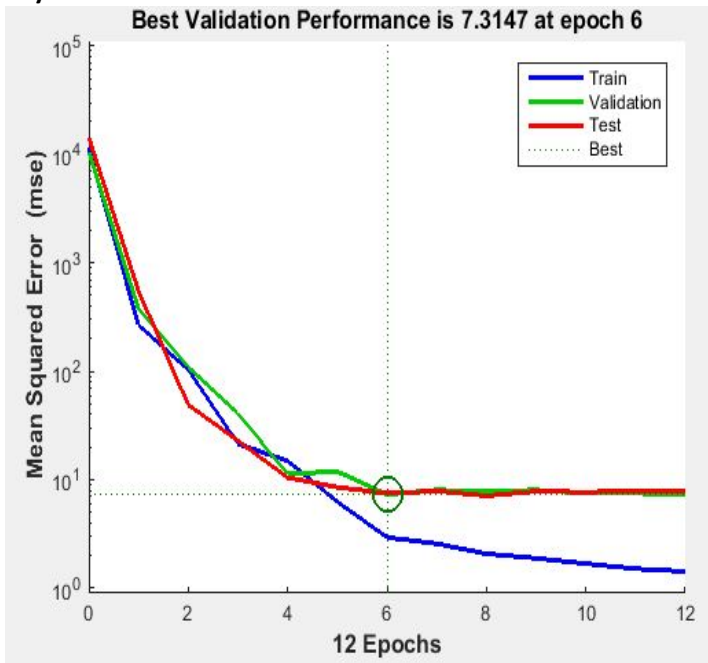

Wind:

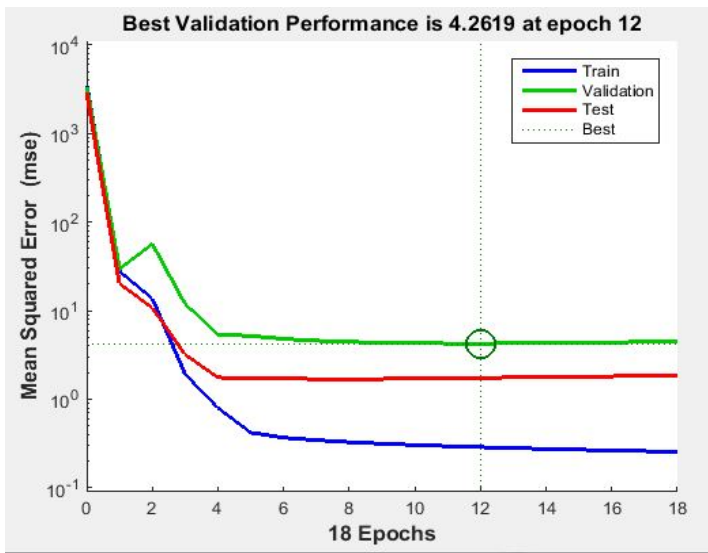

Solar:

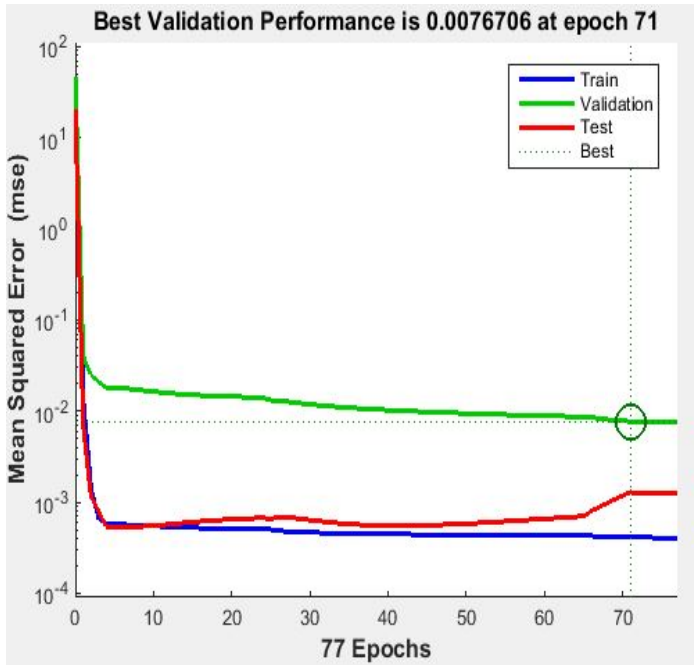

Nuclear:

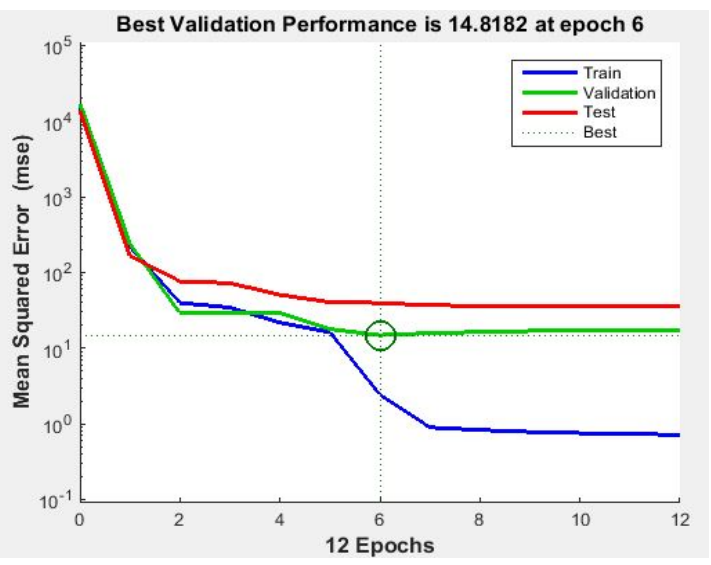

Figure 27- ANN convergence

At the end of the ANN algorithms, a linear regression between the network outputs and the corresponding targets was performed.

Figure 28 shows the results. 
Coal:

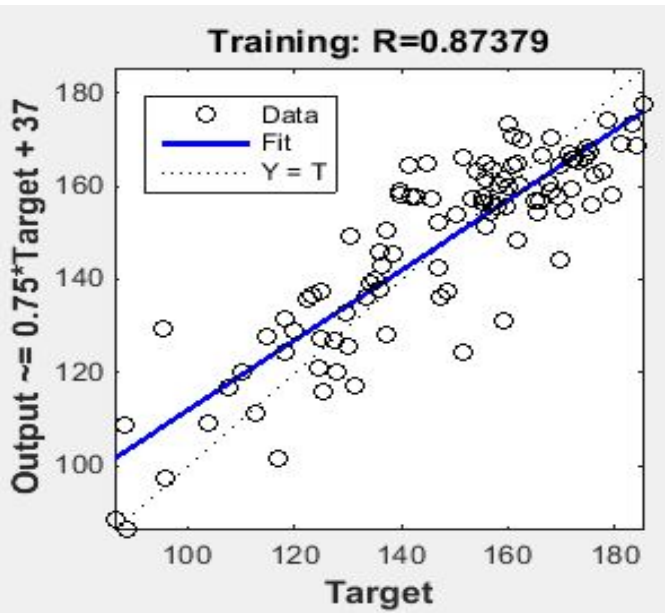

Oil:

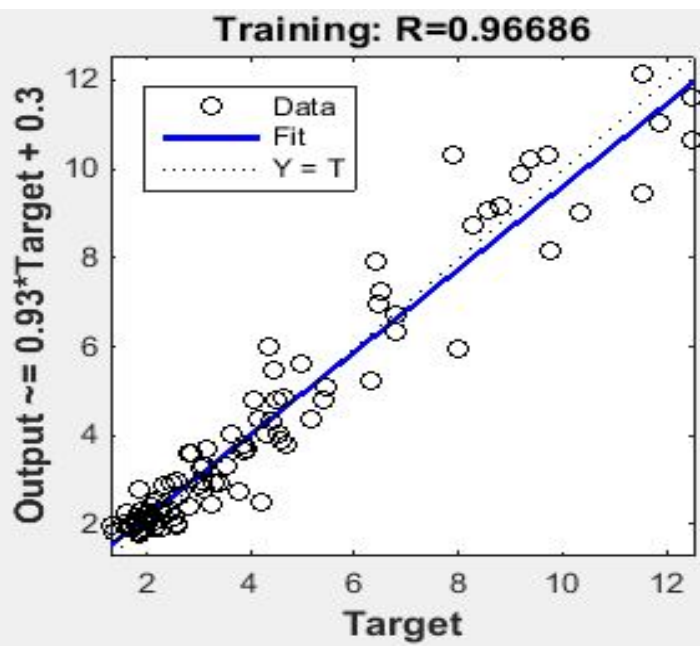

Hydroelectric:

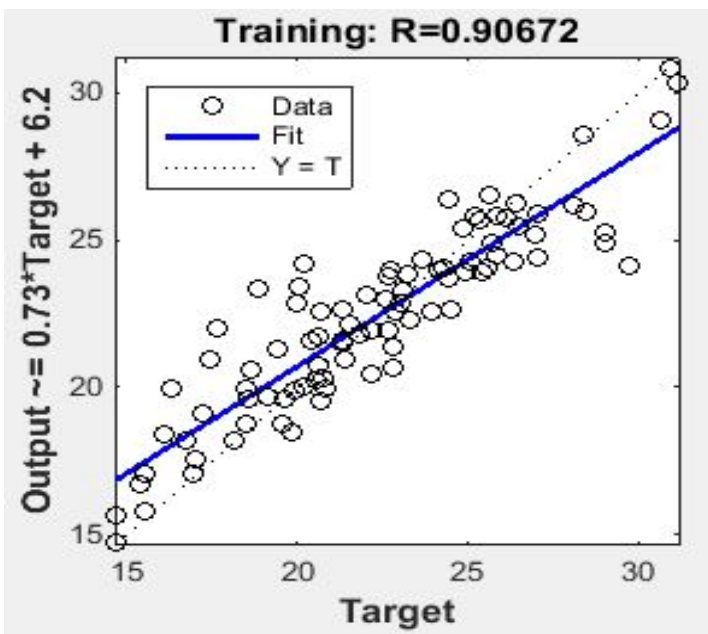

Natural Gas:

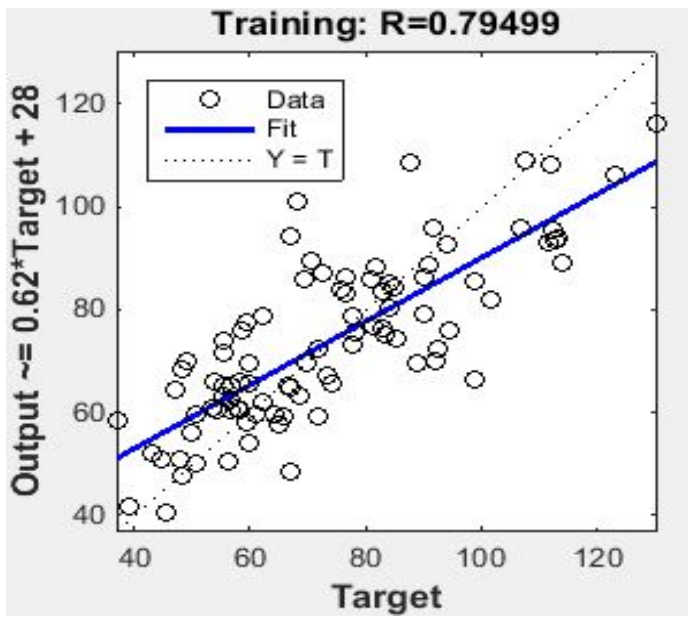

Geothermal:

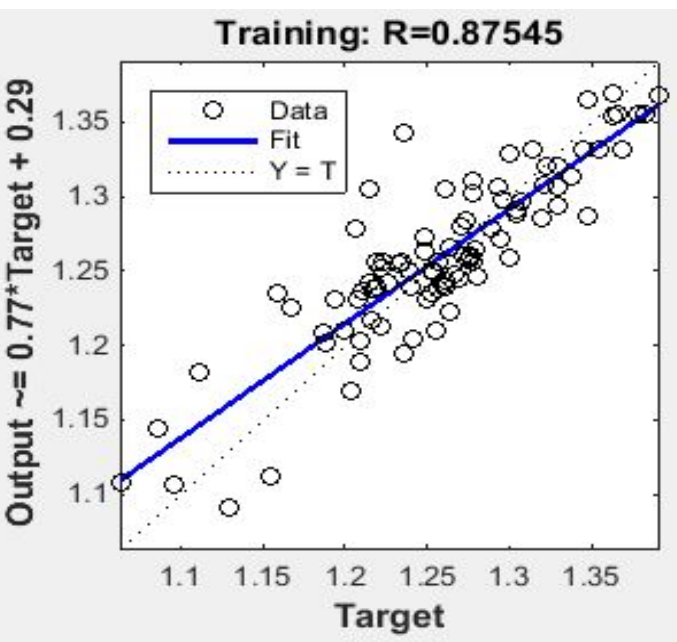

Solar:

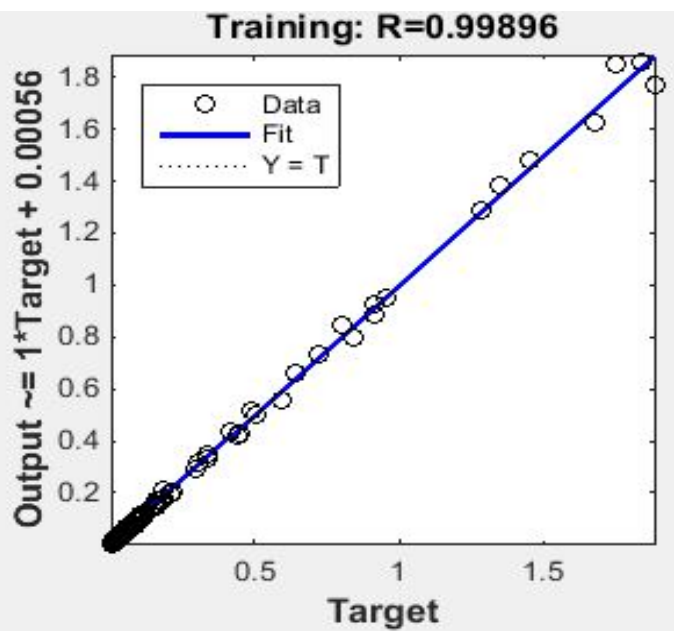


Wind:

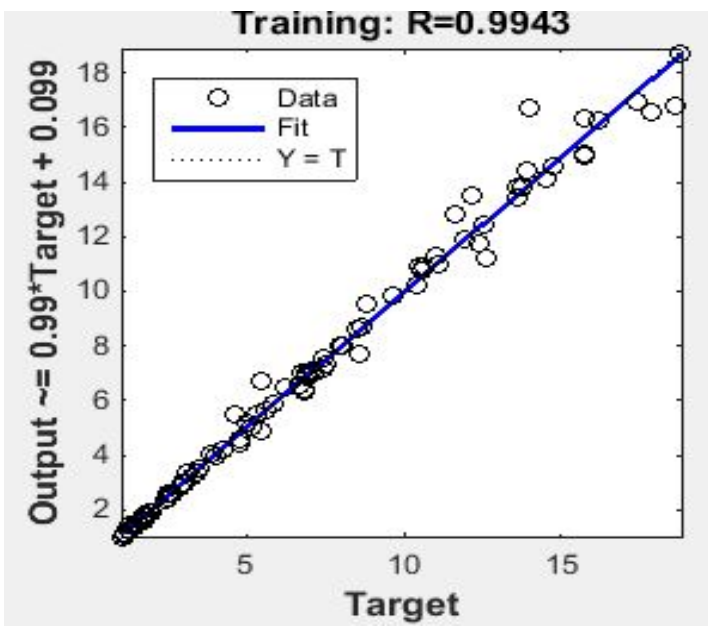

Nuclear:

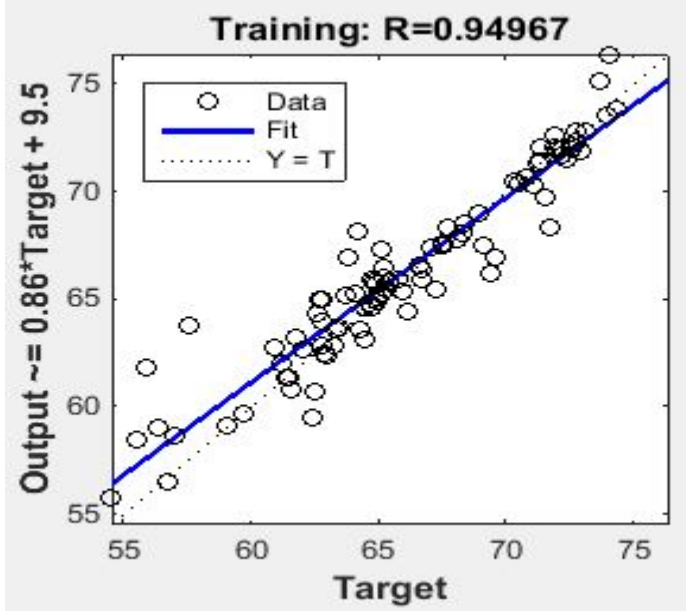

Figure 28- Linear regression between ANN outputs and targets

The process of training an ANN involves finding the values of the weights to optimize network mean square error (MSE). MSE is defined as the average squared error between the network outputs and the target value.

Figure 29 reports the obtained MSE in each ANN. 
Coal:

\begin{tabular}{|l|l|l|}
\hline & Sample & MSE \\
\hline Training & 92 & 132.803 \\
\hline Validation & 20 & 223.592 \\
\hline Test & 20 & 271.747 \\
\hline Predict & 35 & 14.903 \\
\hline
\end{tabular}

Oil:

\begin{tabular}{|l|l|l|}
\hline & Sample & MSE \\
\hline Training & 92 & 54.520 \\
\hline Validation & 20 & 1.082 \\
\hline Test & 20 & 1.310 \\
\hline Predict & 35 & 0.080 \\
\hline
\end{tabular}

Hydroelectric:

\begin{tabular}{|l|l|l|}
\hline & Sample & MSE \\
\hline Training & 92 & 2.943 \\
\hline Validation & 20 & 7.314 \\
\hline Test & 20 & 7.479 \\
\hline Predict & 35 & 321.560 \\
\hline
\end{tabular}

Wind:

\begin{tabular}{|l|l|l|}
\hline & Sample & MSE \\
\hline Training & 92 & 2.881 \\
\hline Validation & 20 & 4.261 \\
\hline Test & 20 & 1.744 \\
\hline Predict & 35 & 344.110 \\
\hline
\end{tabular}

Natural Gas:

\begin{tabular}{|l|l|l|}
\hline & Sample & MSE \\
\hline Training & 92 & 159.254 \\
\hline Validation & 20 & 111.792 \\
\hline Test & 20 & 293.179 \\
\hline Predict & 35 & 343.390 \\
\hline
\end{tabular}

Geothermal:

\begin{tabular}{|l|l|l|}
\hline & Sample & MSE \\
\hline Training & 92 & 0.001 \\
\hline Validation & 20 & 0.166 \\
\hline Test & 20 & 0.097 \\
\hline Predict & 35 & 0.304 \\
\hline
\end{tabular}

Solar:

\begin{tabular}{|l|l|l|}
\hline & Sample & MSE \\
\hline Training & 92 & $4.106 \mathrm{e}-4$ \\
\hline Validation & 20 & $7.670 \mathrm{e}-3$ \\
\hline Test & 20 & $1.285 \mathrm{e}-3$ \\
\hline Predict & 35 & 6.029 \\
\hline
\end{tabular}

Nuclear:

\begin{tabular}{|l|l|l|}
\hline & Sample & MSE \\
\hline Training & 92 & 2.423 \\
\hline Validation & 20 & 14.818 \\
\hline Test & 20 & 39.533 \\
\hline Predict & 35 & 199.760 \\
\hline
\end{tabular}

Figure 29- MSE of ANNS

Tracking signals can indicate if forecast-bias is present. Tracking signals are suggested when the validity of the forecasting model might be in doubt (Trigg, 1964). Figure 30 shows the tracking signals for predicted values starting from January 2014 to November 2017. Equation (3-10) was used to calculate the tracking signals. In this equation, the forecast error was estimated by mean absolute deviation.

Tracking signal $=\frac{\text { Sum of errors }}{\text { Mean absolute deviation }}$

The mean absolute deviation is sum of absolute deviations divided by number of months that was predicted. Thus, equation (3-10) can be rewritten as: 
$T S_{i s}=\frac{\sum_{t=1}^{s}\left(Y_{i t}-\hat{Y}_{i t}\right)}{\sum_{t=1}^{s}\left|Y_{i t}-\hat{Y}_{i t}\right| / s}$

When $T S_{i s}$ is the tracking signal of energy source $i$ in months, $Y_{i t}$ is the amount of electricity generated in month $t$ from energy source $i$, and $\widehat{Y}_{i t}$ is the predicted amount of electricity generated at month $t$ from energy source $i$.

As demonstrated in Figure 30, there are some kind of fluctuations in all tracking signals. It moves up and down which suggests that the ANN does not over-estimate or under-estimate the amount of electricity generated from different primary energy sources. 
Coal:

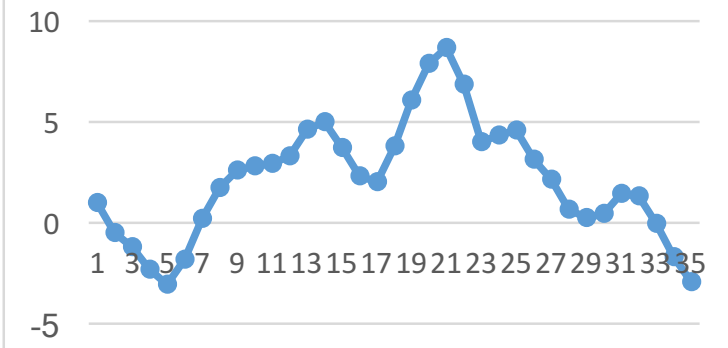

Oil:

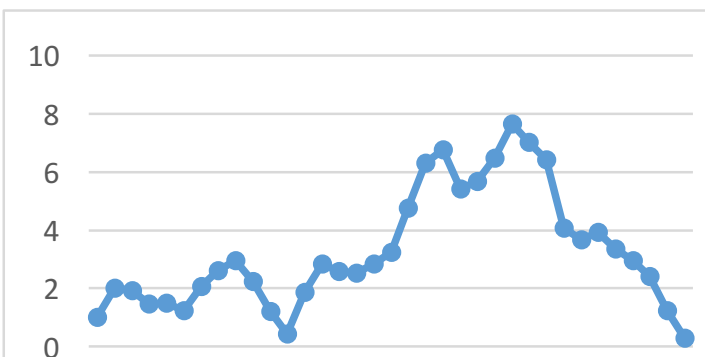

1357911131517192123252729313335

Hydroelectric:

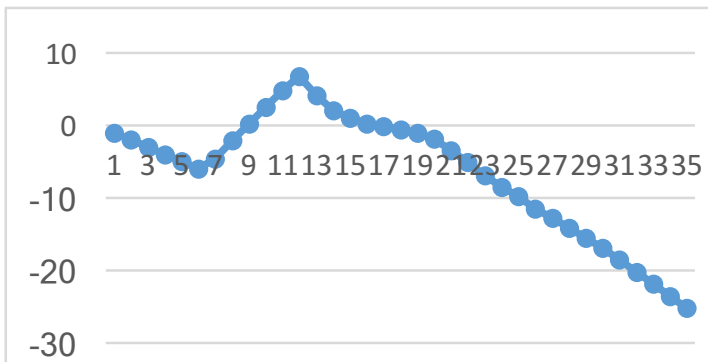

Solar:

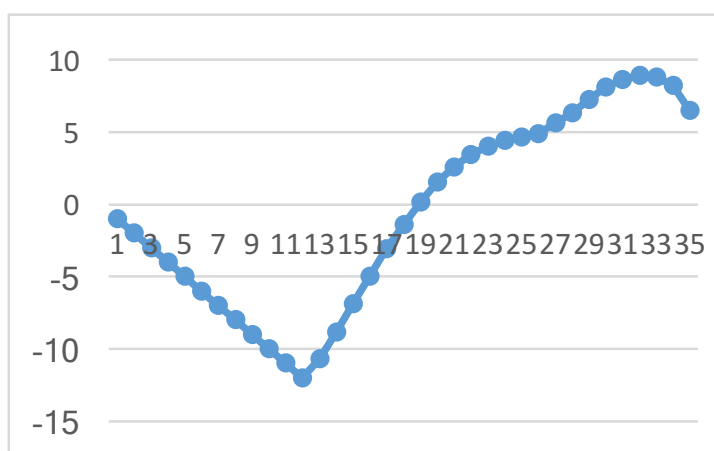

Natural Gas:

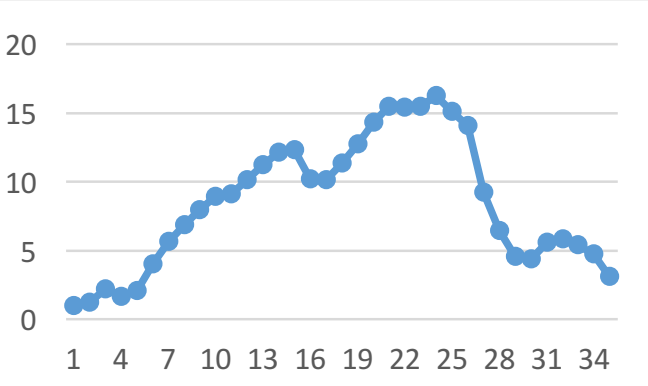

\section{Geothermal:}

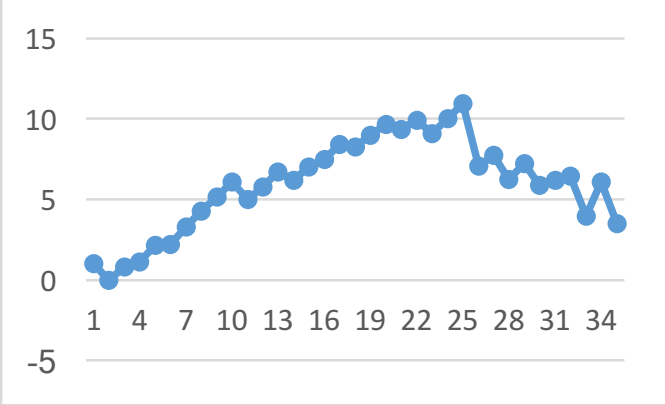

Wind:

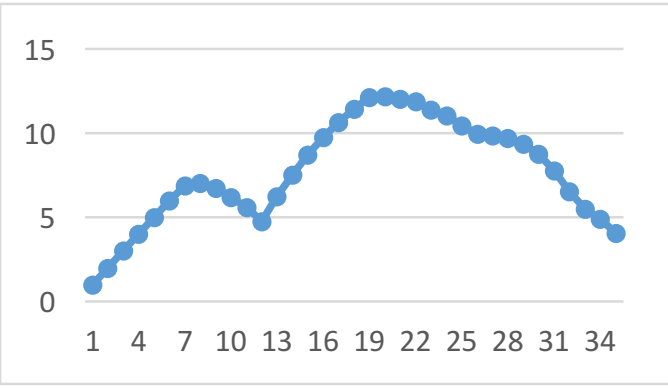

Nuclear:

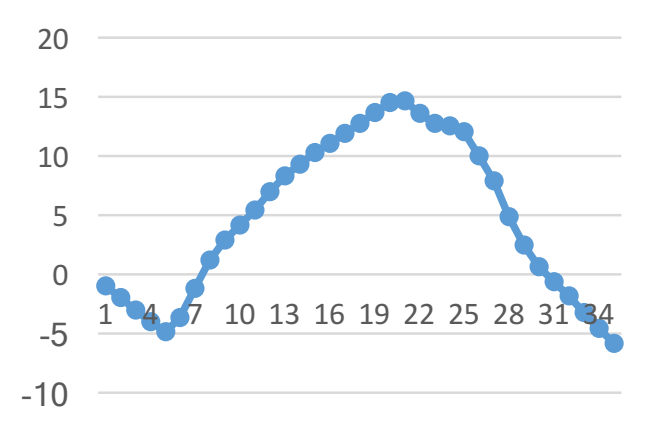

Figure 30- Tracking signal of predicted data (January 2014-November 2017) 


\subsection{ARIMA model for generated electricity}

\subsubsection{Identifying the order of ARIMA}

The parameters of ARIMA are $p$ (the order of the AR model), $d$ (the degree of differencing), and $q$ (the order of the MA model). These parameters were selected based on minimum BIC and AIC using R software.

Figure 31 shows the best fitted ARIMA models which predicted values for electricity generated from each primary energy sources between January 2014 and November 2017 , as well as $95 \%$ and $80 \%$ confidence interval for predicted values.

Coal:

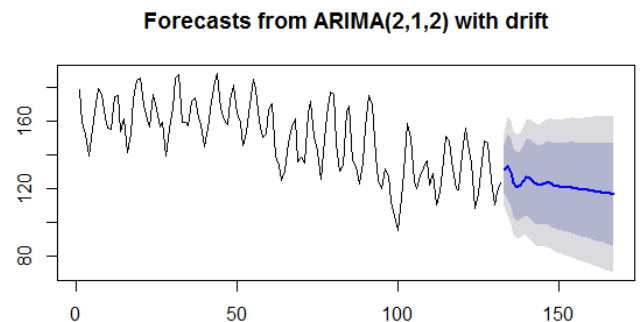

Oil:

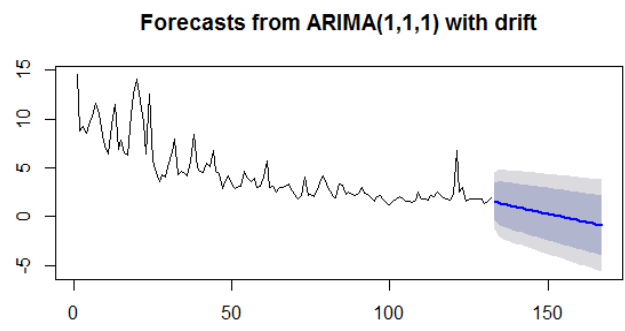

Hydroelectric:

Forecasts from ARIMA $(2,0,1)$ with non-zero mean

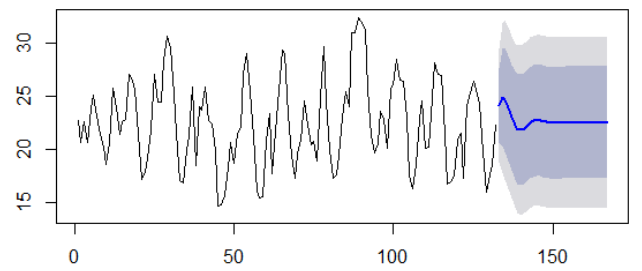

Natural Gas:

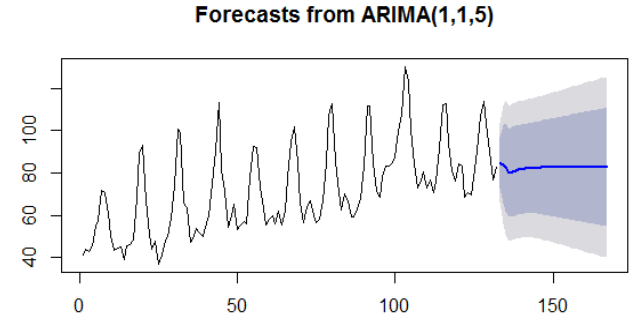

Geothermal:

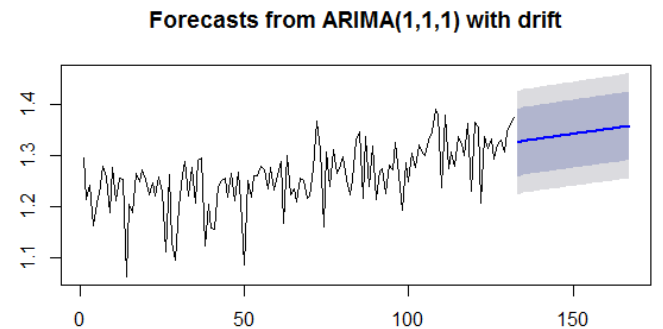

Solar:

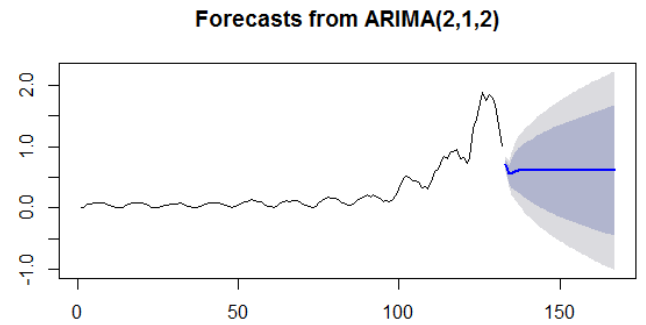


Wind:

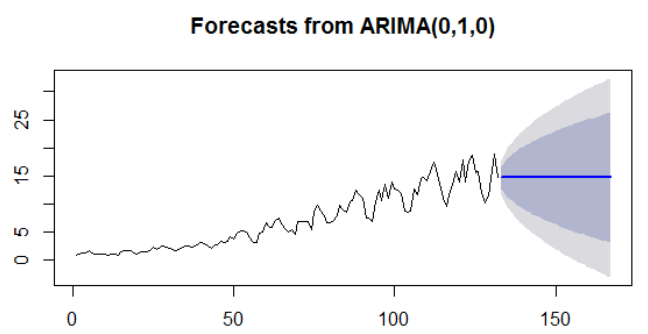

Nuclear:

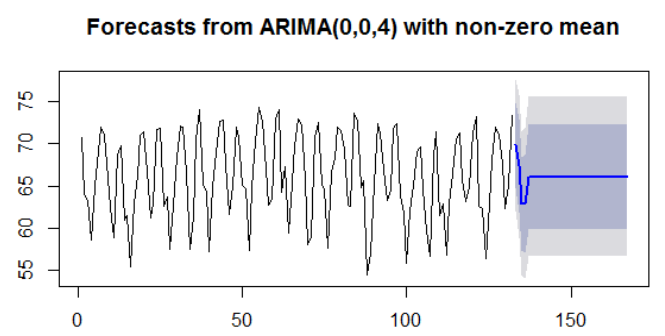

Figure 31- ARIMA model and predicted values

\subsubsection{Fitting non- linear function of the residuals}

After fitting the best ARIMA model and finding the residuals of data from January 2004 to December 2013, a non-linear function which predicts the value of residuals by $d$ past given values were built by an ANN algorithm.

The same training method that was explained in section 3.3.1 was used to design ANN. Only 1 node in the input layer (corresponding to generated electricity), and 15, 20, 20, $15,15,100,40$, and 15 nodes in the hidden layer are defined for coal, natural gas, oil, geothermal, hydroelectric, solar, wind, and nuclear neural networks respectively when $d=12$.

$75 \%$ of data points (92 points), $15 \%$ of data points ( 20 points), and $15 \%$ of data points (20 points) were assigned for training, validating, and testing respectively. Figure 32 shows the linear regression between the network outputs and the corresponding targets.

Coal:

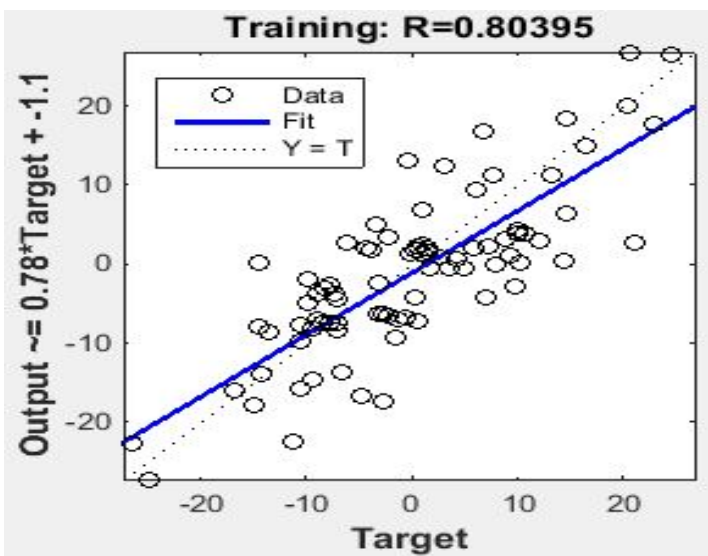

Natural Gas:

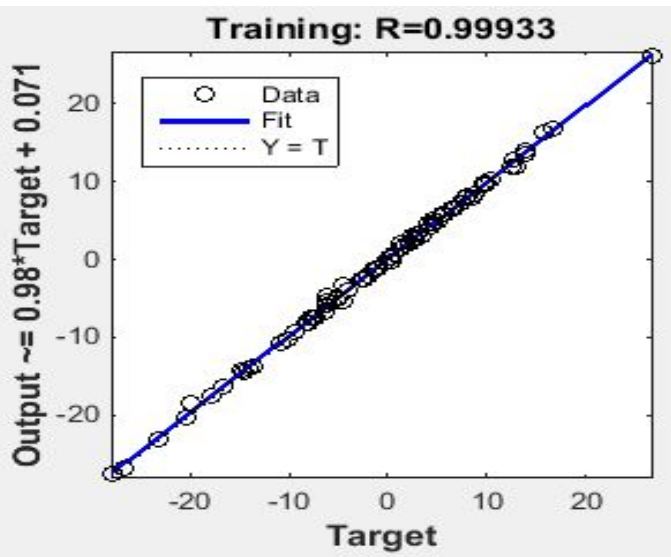


Oil:

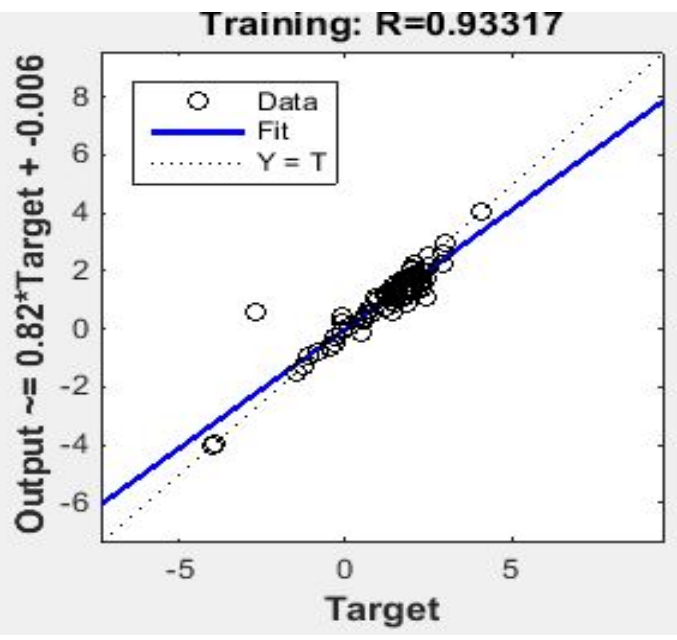

Hydroelectric:

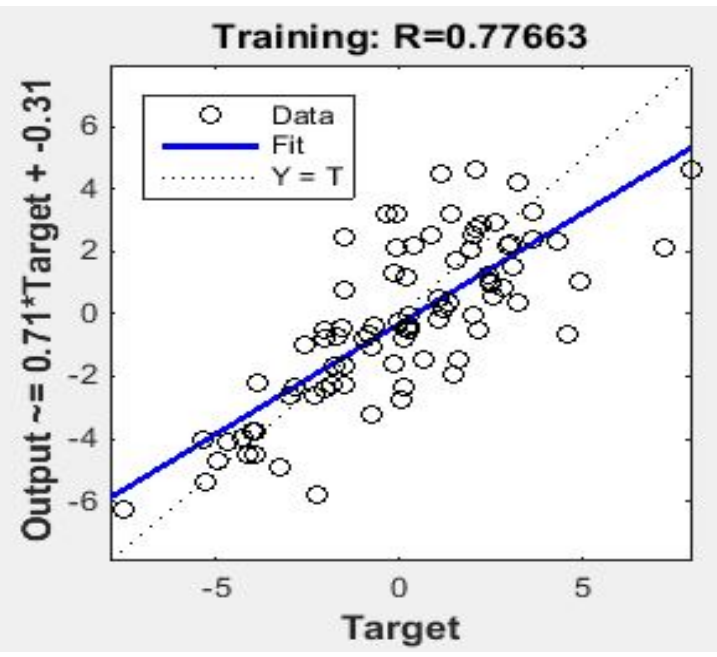

Geothermal:

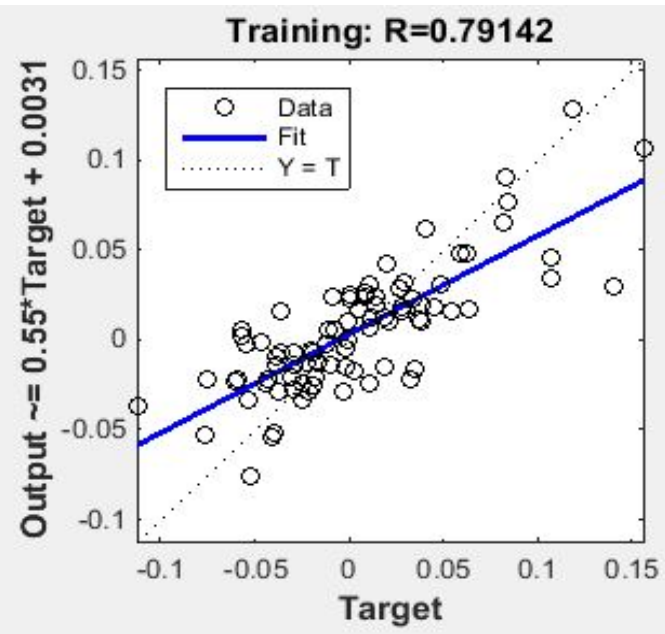

Solar:

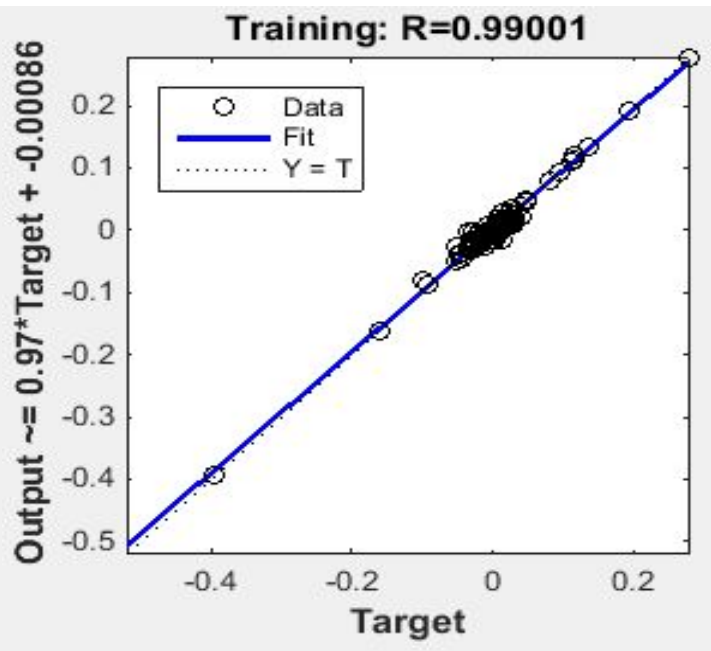

Nuclear:

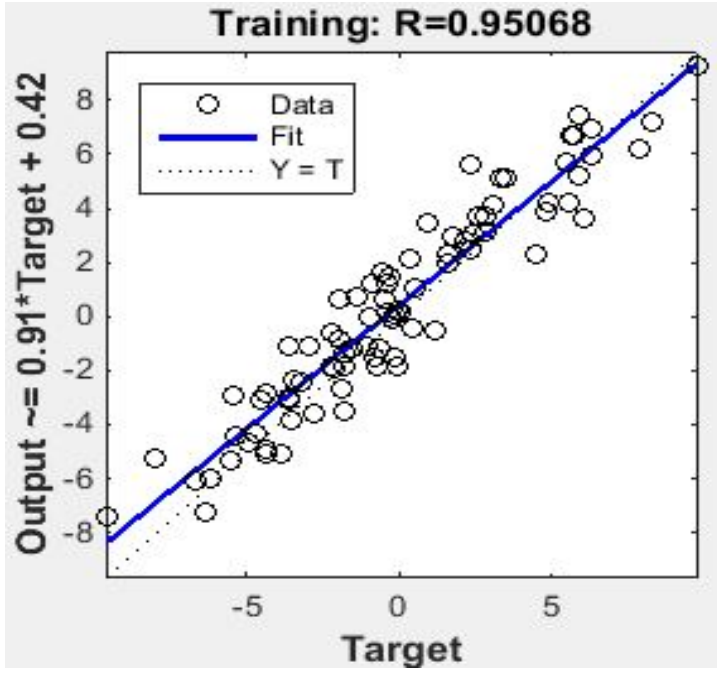

Figure 32- Linear regression between ANN outputs and targets for residuals 


\subsection{Conclusion}

Two forecasting models were fit to data from January 2004 to December 2014 using the ANN algorithm and the hybrid ARIMA and ANN algorithm. Based on these two models, the amount of electricity generation for each primary energy source between January 2015 and November 2017 was predicted and reported in Table 5 to Table 8 (see Appendix 5.4). The predicted values were compared with the actual data, and MSE was computed. Table 2 compares MSE obtained from the ANN algorithm and the hybrid ARIMA and ANN algorithm.

Table 2- MSE obtained from ANN and hybrid ARIMA and ANN

\begin{tabular}{lccc} 
& Sample & ANN & Hybrid ARIMA and ANN \\
\hline Coal & 35 & 14.90 & 964.11 \\
Natural gas & 35 & 343.39 & 772.44 \\
Oil & 35 & 0.08 & 1.51 \\
Geothermal & 35 & 0.30 & 0.01 \\
Hydroelectric & 35 & 321.56 & 35.92 \\
Solar & 35 & 6.03 & 9.37 \\
Wind & 35 & 344.11 & 51.73 \\
Nuclear & 35 & 199.76 & 55.69
\end{tabular}

Figure 33 shows the predicted amount of electricity generated from different primary energy sources in terms of billion kWh from January 2014 to November 2017 as well as the fitted value from January 2004 to December 2014 obtained from ANN, ARIMA, and hybrid ARIMA and ANN algorithms. The predicted values from 2014 to 2017 are shown in Figure 34.

As shown in Figure 33 and Table 2, the ANN algorithm forecasts a good model with lower MSE for coal, natural gas, and oil. The hybrid ARIMA and ANN algorithm fits a more accurate model with lower MSE for geothermal, hydroelectric, solar, wind, and nuclear primary energy sources. However, in order to improve forecast accuracy, more independent variables could be added to the model. Various regression transformations could also be considered to improve the fitted model. 
Coal:

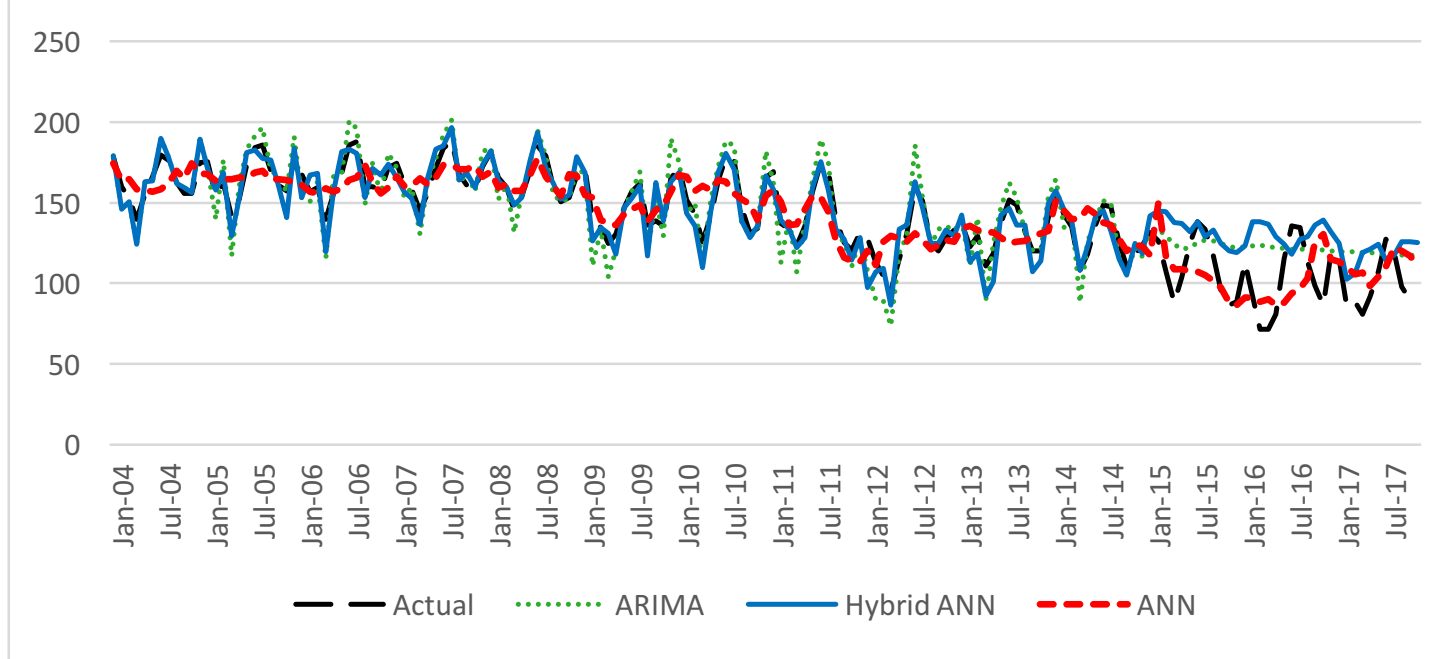

Natural Gas:

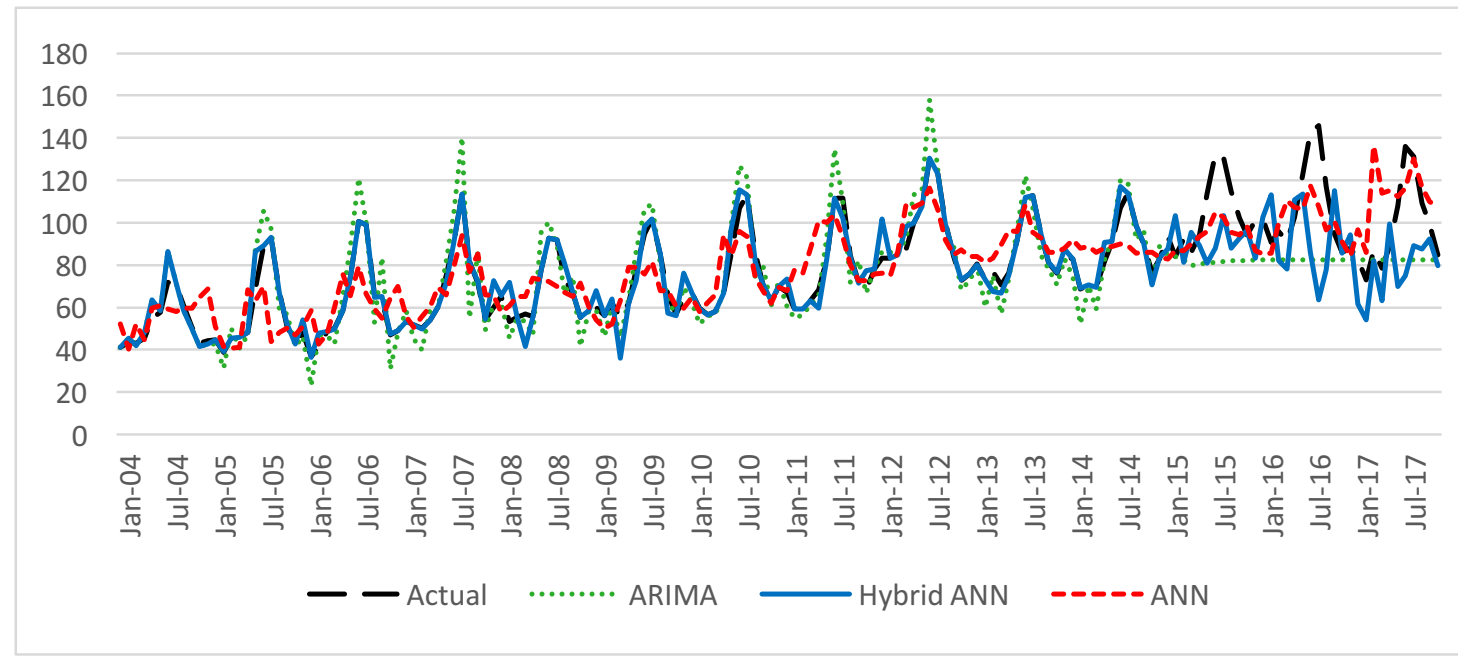

Oil:

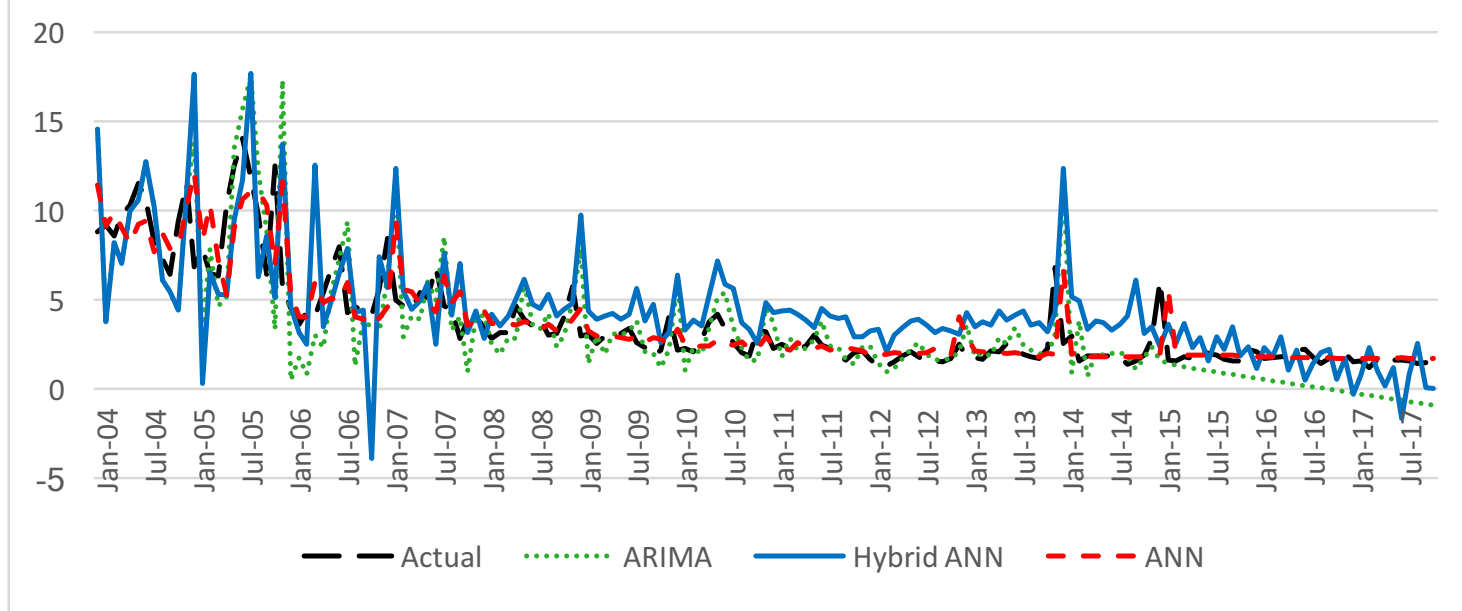


Geothermal:

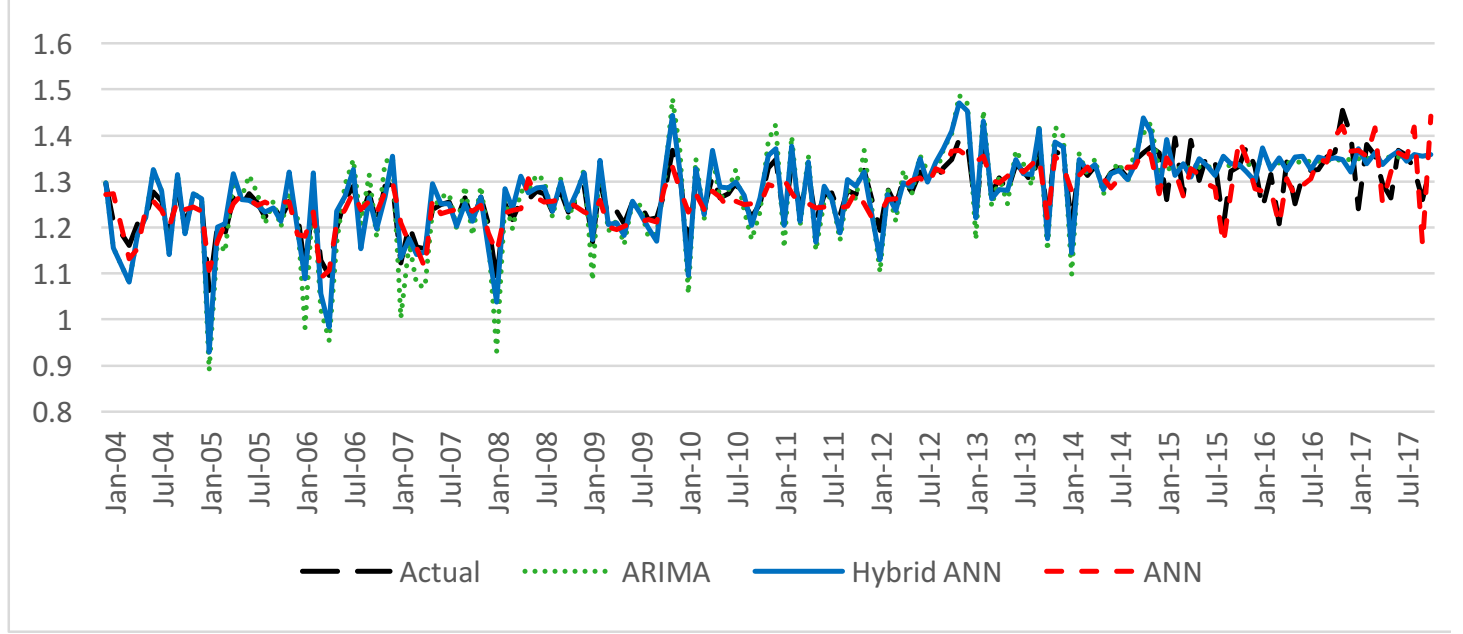

Hydroelectric:

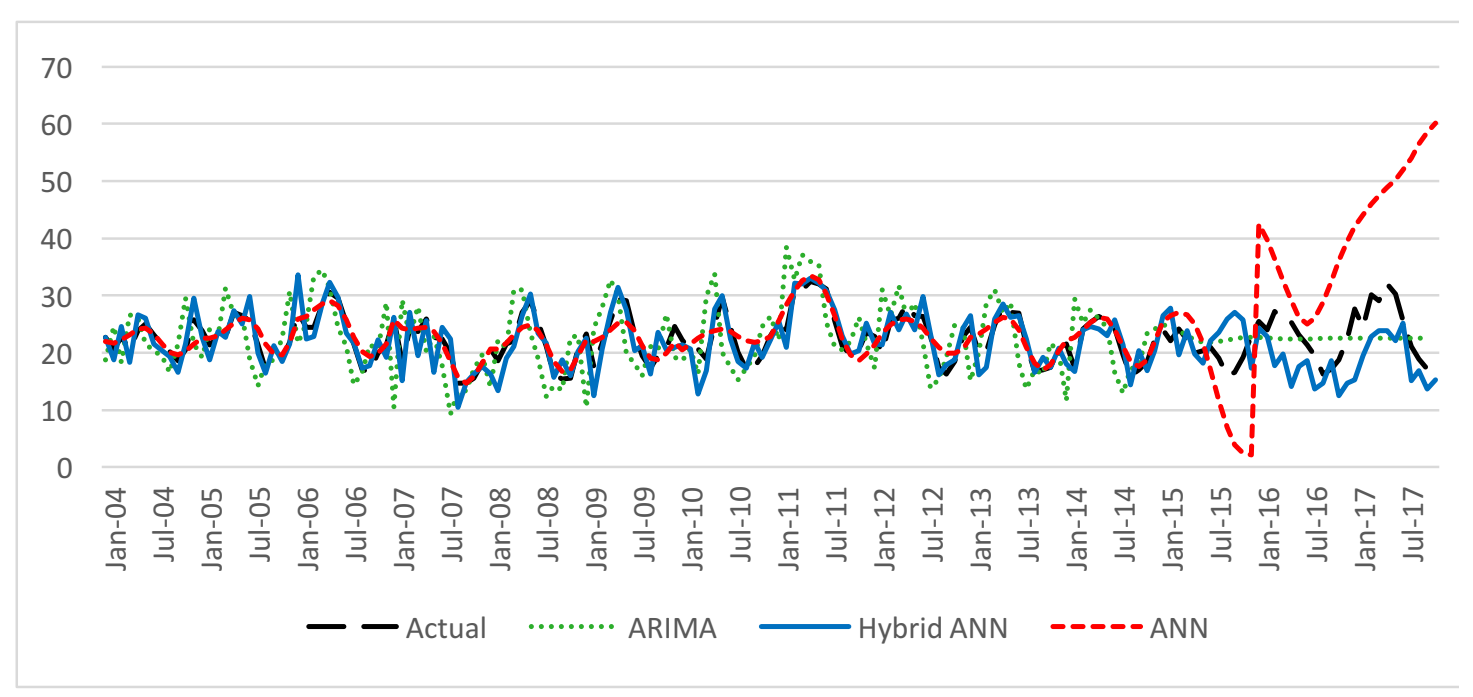

Solar:

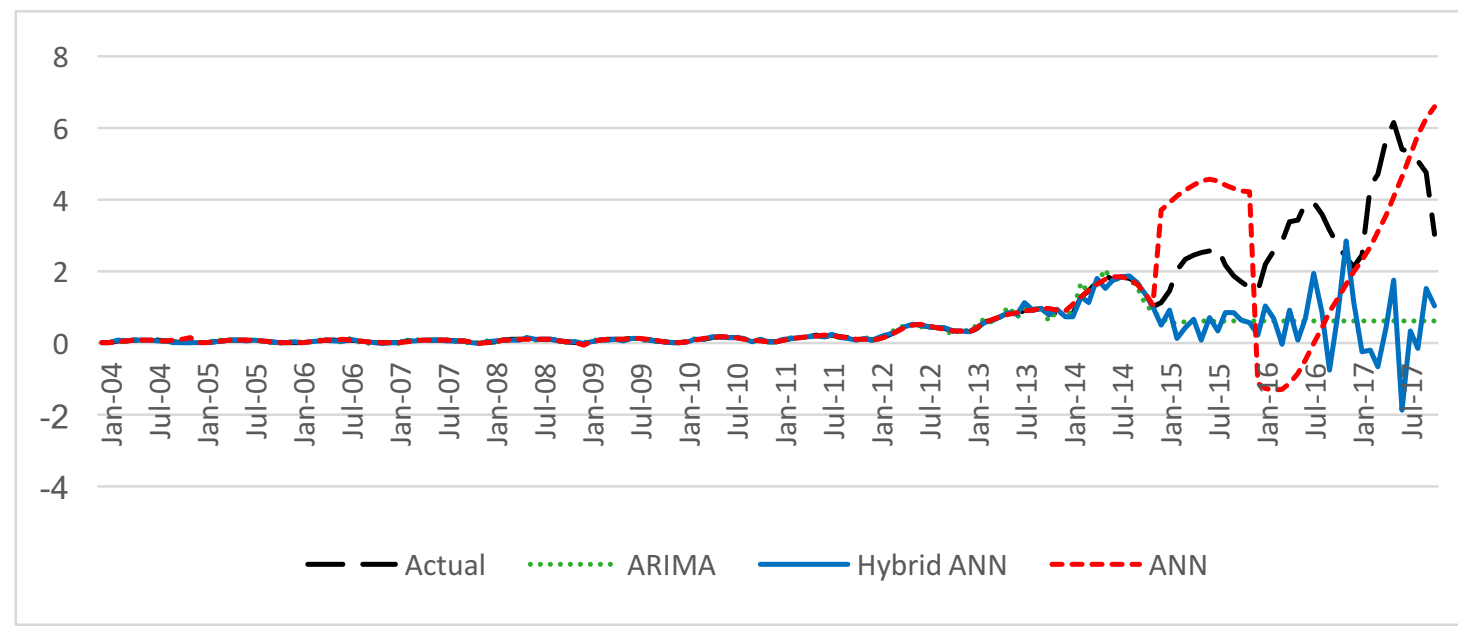


Wind:

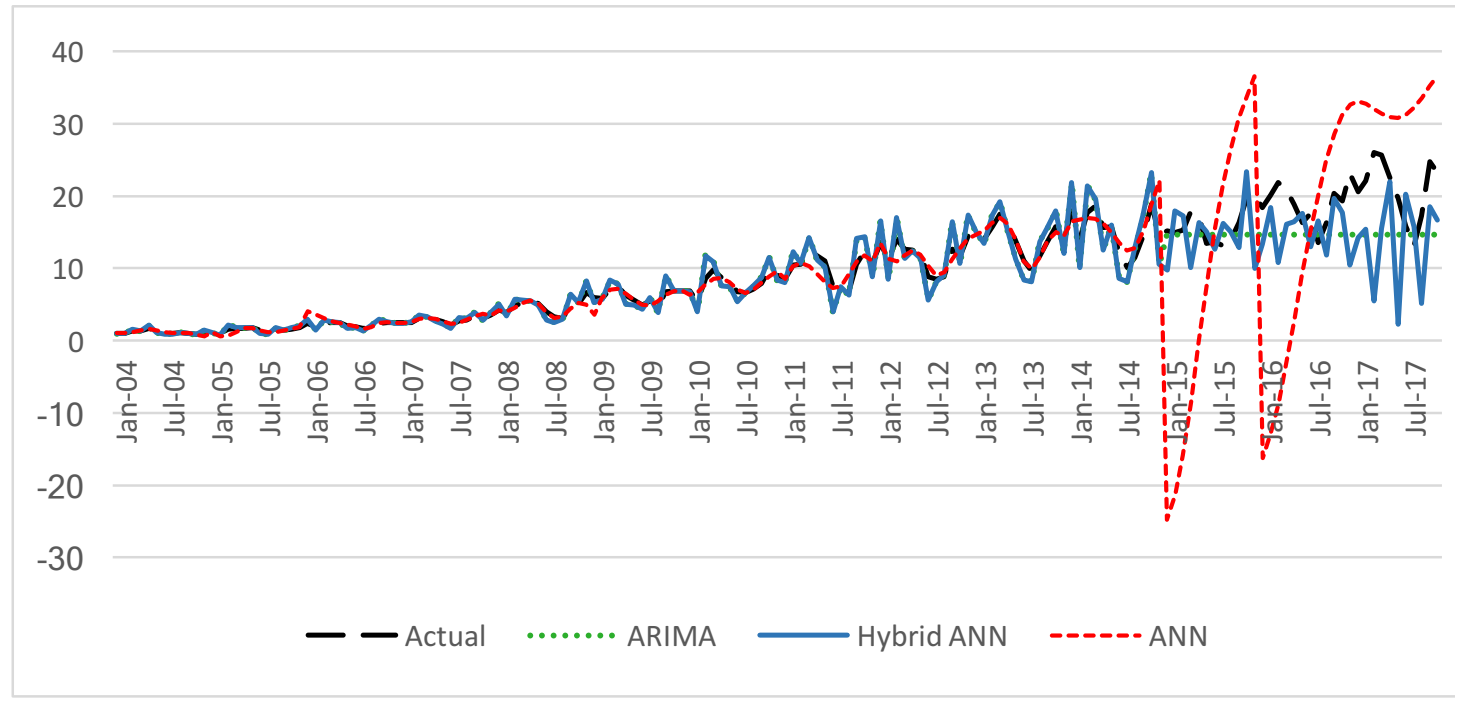

Nuclear:

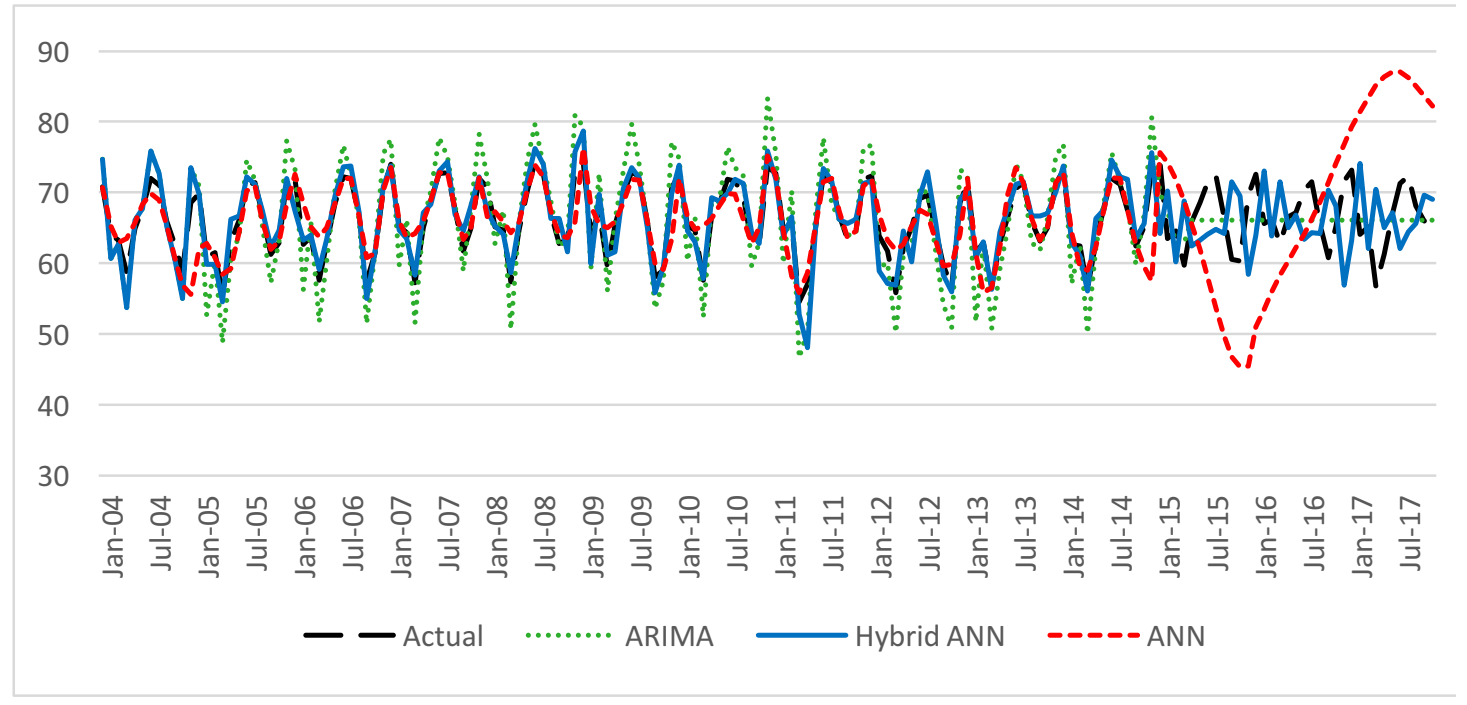

Figure 33- The fitted value of generated electricity vs. actual value 
Coal:

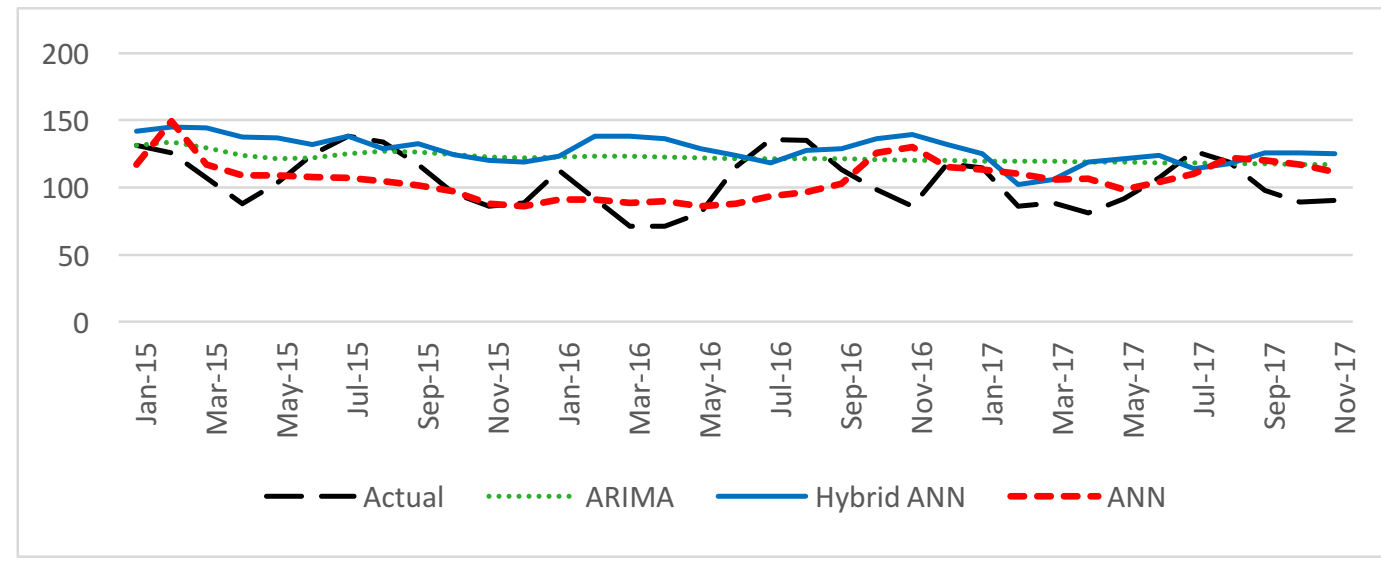

Oil:

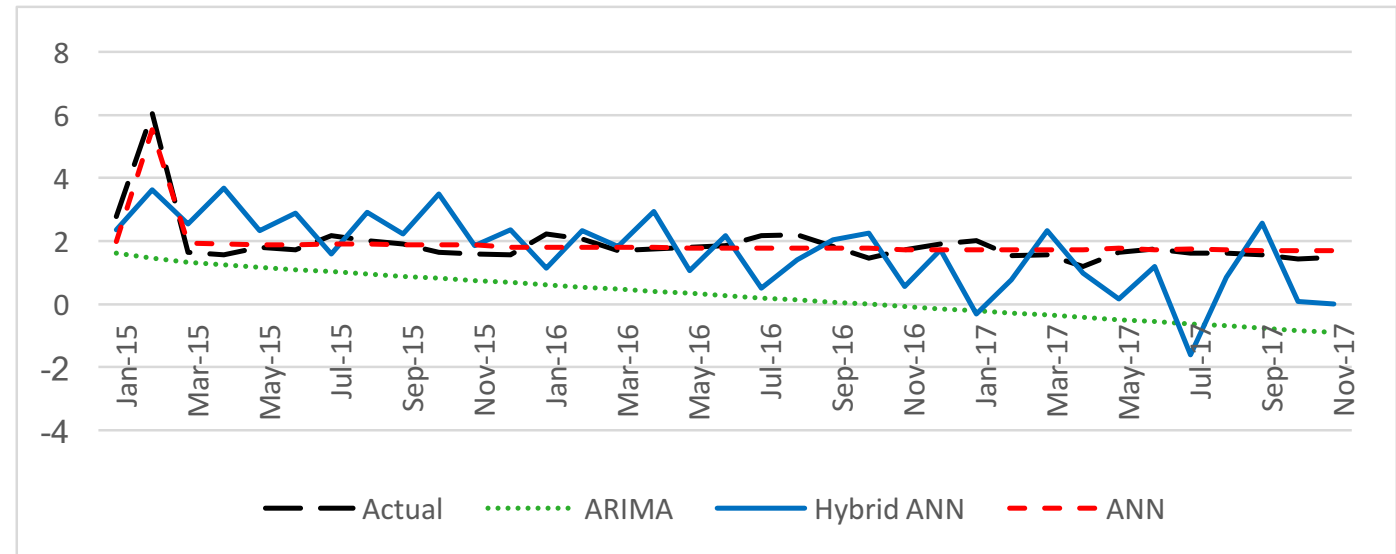

Natural Gas:

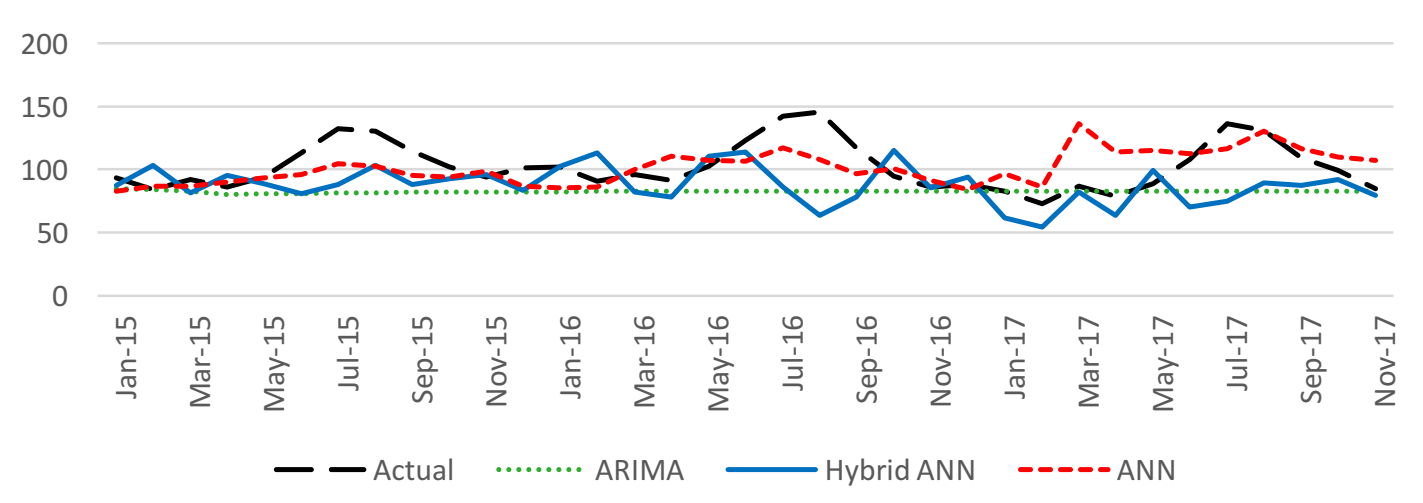

Geothermal:

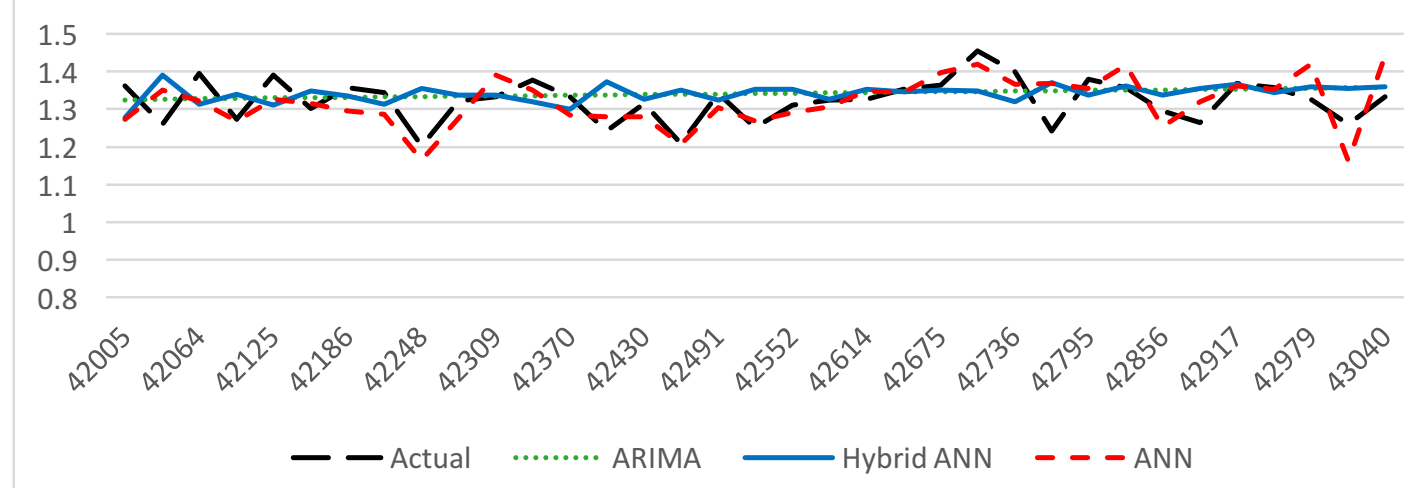

58 
Hydroelectric:

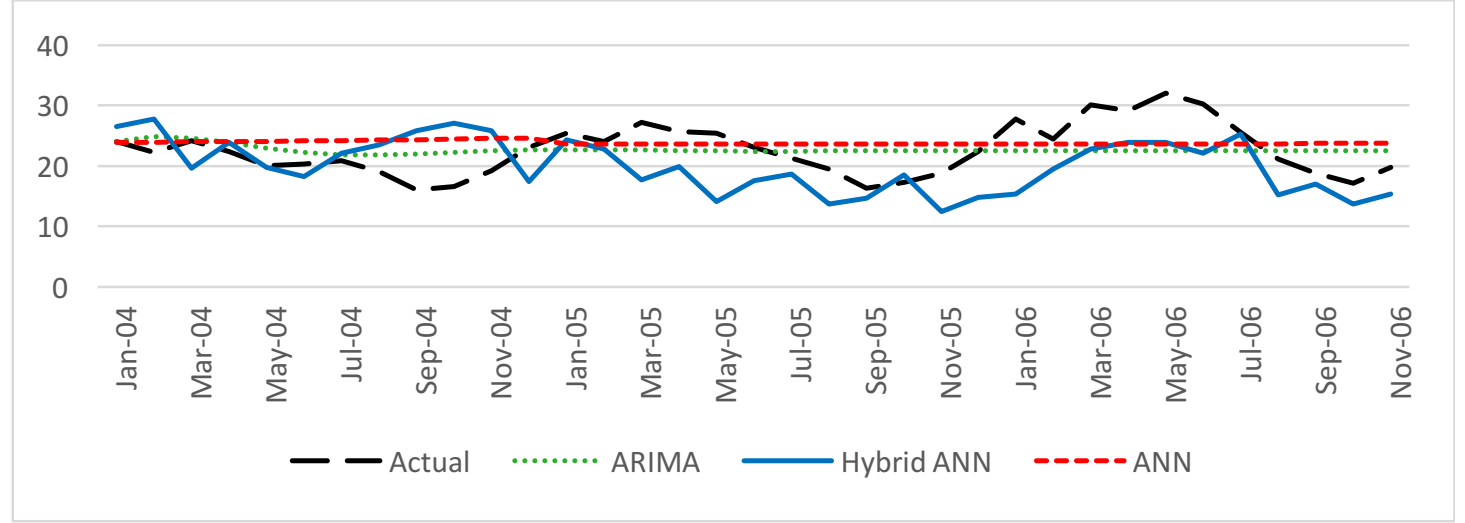

Solar:

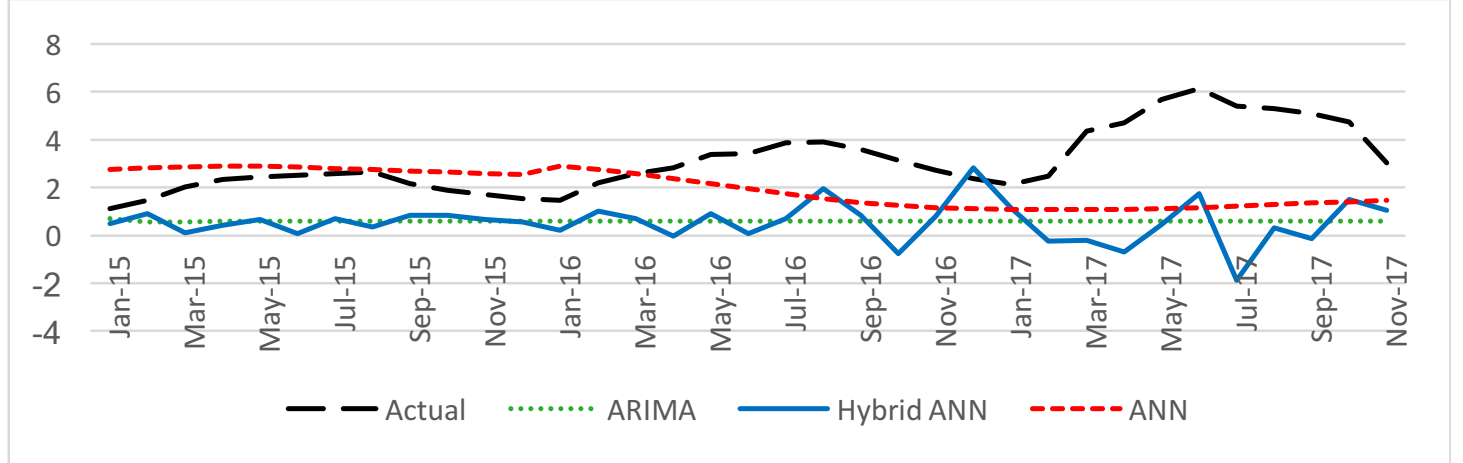

Wind:

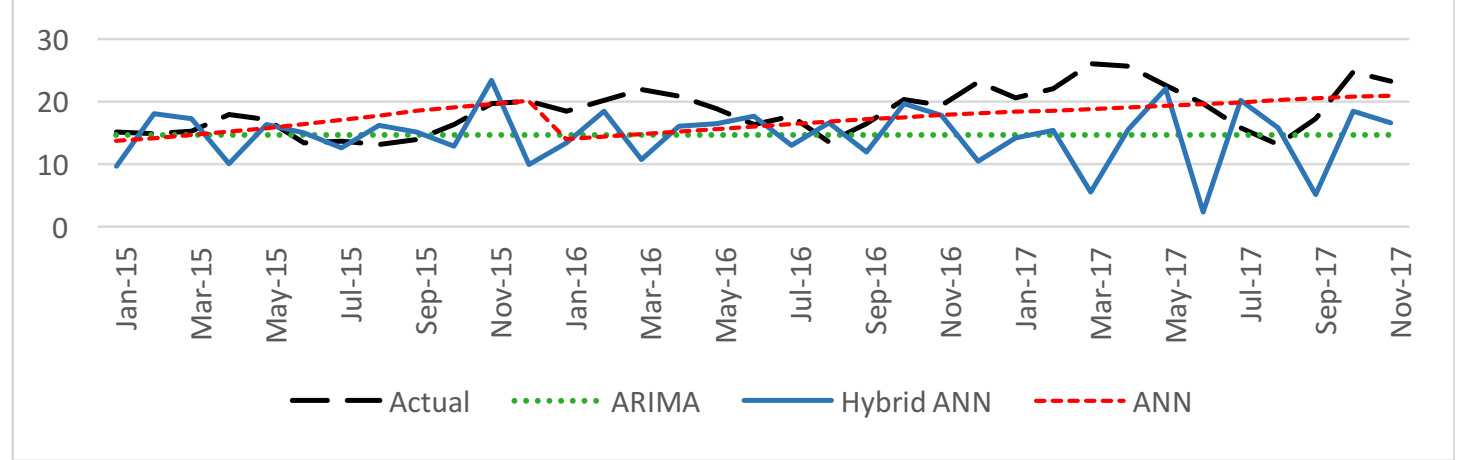

Nuclear:

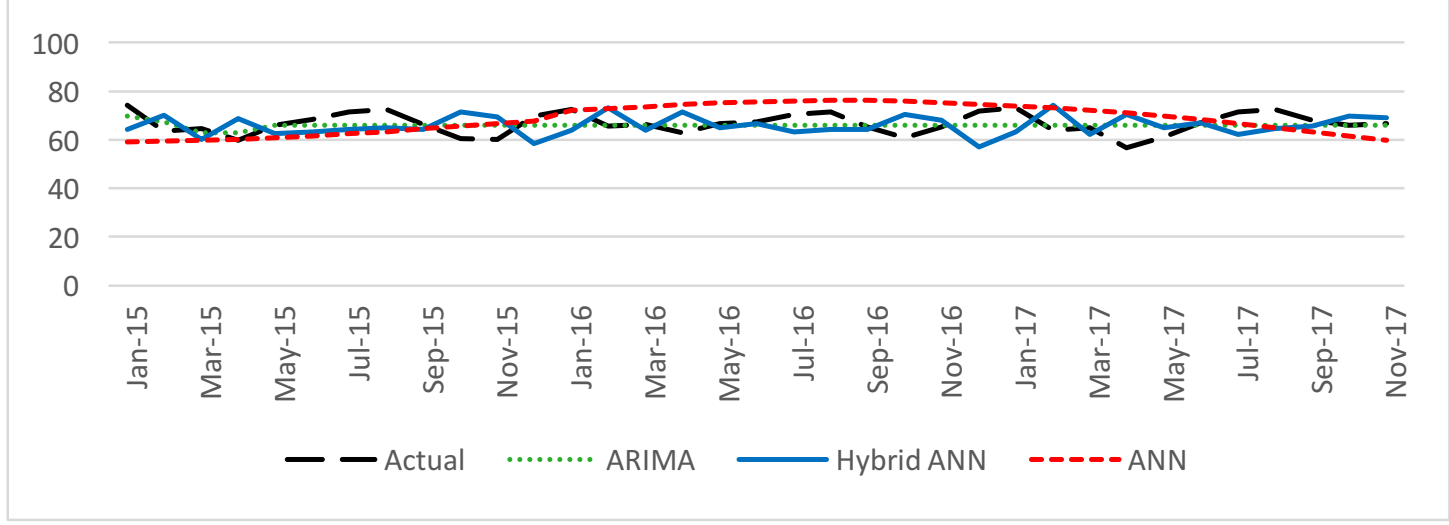

Figure 34- The predicted value of generated electricity vs. actual value 


\section{References}

Akaike, H. 1974. A new look at the statistical model identification. IEEE transactions on automatic control, 19(6): 716-723.

Al-Smadi, A., \& Wilkes, D. 1995. Data-adaptive higher order ARMA model order estimation. Paper presented at the Southeastcon'95. Visualize the Future., Proceedings., IEEE.

Bishop, C. M. 2013. Pattern Recognition and Machine Learning: All "just the Facts 101" Material: Springer.

Box, G. E., Jenkins, G. M., Reinsel, G. C., \& Ljung, G. M. 2015. Time series analysis: forecasting and control: John Wiley \& Sons.

Brown, R. G. 1959. Statistical forecasting for inventory control: McGraw/Hill.

Burnham, K. P., \& Anderson, D. R. 2003. Model selection and multimodel inference: a practical information-theoretic approach: Springer Science \& Business Media.

Cottrell, M., Girard, B., Girard, Y., Mangeas, M., \& Muller, C. 1995. Neural modeling for time series: a statistical stepwise method for weight elimination. IEEE transactions on neural networks, 6(6): 1355-1364.

Davim, J. P. 2011. Machining of hard materials: Springer Science \& Business Media.

De'ath, G., \& Fabricius, K. E. 2000. Classification and regression trees: a powerful yet simple technique for ecological data analysis. Ecology, 81(11): 3178-3192.

Durbin, J., \& Watson, G. S. 1950. TESTING FOR SERIAL CORRELATION IN LEAST SQUARES REGRESSION. I. Biometrika, 37(3-4): 409-428.

EIA. 2012. Annual Energy Review 2011: Government Printing Office.

Faruk, D. Ö. 2010. A hybrid neural network and ARIMA model for water quality time series prediction. Engineering Applications of Artificial Intelligence, 23(4): 586-594. 
Gairaa, K., Khellaf, A., Messlem, Y., \& Chellali, F. 2016. Estimation of the daily global solar radiation based on Box-Jenkins and ANN models: A combined approach. Renewable and Sustainable Energy Reviews, 57: 238-249.

Ginzburg, I., \& Horn, D. 1994. Combined neural networks for time series analysis. Paper presented at the Advances in Neural Information Processing Systems.

Gorr, W. L., Nagin, D., \& Szczypula, J. 1994. Comparative study of artificial neural network and statistical models for predicting student grade point averages. International Journal of Forecasting, 10(1): 17-34.

Hannan, E. J., \& Quinn, B. G. 1979. The determination of the order of an autoregression. Journal of the Royal Statistical Society. Series B (Methodological): 190-195.

Harrison, P. J. 1965. Short-term sales forecasting. Applied Statistics: 102-139.

Hebb, D. 1980. Donald O. Hebb. A history of psychology in autobiography, 7: 273303.

Hill, T., Marquez, L., O'Connor, M., \& Remus, W. 1994. Artificial neural network models for forecasting and decision making. International Journal of Forecasting, 10(1): 5-15.

Ho, S., Xie, M., \& Goh, T. 2002. A comparative study of neural network and Box-Jenkins ARIMA modeling in time series prediction. Computers \& Industrial Engineering, 42(2): 371-375.

Hyndman, R. J., \& Athanasopoulos, G. 2014. Forecasting: principles and practice: OTexts.

Jain, A. K., Mao, J., \& Mohiuddin, K. M. 1996. Artificial neural networks: A tutorial. Computer, 29(3): 31-44.

Karnin, E. D. 1990. A simple procedure for pruning back-propagation trained neural networks. IEEE Transactions on Neural Networks, 1(2): 239-242.

Khashei, M., \& Bijari, M. 2011. A novel hybridization of artificial neural networks and ARIMA models for time series forecasting. Applied Soft Computing, 11(2): 2664-2675. 
Lachtermacher, G., \& Fuller, J. D. 1995. Back propagation in time-series forecasting. Journal of Forecasting, 14(4): 381-393.

Lam, K. C., \& Oshodi, O. S. 2016. Forecasting construction output: a comparison of artificial neural network and Box-Jenkins model. Engineering, Construction and Architectural Management, 23(3): 302-322.

Levenberg, K. 1944. A method for the solution of certain non-linear problems in least squares. Quarterly of applied mathematics, 2(2): 164-168.

Liang, G., Wilkes, D. M., \& Cadzow, J. A. 1993. ARMA model order estimation based on the eigenvalues of the covariance matrix. IEEE Transactions on Signal Processing, 41(10): 3003-3009.

Mohan, S., \& Vedula, S. 1995. Multiplicative seasonal ARIMA model for long-term forecasting of inflows. Water resources management, 9(2): 115-126.

Montgomery, D. C., Jennings, C. L., \& Kulahci, M. 2015. Introduction to time series analysis and forecasting: John Wiley \& Sons.

Niaki, S. T. A., \& Hoseinzade, S. 2013. Forecasting S\&P 500 index using artificial neural networks and design of experiments. Journal of Industrial Engineering International, 9(1): 1.

Pappas, S. S., Ekonomou, L., Karamousantas, D. C., Chatzarakis, G., Katsikas, S., \& Liatsis, P. 2008. Electricity demand loads modeling using AutoRegressive Moving Average (ARMA) models. Energy, 33(9): 1353-1360.

Pelikan, E., De Groot, C., \& Wurtz, D. 1992. Power consumption in West-Bohemia: improved forecasts with decorrelating connectionist networks. Neural Network World, 2(6): 701-712.

Quiza, R., \& Davim, J. 2009. Computational modeling of machining systems.

Reed, R. 1993. Pruning algorithms-a survey. IEEE Transactions on Neural Networks, 4(5): 740-747.

Rose, N. 2015. Applying artificial neural network techniques to the ARMA model. Swinburne University of Technology. 
Samorodnitsky, G., \& Taqqu, M. S. 1994. Stable non-Gaussian random processes: stochastic models with infinite variance: CRC press.

Sandberg, I. W. 2001. Nonlinear dynamical systems: feedforward neural network perspectives: John Wiley \& Sons.

Schwarz, G. 1978. Estimating the dimension of a model. The annals of statistics, 6(2): 461-464.

Slutzky, E. 1937. The summation of random causes as the source of cyclic processes. Econometrica: Journal of the Econometric Society: 105-146.

Tan, M. Y. J., \& Biswas, R. 2012. The reliability of the Akaike information criterion method in cosmological model selection. Monthly Notices of the Royal Astronomical Society, 419(4): 3292-3303.

Tang, Z., \& Fishwick, P. A. 1993. Feedforward neural nets as models for time series forecasting. ORSA Journal on computing, 5(4): 374-385.

Tillman, D. A. 2012. Wood as an energy resource: Elsevier.

Torres, J. L., Garcia, A., De Blas, M., \& De Francisco, A. 2005. Forecast of hourly average wind speed with ARMA models in Navarre (Spain). Solar Energy, 79(1): 65-77.

Trigg, D. 1964. Monitoring a forecasting system. Journal of the Operational Research Society, 15(3): 271-274.

Tse, R. Y. 1997. An application of the ARIMA model to real-estate prices in Hong Kong. Journal of Property Finance, 8(2): 152-163.

Tseng, F.-M., Yu, H.-C., \& Tzeng, G.-H. 2002. Combining neural network model with seasonal time series ARIMA model. Technological Forecasting and Social Change, 69(1): 71-87.

Vedaldi, A., \& Lenc, K. 2015. Matconvnet: Convolutional neural networks for Matlab. Paper presented at the Proceedings of the 23rd ACM international conference on Multimedia. 
Watanabe, S. 2010. Asymptotic equivalence of Bayes cross-validation and widely applicable information criterion in singular learning theory. Journal of Machine Learning Research, 11(Dec): 3571-3594.

Werbos, P. J. 1994. The roots of backpropagation: from ordered derivatives to neural networks and political forecasting: John Wiley \& Sons.

Yu, H., \& Wilamowski, B. M. 2011. Levenberg-marquardt training. Industrial Electronics Handbook, 5(12): 1.

Yu, L., Wang, S., \& Lai, K. K. 2005. A novel nonlinear ensemble forecasting model incorporating GLAR and ANN for foreign exchange rates. Computers \& Operations Research, 32(10): 2523-2541.

Yule, G. U. 1926. Why do we sometimes get nonsense-correlations between TimeSeries?--a study in sampling and the nature of time-series. Journal of the royal statistical society, 89(1): 1-63.

Zhang, G., Patuwo, B. E., \& Hu, M. Y. 1998. Forecasting with artificial neural networks:: The state of the art. International journal of forecasting, 14(1): 35-62.

Zhang, G. P. 2003. Time series forecasting using a hybrid ARIMA and neural network model. Neurocomputing, 50: 159-175. 


\section{Appendix}

\subsection{Consumer price index data}

Table 3 reports monthly Consumer Price Index (CPI) from January 2004 to January 2018 which is obtained from EIA.

Table 3-Consumer price index of U.S.

\begin{tabular}{|c|c|c|c|c|c|}
\hline Month & $\mathrm{CIP}$ & Month & $\mathrm{CIP}$ & Month & $\mathrm{CIP}$ \\
\hline January 2004 & 1.863 & May 2009 & 2.130 & September 2014 & 2.375 \\
\hline February 2004 & 1.867 & June 2009 & 2.148 & October 2014 & 2.374 \\
\hline March 2004 & 1.871 & July 2009 & 2.147 & November 2014 & 2.370 \\
\hline April 2004 & 1.874 & August 2009 & 2.154 & December 2014 & 2.363 \\
\hline May 2004 & 1.882 & September 2009 & 2.159 & January 2015 & 2.348 \\
\hline June 2004 & 1.889 & October 2009 & 2.165 & February 2015 & 2.353 \\
\hline July 2004 & 1.891 & November 2009 & 2.172 & March 2015 & 2.360 \\
\hline August 2004 & 1.892 & December 2009 & 2.173 & May 2013 & 2.319 \\
\hline September 2004 & 1.898 & January 2010 & 2.175 & June 2013 & 2.324 \\
\hline October 2004 & 1.908 & February 2010 & 2.173 & July 2013 & 2.329 \\
\hline November 2004 & 1.917 & March 2010 & 2.174 & August 2013 & 2.335 \\
\hline December 2004 & 1.917 & April 2010 & 2.174 & September 2013 & 2.335 \\
\hline January 2005 & 1.916 & May 2010 & 2.173 & October 2013 & 2.337 \\
\hline February 2005 & 1.924 & June 2010 & 2.172 & November 2013 & 2.341 \\
\hline March 2005 & 1.931 & July 2010 & 2.176 & December 2013 & 2.347 \\
\hline April 2005 & 1.937 & August 2010 & 2.179 & January 2014 & 2.353 \\
\hline May 2005 & 1.936 & September 2010 & 2.183 & February 2014 & 2.355 \\
\hline June 2005 & 1.937 & October 2010 & 2.190 & March 2014 & 2.360 \\
\hline July 2005 & 1.949 & November 2010 & 2.196 & April 2014 & 2.365 \\
\hline August 2005 & 1.961 & December 2010 & 2.205 & May 2014 & 2.369 \\
\hline September 2005 & 1.988 & January 2011 & 2.212 & June 2014 & 2.372 \\
\hline October 2005 & 1.991 & February 2011 & 2.219 & July 2014 & 2.375 \\
\hline November 2005 & 1.981 & March 2011 & 2.230 & August 2014 & 2.374 \\
\hline December 2005 & 1.981 & April 2011 & 2.241 & September 2014 & 2.375 \\
\hline January 2006 & 1.993 & May 2011 & 2.248 & October 2014 & 2.374 \\
\hline February 2006 & 1.994 & June 2011 & 2.248 & November 2014 & 2.370 \\
\hline March 2006 & 1.997 & July 2011 & 2.254 & December 2014 & 2.363 \\
\hline April 2006 & 2.007 & August 2011 & 2.261 & January 2015 & 2.348 \\
\hline May 2006 & 2.013 & September 2011 & 2.266 & February 2015 & 2.353 \\
\hline June 2006 & 2.018 & October 2011 & 2.268 & March 2015 & 2.360 \\
\hline July 2006 & 2.029 & November 2011 & 2.272 & April 2015 & 2.362 \\
\hline
\end{tabular}




\begin{tabular}{|c|c|c|c|c|c|}
\hline August 2006 & 2.038 & December 2011 & 2.272 & May 2015 & 2.370 \\
\hline September 2006 & 2.028 & January 2012 & 2.278 & June 2015 & 2.376 \\
\hline October 2006 & 2.019 & February 2012 & 2.283 & July 2015 & 2.380 \\
\hline November 2006 & 2.020 & March 2012 & 2.288 & August 2015 & 2.380 \\
\hline December 2006 & 2.031 & April 2012 & 2.292 & September 2015 & 2.375 \\
\hline January 2007 & 2.034 & May 2012 & 2.287 & October 2015 & 2.378 \\
\hline February 2007 & 2.042 & June 2012 & 2.285 & November 2015 & 2.381 \\
\hline March 2007 & 2.053 & July 2012 & 2.286 & December 2015 & 2.378 \\
\hline April 2007 & 2.059 & August 2012 & 2.299 & January 2016 & 2.380 \\
\hline May 2007 & 2.068 & September 2012 & 2.310 & February 2016 & 2.375 \\
\hline June 2007 & 2.072 & October 2012 & 2.316 & March 2016 & 2.380 \\
\hline July 2007 & 2.076 & November 2012 & 2.312 & April 2016 & 2.388 \\
\hline August 2007 & 2.077 & December 2012 & 2.312 & May 2016 & 2.394 \\
\hline September 2007 & 2.085 & January 2013 & 2.317 & June 2016 & 2.401 \\
\hline October 2007 & 2.092 & February 2013 & 2.329 & July 2016 & 2.401 \\
\hline November 2007 & 2.108 & March 2013 & 2.323 & August 2016 & 2.406 \\
\hline December 2007 & 2.114 & April 2013 & 2.318 & September 2016 & 2.410 \\
\hline January 2008 & 2.122 & May 2013 & 2.319 & October 2016 & 2.417 \\
\hline February 2008 & 2.127 & June 2013 & 2.324 & November 2016 & 2.421 \\
\hline March 2008 & 2.134 & July 2013 & 2.329 & December 2016 & 2.428 \\
\hline April 2008 & 2.139 & August 2013 & 2.335 & January 2017 & 2.440 \\
\hline May 2008 & 2.152 & September 2013 & 2.335 & February 2017 & 2.441 \\
\hline June 2008 & 2.175 & October 2013 & 2.337 & March 2017 & 2.437 \\
\hline July 2008 & 2.190 & November 2013 & 2.341 & April 2017 & 2.441 \\
\hline August 2008 & 2.187 & December 2013 & 2.347 & May 2017 & 2.439 \\
\hline September 2008 & 2.189 & January 2014 & 2.353 & June 2017 & 2.440 \\
\hline October 2008 & 2.170 & February 2014 & 2.355 & July 2017 & 2.442 \\
\hline November 2008 & 2.132 & March 2014 & 2.360 & August 2017 & 2.453 \\
\hline December 2008 & 2.114 & April 2014 & 2.365 & September 2017 & 2.464 \\
\hline January 2009 & 2.119 & May 2014 & 2.369 & October 2017 & 2.466 \\
\hline February 2009 & 2.127 & June 2014 & 2.372 & November 2017 & 2.474 \\
\hline March 2009 & 2.125 & July 2014 & 2.375 & December 2017 & 2.479 \\
\hline April 2009 & 2.127 & August 2014 & 2.374 & January 2018 & 2.492 \\
\hline
\end{tabular}




\subsection{Average heat rate}

Approximate heat rates for electricity from 2004 to 2017 in terms of Btu per kWh are obtained from EIA. The data was updated in February 2018.

Table 4- Heat rates for electricity (EIA)

\begin{tabular}{cccccc} 
Year & \multicolumn{1}{l}{ Coal } & Petroleum & Natural gas & Nuclear & $\begin{array}{c}\text { Noncombustible } \\
\text { Renewable Energy }\end{array}$ \\
\hline 2004 & 10331 & 10571 & 8647 & 10428 & 10016 \\
2005 & 10373 & 10631 & 8551 & 10436 & 9999 \\
2006 & 10351 & 10809 & 8471 & 10435 & 9919 \\
2007 & 10375 & 10794 & 8403 & 10489 & 9884 \\
2008 & 10378 & 11015 & 8305 & 10452 & 9854 \\
2009 & 10414 & 10923 & 8160 & 10459 & 9760 \\
2010 & 10415 & 10984 & 8185 & 10452 & 9756 \\
2011 & 10444 & 10829 & 8152 & 10464 & 9716 \\
2012 & 10498 & 10991 & 8039 & 10479 & 9516 \\
2013 & 10459 & 10713 & 7948 & 10449 & 9541 \\
2014 & 10428 & 10814 & 7907 & 10459 & 9510 \\
2015 & 10495 & 10687 & 7878 & 10458 & 9319 \\
2016 & 10493 & 10811 & 7870 & 10459 & 9232 \\
2017 & 10493 & 10811 & 7870 & 10459 & 9232
\end{tabular}

Note that coal includes anthracite, bituminous, sub-bituminous and lignite coal, waste coal and synthetic coal. Petroleum includes distillate fuel oil, residual fuel oil, fuel oil, jet fuel, kerosene, petroleum coke, and waste oil.

The fossil-fuels heat rate is used as the thermal conversion factor for electricity net Also, the heat and power plants are combined. All plants in the commercial and industrial sectors are excluded from the calculations. 


\subsection{EIA's LCOE projections}

Historical summary of EIA's LCOE projections from 2010 to 2017 obtained from wikipedia.org ${ }^{2}$.

Historical summary of EIA's LCOE projections (2010-2017)

\begin{tabular}{|c|c|c|c|c|c|c|c|c|c|c|}
\hline \multicolumn{3}{|c|}{ Estimate in \$/MWh } & $\begin{array}{c}\text { Coal } \\
\text { convent'l }\end{array}$ & \multicolumn{2}{|c|}{ NG combined cycle } & $\begin{array}{l}\text { Nuclear } \\
\text { advanced }\end{array}$ & \multicolumn{2}{|c|}{ Wind } & \multicolumn{2}{|c|}{ Solar } \\
\hline 2010 & [54] & 2016 & 100.4 & 83.1 & 79.3 & 119.0 & 149.3 & 191.1 & 396.1 & 256.6 \\
\hline 2011 & [55] & 2016 & 95.1 & 65.1 & 62.2 & 114.0 & 96.1 & 243.7 & 211.0 & 312.2 \\
\hline 2012 & [56] & 2017 & 97.7 & 66.1 & 63.1 & 111.4 & 96.0 & $N / A$ & 152.4 & 242.0 \\
\hline 2014 & [58] & 2019 & 95.6 & 66.3 & 64.4 & 96.1 & 80.3 & 204.1 & 130.0 & 243.1 \\
\hline 2015 & [53] & 2020 & 95.1 & 75.2 & 72.6 & 95.2 & 73.6 & 196.9 & 125.3 & 239.7 \\
\hline 2016 & [59] & 2022 & NB & 58.1 & 57.2 & 102.8 & 64.5 & 158.1 & 84.7 & 235.9 \\
\hline
\end{tabular}

Note: Projected LCOE are adjusted for inflation and calculated on constant dollars based on two years prior to the release year of the estimate. Estimates given without any subsidies. Transmission cost for non-dispatchable sources are on average much higher.

NB = "Not built" (No capacity additions are expected.)

\footnotetext{
${ }^{2}$ https://en.wikipedia.org/wiki/Cost_of_electricity_by_source
} 


\subsection{The predicted value of electricity generation using the ANN}

\section{and the hybrid ARIMA and ANN:}

Table 5, Table 6, Table 7, Table 8 , report the monthly predicted value of electricity generation from different primary energy sources in terms of billion kWh from January 2015 to November 2017.

Table 5- Actual and predicted value of electricity generation from coal and oil between 2004 to 2017

\begin{tabular}{|c|c|c|c|c|c|c|}
\hline \multirow[b]{2}{*}{ Date } & \multirow{2}{*}{$\begin{array}{l}\text { Actual } \\
\text { value } \\
\text { (Coal) }\end{array}$} & \multicolumn{2}{|c|}{ Fitted value } & \multirow{2}{*}{$\begin{array}{c}\text { Actual } \\
\text { value (Oil) }\end{array}$} & \multicolumn{2}{|c|}{ Fitted value } \\
\hline & & ANN & Hybrid & & ANN & Hybrid \\
\hline Jan-14 & 155.9163 & 117.2494 & 141.6109 & 6.7841 & 1.9821 & 2.3511 \\
\hline Feb-14 & 142.2176 & 149.2783 & 144.8578 & 2.5778 & 5.5400 & 3.6380 \\
\hline Mar-14 & 135.2902 & 116.8060 & 144.2032 & 2.9988 & 1.9317 & 2.5476 \\
\hline Apr-14 & 108.2787 & 108.7611 & 137.5928 & 1.5834 & 1.9066 & 3.6859 \\
\hline May-14 & 117.7384 & 108.9004 & 136.8646 & 1.8702 & 1.8931 & 2.3328 \\
\hline Jun-14 & 136.4698 & 107.5873 & 131.8706 & 1.8451 & 1.8841 & 2.8904 \\
\hline Jul-14 & 148.4722 & 107.1394 & 138.0515 & 1.8675 & 1.8961 & 1.5962 \\
\hline Aug-14 & 147.3290 & 104.8720 & 128.9580 & 1.8729 & 1.8997 & 2.9142 \\
\hline Sep-14 & 125.0617 & 101.4761 & 132.8322 & 1.7773 & 1.8911 & 2.2363 \\
\hline Oct-14 & 110.3222 & 97.2764 & 124.6784 & 1.3679 & 1.8844 & 3.5080 \\
\hline Nov-14 & 118.1175 & 88.2236 & 120.2392 & 1.5769 & 1.8734 & 1.8679 \\
\hline Dec-14 & 123.5607 & 86.2770 & 119.0140 & 1.9211 & 1.7969 & 2.3495 \\
\hline Jan-15 & 131.4307 & 91.3026 & 123.2784 & 2.7889 & 1.8008 & 1.1341 \\
\hline Feb-15 & 126.0236 & 91.1259 & 138.1820 & 6.0736 & 1.7960 & 2.3252 \\
\hline Mar-15 & 107.4710 & 88.5805 & 138.3800 & 1.6440 & 1.8030 & 1.8224 \\
\hline Apr-15 & 88.1470 & 90.1245 & 136.5760 & 1.5702 & 1.7918 & 2.9509 \\
\hline May-15 & 103.6716 & 86.2403 & 128.9302 & 1.7937 & 1.7730 & 1.0539 \\
\hline Jun-15 & 124.6771 & 88.1285 & 124.0496 & 1.7228 & 1.7746 & 2.1854 \\
\hline Jul-15 & 138.0605 & 93.6065 & 118.0554 & 2.1854 & 1.7781 & 0.4945 \\
\hline Aug-15 & 133.6513 & 96.7822 & 127.4083 & 2.0132 & 1.7674 & 1.4025 \\
\hline Sep-15 & 117.0054 & 102.9182 & 128.9817 & 1.8987 & 1.7648 & 2.0315 \\
\hline Oct-15 & 95.8715 & 125.5690 & 136.0737 & 1.6572 & 1.7704 & 2.2481 \\
\hline Nov-15 & 86.3620 & 130.2755 & 139.3357 & 1.5827 & 1.7345 & 0.5590 \\
\hline Dec-15 & 88.6217 & 115.0935 & 131.9650 & 1.5748 & 1.7256 & 1.7183 \\
\hline Jan-16 & 112.6240 & 113.5627 & 124.9023 & 2.2171 & 1.7175 & 0 \\
\hline Feb-16 & 91.9092 & 109.9647 & 102.4731 & 2.0790 & 1.7145 & 0.7731 \\
\hline Mar-16 & 71.3458 & 105.6999 & 106.1971 & 1.6952 & 1.7236 & 2.3298 \\
\hline Apr-16 & 71.4191 & 106.7556 & 118.8680 & 1.7452 & 1.7153 & 0.9953 \\
\hline May-16 & 80.9347 & 98.5778 & 121.1342 & 1.8143 & 1.7648 & 0.1657 \\
\hline Jun-16 & 115.1967 & 104.2240 & 123.9511 & 1.8472 & 1.7326 & 1.1891 \\
\hline Jul-16 & 135.4201 & 110.0884 & 114.2703 & 2.1857 & 1.7605 & 0 \\
\hline Aug-16 & 134.7624 & 122.3026 & 117.5752 & 2.2103 & 1.7167 & 0.8406 \\
\hline
\end{tabular}




$\begin{array}{lllllll}\text { Sep-16 } & 113.3470 & 120.1123 & 125.6076 & 1.8217 & 1.6982 & 2.5761 \\ \text { Oct-16 } & 98.4738 & 116.9672 & 125.9757 & 1.4496 & 1.7041 & 0.0769 \\ \text { Nov-16 } & 86.2753 & 111.5201 & 125.3286 & 1.7367 & 1.6992 & 0.0148 \\ \text { Dec-16 } & 117.9548 & 117.2494 & 141.6109 & 1.9084 & 1.9821 & 2.3511 \\ \text { Jan-17 } & 114.7028 & 149.2783 & 144.8578 & 2.0109 & 5.5400 & 3.6380 \\ \text { Feb-17 } & 86.1792 & 116.8060 & 144.2032 & 1.5442 & 1.9317 & 2.5476 \\ \text { Mar-17 } & 88.7252 & 108.7611 & 137.5928 & 1.5625 & 1.9066 & 3.6859 \\ \text { Apr-17 } & 80.9206 & 108.9004 & 136.8646 & 1.1994 & 1.8931 & 2.3328 \\ \text { May-17 } & 91.8081 & 107.5873 & 131.8706 & 1.6537 & 1.8841 & 2.8904 \\ \text { Jun-17 } & 106.9991 & 107.1394 & 138.0515 & 1.7630 & 1.8961 & 1.5962 \\ \text { Jul-17 } & 127.2503 & 104.8720 & 128.9580 & 1.6185 & 1.8997 & 2.9142 \\ \text { Aug-17 } & 119.1462 & 101.4761 & 132.8322 & 1.6082 & 1.8911 & 2.2363 \\ \text { Sep-17 } & 97.7310 & 97.2764 & 124.6784 & 1.5681 & 1.8844 & 3.5080 \\ \text { Oct-17 } & 89.3812 & 88.2236 & 120.2392 & 1.4443 & 1.8734 & 1.8679 \\ \text { Nov-17 } & 90.4921 & 86.2770 & 119.0140 & 1.4860 & 1.7969 & 2.3495\end{array}$

Table 6- Actual and predicted value of electricity generation from natural gas and geothermal between 2004 to 2017

\begin{tabular}{|c|c|c|c|c|c|c|}
\hline \multirow[b]{2}{*}{ Date } & \multirow{2}{*}{$\begin{array}{l}\text { Actual } \\
\text { value } \\
\text { (NG) }\end{array}$} & \multicolumn{2}{|c|}{ Fitted value } & \multirow{2}{*}{$\begin{array}{l}\text { Actual } \\
\text { value } \\
\text { (Geo) }\end{array}$} & \multicolumn{2}{|c|}{ Fitted value } \\
\hline & & ANN & Hybrid & & ANN & Hybrid \\
\hline Jan-14 & 82.9691 & 83.0075 & 87.6510 & 1.3550 & 1.2729 & 1.2777 \\
\hline Feb-14 & 68.7296 & 86.7136 & 103.1229 & 1.2061 & 1.3509 & 1.3905 \\
\hline Mar-14 & 70.5173 & 86.5973 & 81.3693 & 1.3377 & 1.3231 & 1.3139 \\
\hline Apr-14 & 69.5833 & 89.9967 & 95.4354 & 1.3135 & 1.2688 & 1.3391 \\
\hline May-14 & 81.6449 & 93.6384 & 88.9946 & 1.3324 & 1.3271 & 1.3104 \\
\hline Jun-14 & 90.9025 & 95.7452 & 81.0318 & 1.2934 & 1.3157 & 1.3493 \\
\hline Jul-14 & 106.6955 & 104.6966 & 88.1242 & 1.3196 & 1.2946 & 1.3346 \\
\hline Aug-14 & 113.9098 & 102.5303 & 103.1549 & 1.3292 & 1.2869 & 1.3131 \\
\hline Sep-14 & 98.6902 & 95.3307 & 88.1544 & 1.3075 & 1.1640 & 1.3554 \\
\hline Oct-14 & 90.0534 & 94.1768 & 92.8234 & 1.3451 & 1.2749 & 1.3378 \\
\hline Nov-14 & 76.7106 & 98.3671 & 96.0746 & 1.3625 & 1.3903 & 1.3373 \\
\hline Dec-14 & 82.7661 & 86.7137 & 83.2432 & 1.3750 & 1.3502 & 1.3204 \\
\hline Jan-15 & 93.4496 & 85.4020 & 102.6468 & 1.3619 & 1.2836 & 1.3000 \\
\hline Feb-15 & 84.2069 & 85.7714 & 113.3129 & 1.2601 & 1.2790 & 1.3733 \\
\hline Mar-15 & 92.1103 & 99.7270 & 82.1895 & 1.3940 & 1.2799 & 1.3262 \\
\hline Apr-15 & 85.8277 & 110.2472 & 78.2063 & 1.2724 & 1.2068 & 1.3510 \\
\hline May-15 & 94.1240 & 107.1126 & 110.7412 & 1.3902 & 1.3053 & 1.3236 \\
\hline Jun-15 & 113.3901 & 106.4896 & 113.6848 & 1.3016 & 1.2699 & 1.3523 \\
\hline Jul-15 & 132.2659 & 117.4606 & 86.1781 & 1.3567 & 1.2911 & 1.3540 \\
\hline Aug-15 & 130.3142 & 107.7688 & 63.7594 & 1.3441 & 1.3058 & 1.3258 \\
\hline Sep-15 & 114.7917 & 96.4652 & 77.8131 & 1.2029 & 1.3497 & 1.3538 \\
\hline Oct-15 & 102.0218 & 100.6604 & 115.0646 & 1.3230 & 1.3431 & 1.3469 \\
\hline Nov-15 & 94.1323 & 91.1104 & 85.6837 & 1.3336 & 1.3980 & 1.3512 \\
\hline
\end{tabular}




$\begin{array}{lllllll}\text { Dec-15 } & 101.0218 & 83.9242 & 94.1627 & 1.3770 & 1.4199 & 1.3481 \\ \text { Jan-16 } & 101.7862 & 96.7019 & 61.8147 & 1.3320 & 1.3666 & 1.3203 \\ \text { Feb-16 } & 90.8494 & 85.9365 & 54.1289 & 1.2434 & 1.3681 & 1.3710 \\ \text { Mar-16 } & 95.8487 & 136.3440 & 82.0701 & 1.3152 & 1.3548 & 1.3382 \\ \text { Apr-16 } & 91.2573 & 113.8152 & 63.3153 & 1.2090 & 1.4168 & 1.3618 \\ \text { May-16 } & 102.4819 & 115.2682 & 99.4953 & 1.3418 & 1.2535 & 1.3376 \\ \text { Jun-16 } & 123.0428 & 112.4245 & 69.9057 & 1.2514 & 1.3198 & 1.3557 \\ \text { Jul-16 } & 142.5580 & 116.2048 & 74.8729 & 1.3112 & 1.3615 & 1.3662 \\ \text { Aug-16 } & 145.6101 & 130.1436 & 89.1414 & 1.3243 & 1.3527 & 1.3436 \\ \text { Sep-16 } & 117.1967 & 116.5169 & 87.5973 & 1.3267 & 1.4190 & 1.3590 \\ \text { Oct-16 } & 94.7541 & 109.9944 & 92.2938 & 1.3532 & 1.1622 & 1.3546 \\ \text { Nov-16 } & 85.9068 & 107.1446 & 79.7549 & 1.3639 & 1.4417 & 1.3587 \\ \text { Dec-16 } & 88.0876 & 83.0075 & 87.6510 & 1.4539 & 1.2729 & 1.2777 \\ \text { Jan-17 } & 82.8778 & 86.7136 & 103.1229 & 1.3995 & 1.3509 & 1.3905 \\ \text { Feb-17 } & 72.9904 & 86.5973 & 81.3693 & 1.2413 & 1.3231 & 1.3139 \\ \text { Mar-17 } & 86.9471 & 89.9967 & 95.4354 & 1.3798 & 1.2688 & 1.3391 \\ \text { Apr-17 } & 78.6219 & 93.6384 & 88.9946 & 1.3573 & 1.3271 & 1.3104 \\ \text { May-17 } & 88.9479 & 95.7452 & 81.0318 & 1.2951 & 1.3157 & 1.3493 \\ \text { Jun-17 } & 107.9290 & 104.6966 & 88.1242 & 1.2647 & 1.2946 & 1.3346 \\ \text { Jul-17 } & 136.0430 & 102.5303 & 103.1549 & 1.3678 & 1.2869 & 1.3131 \\ \text { Aug-17 } & 131.2785 & 95.3307 & 88.1544 & 1.3570 & 1.1640 & 1.3554 \\ \text { Sep-17 } & 109.0336 & 94.1768 & 92.8234 & 1.3254 & 1.2749 & 1.3378 \\ \text { Oct-17 } & 99.2773 & 98.3671 & 96.0746 & 1.2609 & 1.3903 & 1.3373 \\ \text { Nov-17 } & 84.8566 & 86.7137 & 83.2432 & 1.3341 & 1.3502 & 1.3204\end{array}$

Table 7- Actual and predicted value of electricity generation from hydroelectric and solar between 2004 to 2017

\begin{tabular}{|c|c|c|c|c|c|c|}
\hline \multirow[b]{2}{*}{ Date } & \multirow{2}{*}{$\begin{array}{l}\text { Actual } \\
\text { value } \\
\text { (Hydro) }\end{array}$} & \multicolumn{2}{|c|}{ Fitted value } & \multirow{2}{*}{$\begin{array}{l}\text { Actual } \\
\text { value } \\
\text { (Solar) }\end{array}$} & \multicolumn{2}{|c|}{ Fitted value } \\
\hline & & ANN & Hybrid & & ANN & Hybrid \\
\hline Jan-14 & 21.5101 & 25.5310 & 26.5284 & 0.7340 & 3.7183 & 0.4916 \\
\hline Feb-14 & 17.2889 & 26.4634 & 27.7529 & 0.8139 & 3.9082 & 0.9112 \\
\hline Mar-14 & 24.1388 & 27.0361 & 19.6287 & 1.2865 & 4.0909 & 0.1263 \\
\hline Apr-14 & 25.3095 & 26.6935 & 23.9195 & 1.4529 & 4.2611 & 0.4275 \\
\hline May-14 & 26.4104 & 24.9973 & 19.7174 & 1.7101 & 4.4059 & 0.6641 \\
\hline Jun-14 & 25.6405 & 21.7082 & 18.1840 & 1.8828 & 4.5129 & 0.0736 \\
\hline Jul-14 & 24.2649 & 16.9520 & 22.0720 & 1.7482 & 4.5560 & 0.6970 \\
\hline Aug-14 & 19.7085 & 11.6137 & 23.5340 & 1.8387 & 4.5139 & 0.3429 \\
\hline Sep-14 & 15.9858 & 6.9881 & 25.8846 & 1.7954 & 4.4101 & 0.8385 \\
\hline Oct-14 & 17.0635 & 3.9128 & 27.0196 & 1.6799 & 4.3067 & 0.8442 \\
\hline Nov-14 & 18.5239 & 2.4149 & 25.7549 & 1.3509 & 4.2447 & 0.6498 \\
\hline Dec-14 & 22.2015 & 2.2187 & 17.3718 & 1.0107 & 4.2244 & 0.5752 \\
\hline Jan-15 & 24.0140 & 42.5263 & 24.3114 & 1.1342 & 0 & 0.2127 \\
\hline Feb-15 & 22.1789 & 39.6839 & 22.8024 & 1.4593 & 0 & 1.0312 \\
\hline
\end{tabular}




$\begin{array}{lllllll}\text { Mar-15 } & 24.1480 & 36.3490 & 17.7265 & 2.0373 & 0 & 0.6923 \\ \text { Apr-15 } & 22.3305 & 32.6418 & 19.8577 & 2.3378 & 0 & 0 \\ \text { May-15 } & 19.9954 & 29.0622 & 14.1566 & 2.4561 & 0 & 0.9088 \\ \text { Jun-15 } & 20.2966 & 26.2598 & 17.5564 & 2.5120 & 0 & 0.0851 \\ \text { Jul-15 } & 20.8959 & 25.0446 & 18.6372 & 2.5795 & 0 & 0.6923 \\ \text { Aug-15 } & 19.0295 & 25.9847 & 13.6675 & 2.6394 & 0 & 1.9500 \\ \text { Sep-15 } & 16.0151 & 28.8057 & 14.6620 & 2.1778 & 0.4385 & 0.8569 \\ \text { Oct-15 } & 16.5132 & 32.5137 & 18.5808 & 1.8754 & 0.8675 & 0 \\ \text { Nov-15 } & 19.2020 & 36.1536 & 12.4541 & 1.7015 & 1.2527 & 0.7902 \\ \text { Dec-15 } & 23.0165 & 39.4920 & 14.7502 & 1.5453 & 1.6284 & 2.8394 \\ \text { Jan-16 } & 25.4639 & 42.1251 & 15.2921 & 1.4582 & 1.9761 & 1.1593 \\ \text { Feb-16 } & 24.0058 & 44.1557 & 19.4752 & 2.2005 & 2.3069 & 0 \\ \text { Mar-16 } & 27.2256 & 45.9605 & 22.8212 & 2.5708 & 2.6826 & 0 \\ \text { Apr-16 } & 25.7349 & 47.5204 & 23.9342 & 2.8311 & 3.1068 & 0 \\ \text { May-16 } & 25.3554 & 48.8893 & 23.8608 & 3.3750 & 3.5712 & 0.4569 \\ \text { Jun-16 } & 23.1255 & 50.2744 & 22.1516 & 3.4177 & 4.0811 & 1.7457 \\ \text { Jul-16 } & 21.3367 & 51.9687 & 25.2303 & 3.8865 & 4.6481 & 0 \\ \text { Aug-16 } & 19.4580 & 54.0890 & 15.1528 & 3.9084 & 5.2396 & 0.3322 \\ \text { Sep-16 } & 16.2789 & 56.4242 & 16.9352 & 3.5842 & 5.8000 & 0 \\ \text { Oct-16 } & 17.2294 & 58.5321 & 13.7256 & 3.1466 & 6.2612 & 1.5152 \\ \text { Nov-16 } & 18.7215 & 60.1616 & 15.2858 & 2.7294 & 6.5952 & 1.0450 \\ \text { Dec-16 } & 22.3903 & 25.5310 & 26.5284 & 2.3890 & 3.7183 & 0.4916 \\ \text { Jan-17 } & 27.7116 & 26.4634 & 27.7529 & 2.1232 & 3.9082 & 0.9112 \\ \text { Feb-17 } & 24.4105 & 27.0361 & 19.6287 & 2.4630 & 4.0909 & 0.1263 \\ \text { Mar-17 } & 30.0691 & 26.6935 & 23.9195 & 4.3699 & 4.2611 & 0.4275 \\ \text { Apr-17 } & 29.1728 & 24.9973 & 19.7174 & 4.7057 & 4.4059 & 0.6641 \\ \text { May-17 } & 32.0194 & 21.7082 & 18.1840 & 5.6779 & 4.5129 & 0.0736 \\ \text { Jun-17 } & 30.2741 & 16.9520 & 22.0720 & 6.1517 & 4.5560 & 0.6970 \\ \text { Jul-17 } & 25.5997 & 11.6137 & 23.5340 & 5.4123 & 4.5139 & 0.3429 \\ \text { Aug-17 } & 21.1134 & 6.9881 & 25.8846 & 5.3116 & 4.4101 & 0.8385 \\ \text { Sep-17 } & 18.8503 & 3.9128 & 27.0196 & 5.0796 & 4.3067 & 0.8442 \\ \text { Oct-17 } & 17.0936 & 2.4149 & 25.7549 & 4.7449 & 4.2447 & 0.6498 \\ \text { Nov-17 } & 19.7057 & 2.2187 & 17.3718 & 3.0380 & 4.2244 & 0.5752 \\ & & & & & & \end{array}$

Table 8- Actual and predicted value of electricity generation from wind and nuclear between 2004 to 2017

\begin{tabular}{|c|c|c|c|c|c|c|}
\hline \multirow[b]{2}{*}{ Date } & \multirow{2}{*}{$\begin{array}{l}\text { Actual } \\
\text { value } \\
\text { (Wind) }\end{array}$} & \multicolumn{2}{|c|}{ Fitted value } & \multirow{2}{*}{$\begin{array}{c}\text { Actual } \\
\text { value } \\
\text { (Nuclear) }\end{array}$} & \multicolumn{2}{|c|}{ Fitted value } \\
\hline & & ANN & Hybrid & & ANN & Hybrid \\
\hline Jan-14 & 17.8946 & 0 & 9.7087 & 73.1626 & 75.6129 & 64.1995 \\
\hline Feb-14 & 13.9966 & 0 & 17.9957 & 62.6390 & 74.2272 & 70.2383 \\
\hline Mar-14 & 17.7221 & 0 & 17.2287 & 62.3971 & 71.9062 & 60.1639 \\
\hline Apr-14 & 18.6213 & 0 & 10.0961 & 56.3846 & 68.8486 & 68.7919 \\
\hline May-14 & 15.5906 & 0 & 16.3641 & 62.9474 & 65.4993 & 62.4239 \\
\hline
\end{tabular}




\begin{tabular}{|c|c|c|c|c|c|c|}
\hline Jun-14 & 15.7862 & 7.8905 & 15.0389 & 68.1382 & 61.9456 & 63.3194 \\
\hline Jul-14 & 12.1764 & 15.1735 & 12.6140 & 71.9401 & 58.0375 & 64.1393 \\
\hline Aug-14 & 10.1621 & 21.4233 & 16.2247 & 71.1287 & 53.7743 & 64.8270 \\
\hline Sep-14 & 11.5098 & 26.6164 & 15.0828 & 67.5345 & 49.6874 & 64.1736 \\
\hline Oct-14 & 14.4923 & 30.6813 & 12.8775 & 62.3910 & 46.7240 & 71.4765 \\
\hline Nov-14 & 18.8475 & 33.8172 & 23.3739 & 65.1402 & 45.3548 & 69.5145 \\
\hline Dec-14 & 14.6965 & 36.5152 & 9.9600 & 73.3625 & 45.4857 & 58.4053 \\
\hline Jan-15 & 15.1463 & 0 & 13.3469 & 74.2700 & 50.9651 & 63.9158 \\
\hline Feb-15 & 14.9076 & 0 & 18.4303 & 63.4615 & 53.4520 & 73.0730 \\
\hline Mar-15 & 15.2930 & 0 & 10.7471 & 64.5468 & 55.9555 & 63.8002 \\
\hline Apr-15 & 17.8505 & 0 & 16.0699 & 59.7845 & 58.2981 & 71.4933 \\
\hline May-15 & 17.1364 & 2.8875 & 16.4315 & 65.8265 & 60.3566 & 64.9724 \\
\hline Jun-15 & 13.4096 & 9.1078 & 17.6232 & 68.5162 & 62.2335 & 66.7648 \\
\hline Jul-15 & 13.6656 & 15.0304 & 12.9933 & 71.4122 & 64.1307 & 63.3344 \\
\hline Aug-15 & 13.0702 & 20.3573 & 16.6198 & 72.4154 & 66.2337 & 64.3121 \\
\hline Sep-15 & 13.9610 & 24.9650 & 11.8948 & 66.4764 & 68.6649 & 64.1577 \\
\hline Oct-15 & 16.3635 & 28.6407 & 19.6385 & 60.5709 & 71.3426 & 70.3380 \\
\hline Nov-15 & 19.6631 & 31.2028 & 17.7347 & 60.2639 & 74.0595 & 68.0606 \\
\hline Dec-15 & 20.0802 & 32.6950 & 10.4025 & 69.6337 & 76.8244 & 56.9360 \\
\hline Jan-16 & 18.4469 & 33.0954 & 14.2124 & 72.5248 & 79.2849 & 63.2366 \\
\hline Feb-16 & 20.1184 & 32.8083 & 15.4120 & 65.6381 & 81.3942 & 74.0434 \\
\hline Mar-16 & 21.9198 & 32.1214 & 5.5471 & 66.1489 & 83.4134 & 62.0413 \\
\hline Apr-16 & 20.7810 & 31.3714 & 15.4696 & 62.7318 & 85.1524 & 70.4576 \\
\hline May-16 & 18.8320 & 30.8885 & 21.9848 & 66.5765 & 86.3982 & 65.0702 \\
\hline Jun-16 & 16.2898 & 30.8220 & 2.3194 & 67.1753 & 87.0401 & 67.1431 \\
\hline Jul-16 & 17.6051 & 31.2386 & 20.2313 & 70.3493 & 87.0010 & 62.0991 \\
\hline Aug-16 & 13.5788 & 32.1662 & 15.7689 & 71.5264 & 86.2803 & 64.4513 \\
\hline Sep-16 & 16.3907 & 33.5452 & 5.1811 & 65.4482 & 85.0482 & 65.5780 \\
\hline Oct-16 & 20.3179 & 35.1430 & 18.4894 & 60.7333 & 83.6112 & 69.6035 \\
\hline Nov-16 & 19.3878 & 36.6797 & 16.6495 & 65.1788 & 82.2431 & 69.0040 \\
\hline Dec-16 & 23.1220 & 0 & 9.7087 & 71.6624 & 75.6129 & 64.1995 \\
\hline Jan-17 & 20.5921 & 0 & 17.9957 & 73.1206 & 74.2272 & 70.2383 \\
\hline Feb-17 & 22.0727 & 0 & 17.2287 & 64.0528 & 71.9062 & 60.1639 \\
\hline Mar-17 & 26.0081 & 0 & 10.0961 & 65.0932 & 68.8486 & 68.7919 \\
\hline Apr-17 & 25.7019 & 0 & 16.3641 & 56.7434 & 65.4993 & 62.4239 \\
\hline May-17 & 22.5873 & 7.8905 & 15.0389 & 61.3094 & 61.9456 & 63.3194 \\
\hline Jun-17 & 19.6267 & 15.1735 & 12.6140 & 67.0108 & 58.0375 & 64.1393 \\
\hline Jul-17 & 15.8339 & 21.4233 & 16.2247 & 71.3142 & 53.7743 & 64.8270 \\
\hline Aug-17 & 13.1366 & 26.6164 & 15.0828 & 72.3842 & 49.6874 & 64.1736 \\
\hline Sep-17 & 17.2776 & 30.6813 & 12.8775 & 68.0734 & 46.7240 & 71.4765 \\
\hline Oct-17 & 24.7669 & 33.8172 & 23.3739 & 65.9948 & 45.3548 & 69.5145 \\
\hline Nov-17 & 23.2997 & 36.5152 & 9.9600 & 66.6179 & 45.4857 & 58.4053 \\
\hline
\end{tabular}

